Acta Crystallographica Section B

Structural

Science

ISSN 0108-7681

\section{Frank H. Herbstein}

Department of Chemistry, Technion-Israel Institute of Technology, Haifa 32000, Israel

Correspondence e-mail:

chr03fh@tx.technion.ac.il

\title{
On the mechanism of some first-order enantiotropic solid-state phase transitions: from Simon through Ubbelohde to Mnyukh
}

The first (so-called) lambda transition in solids was found in the specific heat measurements for $\mathrm{NH}_{4} \mathrm{Cl}$ at $242 \mathrm{~K}$ by $\mathrm{F}$. Simon in 1922 [Simon (1922). Ann. Phys. 68, 241-280]. Analogous phenomena found in many other solids gave rise to doubts (expressed most clearly by A. R. Ubbelohde some 50 years ago) about the applicability of classical thermodynamics to some phase transitions [Ubbelohde (1956). Brit. J. Appl. Phys. 7, 313-321]. However, Y. Mnyukh's studies of enantiotropic phase transitions in eight organic crystals showed that all proceed by a nucleation-and-growth mechanism [summarized in Mnyukh (2001), Fundamentals of Solid State Phase Transitions, Ferromagnetism and Ferroelectricity. 1st Books]. Nucleation is localized at defects in the parent phase; growth can be epitaxic and oriented if parent and daughter phases have closely similar structures, or random (not oriented) if there are substantial structural differences. This conclusion is supported by a critical review of Mnyukh's eight examples and other results published in the interim. It seems that Ubbelohde's invocation of 'hybrid crystals' and 'smeared transitions' can mostly be accounted for by lack of equilibrium in the phase-transition studies cited by him. However, the intermediate phase in $4,4^{\prime}$-dichlorobenzophenone appears to have structural resemblances to Ubbelohde's' 'hybrid crystal'.

\section{Introduction}

Many chemical substances exist in more than one crystalline form - this is polymorphism (Bernstein, 2002). When Phase $L$ (stable at lower temperatures) transforms to Phase $H$ (stable at higher temperatures) at some temperature between $0 \mathrm{~K}$ and the melting point, the system is called 'enantiotropic'. ${ }^{\mathbf{1}}$ Use of the phrase 'solid-state' means that we do not include the transitions 'melting', 'sublimation' and 'vaporization'; 'first order' is defined below. Solid-state phase transitions have been the subject of intense investigation for perhaps 200 years; their relevance to mineralogy, condensed matter physics, chemistry and crystallography is obvious. The literature is voluminous and confusing; in particular, many mechanisms have been proposed for such transitions and most systems are treated sui generis. Some features of a formal thermodynamic treatment of phase ransitions are set out below, but it has been suggested that this has its deficiencies. The problems set out in this review first arose in 1922 when Simon reported that the

\footnotetext{
1 'When each of two polymorphs is thermodynamically stable in a definite range of temperature and pressure, the pair is said to be enantiotropic... When one of two polymorphs is thermodynamically unstable at all temperatures below the melting point, the two are said to be monotropic' (see Westrum \& McCullough, 1963, p. 73). This definition tacitly assumes working at fixed (generally atmospheric) pressure.
}

Received 6 January 2006 Accepted 8 March 2006
(C) 2006 International Union of Crystallography Printed in Great Britain - all rights reserved 
phase transition in ammonium chloride at $242 \mathrm{~K}$ showed a socalled $\Lambda$-point anomaly in its specific heat curve (Simon, 1922). ${ }^{2}$ This was followed by studies of $\mathrm{NH}_{4} \mathrm{Cl}$ by other techniques and extension to other materials; the diffraction studies of $\mathrm{NH}_{4} \mathrm{Cl}$ by Dinichert in 1942 are especially noteworthy. The next 'milestone' in this journey is conveniently marked by a group of five review papers by Ubbelohde (1956, 1957, 1962, 1963, 1966; Scheme 1). Ubbelohde drew attention to premonitory phenomena preceding phase transformations, to hysteresis in the transition itself, the heating transition occurring at a higher temperature than the equilibrium temperature and the cooling transition at a lower temperature, to the formation of 'hybrid crystals' and to 'smeared transitions' (Scheme 2).

A series of investigations by Hartshorne and coworkers over the period 1935-1967 (the reference is given only for the last of these investigations: Briske \& Hartshorne, 1967) led on to the next milestone which is surely marked by some 12 publications by Mnyukh over the period 1963-1983, and the integrated and expanded account of this work that appeared in book form in 2001 (Mnyukh, 2001). Mnyukh claimed that all first-order enantiotropic solid-state phase transitions occur by a nucleation-and-growth mechanism, basing this contention on direct optical-microscope and X-ray studies of suitable crystals, and analysis of literature data. ${ }^{3}$ One of the purposes of this review is to assess whether particular phase transitions are better described by Mnyukh's nucleation-and-growth model or by Ubbelohde's 'hybrid crystals' and 'smeared transitions'. This is done through a critical examination of the experimental evidence, including more recent material not available to Ubbelohde or Mnyukh. After some introductory material, we contrast their approaches to the mechanism of phase transitions given in $\$ 5$.

Most papers on phase transitions ${ }^{4}$ deal with the structures and properties of the individual phases and the differences between them in order to infer the driving force for the transformation. This is a combination of enthalpic (packing) and entropic (generally vibrational) factors. There are relatively few papers about the actual transition directly viewed by microscopic techniques in order to infer the mechanism, and not many about changes in crystal structure, including changes in cell dimensions, as the system passes through the transition. Among the few systems that have been studied by most of the available techniques are ammonium chloride and \{TTFchloranil\}. Lacunae in the literature are noted in the hope that this will encourage research to fill the gaps.

We first summarize the thermodynamic background and set this in the historical context of the developments in the

\footnotetext{
${ }^{2}$ Ubbelohde (1957) writes 'The fancied resemblance of such curves to the Greek capital letter $\Lambda$ (lambda) has led to the description of such phenomena as "lambda-point anomalies". I have not been able to locate the first use of this term.

${ }^{3}$ Mnyukh's book also deals with second-order transitions (in passing) and, more substantially, with ferromagnetism and ferroelectricity. However, these topics are outside the bounds of the present review.

${ }^{4}$ For brevity our reference is generally to 'phase transitions', but it must be understood that the full phrase 'first-order enantiotropic solid-state phase transitions' is always implied, and we hardly move outside these boundaries.
}

treatment of phase transitions over the last 80 years $(\S 2)$. The classic text, although limited to metals and alloys, is by J. W. Christian (1965); many general concepts are set out with great clarity. Current mainstream notions about the mechanism of first-order enantiotropic solid-state phase transitions are described in the book 'Reconstructive Phase Transitions' (Tolédano \& Dmitriev, 1996) in which variants of Landau's theory of second-order transitions are adapted to first-order transitions, including the presentation of revised versions of the classical Burgers and Bain mechanisms for the b.c.c.-h.c.p. (body-centered cubic to hexagonal close packed) and b.c.c.f.c.c. (body-centered cubic to face-centered cubic) transitions. Mnyukh's approach in which all first-order transitions are described in terms of a nucleation and growth mechanism is quite different (see $\S \S 3$ and 5). The main points of this approach are summarized, including remarks about experimental techniques (\$4). Two classical systems - the veteran ammonium chloride and the more recent $\{$ TTF-chloranil $\}$ - are described in detail (\$6). We then return to an integrated and critical survey of the (updated) results available for the eight systems presented in Mnyukh's book (\$7). To these we add some reported more recently to check whether these too fit into the nucleation and growth pattern ( $\S 8-13)$. One caveat is necessary - the systems discussed here are virtually all molecular in nature, ammonium chloride being the only exception. Toledano \& Dmitriev discuss only network systems and an important question, not resolved here, is whether all crystals behave in much the same way, or do transitions in molecular and network crystals differ in non-trivial ways?

\section{REVIEW PAPERS BY A.R. UBBELOHDE, 1956-1966.}

1. Crystallography and the Phase Rule. Brit. J. Appl. Phys. 7, 313-321 (1956).

2. Thermal Transformations in Solids, Quart. Revs., 11, 246-272 (1957).

3. Transitions between Condensed Phases of Matter (Second Van ' $t$ Hoff lecture). Kon. Ned. Akad. Wetens. Proc. 65 B, 459-471 (1962).

4. Premonitory Phenomena in Phase Transitions in Solids. Z. phys. Chem. N. F. 37, 183-195 (1963).

5. Molecular movements and phase transitions in solids. 1Thermodynamic and structural aspects of phase transitions that are wholly or partly continuous. J. Chim. Phys. 62, 33-42 (1966).

Scheme 1

\section{The thermodynamics of phase transitions}

We consider a one-component system with variables $P$ and $T$; phase $L$ is stable at lower temperatures than phase $H$. The Gibbs free energy $G$ of phase $L\left[G_{L}(P, T)\right]$ is defined by a surface in $P-T$ space; $G_{H}$ will be the analogous surface applying to phase $H$. The intersection between these two $G$ surfaces gives the paired $P$ and $T$ coordinates of the curve of equilibrium between phases $L$ and $H$. The passage across this 
curve is the transition between the two phases. Ehrenfest (1933) defined the order of a transition as 'determined by the lowest order of the differential coefficient of the Gibbs function which shows a discontinuity on the transition line'. ${ }^{\mathbf{5}}$ For a first-order transition (to which our attention will be almost entirely restricted) this 'meeting' will be a sharp intersection, resulting in discontinuities for all the extensive physical properties of the system (such as volume, enthalpy and entropy) and the heat capacity will become infinite at the transition. For an isobaric transition, one takes a constant $P$ section through $P-T$ space and the surfaces become curves. Ubbelohde's proposal was essentially that the $G_{L}$ and $G_{H}$ curves become smeared and their intersection is no longer sharp (Scheme 2).

Most systems appear to be well behaved in terms of classical thermodynamics, with some of the reported exceptions as the subject of this review. Before detailing these, we must bear in mind that in classical thermodynamics one considers the interrelation of macroscopic measured quantities such as $G, H, S$, $V$. There is no mention of particles, molecules or atoms, nor of symmetry and anisotropy. How does one make the connection between free energy, enthalpy, entropy ${ }^{6}$ and oriented single crystals? Are only observations on randomly oriented polycrystals valid for comparison with measured thermodynamic quantities? Ubbelohde was well aware of these questions, which appear to have guided much of his thinking.

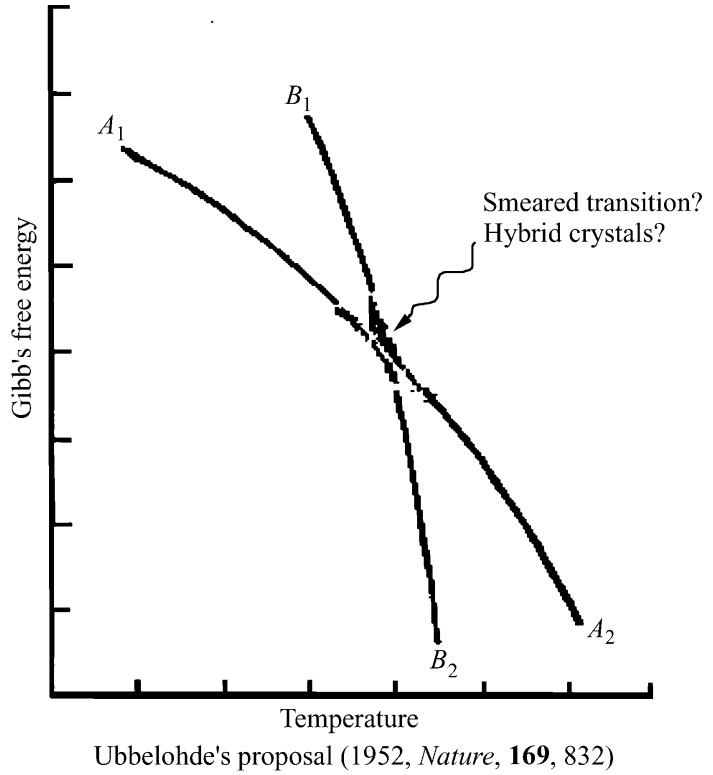

Scheme 2

How many crystals show first-order phase transitions and to what extent are those that have been studied in some depth representative of the population as a whole? A preliminary answer to our first question has been given by Nichol \& Clegg (2005) who report that a SciFinder Scholar (American Chemical Society, 2004) search for 'phase transition' gave

\footnotetext{
5 The phrase is actually taken from Pippard (1964), p. 136.

${ }^{6}$ Note the omission of $V$ from this list.
}

Table 1

Data for crystals studied by Mnyukh.

Thermodynamic values from Petropavlov et al. (1988). $T_{0}$ : phase-transition temperature; $T_{m}$ : melting point.

\begin{tabular}{lllll}
\hline Compound & $T_{0}(\mathrm{~K})$ & $T_{m}(\mathrm{~K})$ & $\begin{array}{l}\Delta H \\
\left(\mathrm{~kJ} \mathrm{~mol}^{-1}\right)\end{array}$ & $\begin{array}{l}\Delta S \\
\left(\mathrm{~J} \mathrm{~mol}^{-1} \mathrm{~K}^{-1}\right)\end{array}$ \\
\hline p-Dichlorobenzene & - & 326.35 & - & - \\
& 303.95 & - & 0.2 & 0.6 \\
Hexachloroethane & 316.75 & $459.85 \dagger$ & $2.4 ; 2.56 \ddagger$ & 6.6 \\
& 344.25 & - & 6.3 & 18.3 \\
Malonic acid & 351.15 & 408.15 & 1.6 & 4.6 \\
Glutaric acid & 337.15 & 370.65 & 2.4 & 7.4 \\
Octahydroanthracene & $(331.15)$ & 346.15 & 2.4 & 7.2 \\
Hexamethylbenzene & 110 & 439.15 & - & - \\
& 383.95 & - & 1.5 & 3.9 \\
Tetrabromomethane & 320.05 & 366.65 & - & - \\
D,L-Norleucine & 390.35 & - & 4.2 & 10.7 \\
\hline
\end{tabular}

$\dagger$ Triple point (Wiebenga, 1935). $\$$ Seki \& Momotani (1950).

almost 140000 hits, 9013 in 2003 . The second question is more difficult to answer as the population of polymorphic transitions contains many sub-groups with different types of behavior; while these have been discussed in a qualitative way (Herbstein, 2001, and references therein), no quantitative assessment exists.

\section{The approach of Mnyukh, the systems investigated and the inferences drawn}

The primary features of Mnyukh's experimental approach are 'to use small transparent single crystals of good quality [and] to rely on visual observations [polarizing microscope] under controlled temperature conditions. Eight different organic crystals (Table 2.1 of Mnyukh, 2001) were chosen for the study'. These are listed in Table 1.

Mnyukh drew the following inferences from the experimental studies of these compounds; many of the crucial experiments were carried out on the forward and reverse EII$\alpha /$ EIII- $\beta$ transitions in $p$-dichlorobenzene. ${ }^{7}$ There is also a study by Reynolds (1977) on the reverse transition. Although expressed in somewhat different terms, many of Reynolds' observations are similar to those of Mnyukh; we append some of these for comparison with Mnyukh's inferences. Many of the features emphasized by Mnyukh were also appreciated by Ubbelohde and we include appropriate quotations and references from Ubbelohde's reviews in square brackets.

(i) The transitions proceed by a nucleation-and-growth mechanism. The nuclei of the daughter phase form at defects in the parent phase; Mnyukh (2001, p. 86) states 'Formation of a nucleus is a rare and reproducible act bound to a predetermined location. Homogenous nucleation is impossible'. By a process of elimination Mnyukh concluded that the defects where nucleation occurs are an optimum agglomeration of vacancies (see Mnyukh, 2001, pp. 80-89). The various

${ }^{7}$ The nomenclature of Herbstein (2001) is used for the phases (see Appendix $A$ ), while crystal data are given through the CSD (Cambridge Structural Database) refcode as well as in the standard manner. 
temperatures shown in Fig. 4 (below) are governed by the structures of the defects.

[Reynolds: 'In crystals grown from solution or by sublimation the phase transformation is apparently initiated at specific defective points in the crystal... The nucleation process is facilitated in $\beta$-crystals by pricking [with a needle]... The most perfect $\beta$-crystals cannot be induced to transform even by vigorous mechanical coercion (Kitaigorodsky et al., 1965)'.]

[Ubbelohde (1963; p. 187): 'Starting with a single-crystal of form $\mathbf{1}$ its geometrical transformation into form $\mathbf{2}$ can often be described in terms of operations of translation and orientation that in principle might follow a continuous path $\mathbf{1} \Rightarrow \mathbf{2}$ without any fresh nucleation. However, if this path were actually to be followed the potential energy barriers to be surmounted might be so large, compared to $k T$, that in practice the transformation $\mathbf{1} \Rightarrow \mathbf{2}$ may prefer to follow a more discontinuous process of nucleation and regrowth'.]

(ii) Growth proceeds by an interface mechanism, where the interface plane is an irrational plane in the parent phase, but a crystallographic plane in the daughter phase (Fig. 1; but see later for the case of epitaxic growth). This implies that the phase transition has many of the features of crystal growth from the melt.

[Reynolds: 'It proceeds by steps running across the face of the well faceted daughter crystal'.]

(iii) There is no orientation relationship between parent and daughter phases (again with a caveat for epitaxic growth). Reynolds draws attention to an apparent contradiction between the results of Tseneva (1969), who noted a preference for certain mutual orientations between EIII- $\beta$ [(100) plates] and EII- $\alpha$ of $p$-dichlorobenzene, whereas Mnyukh \& Petro-

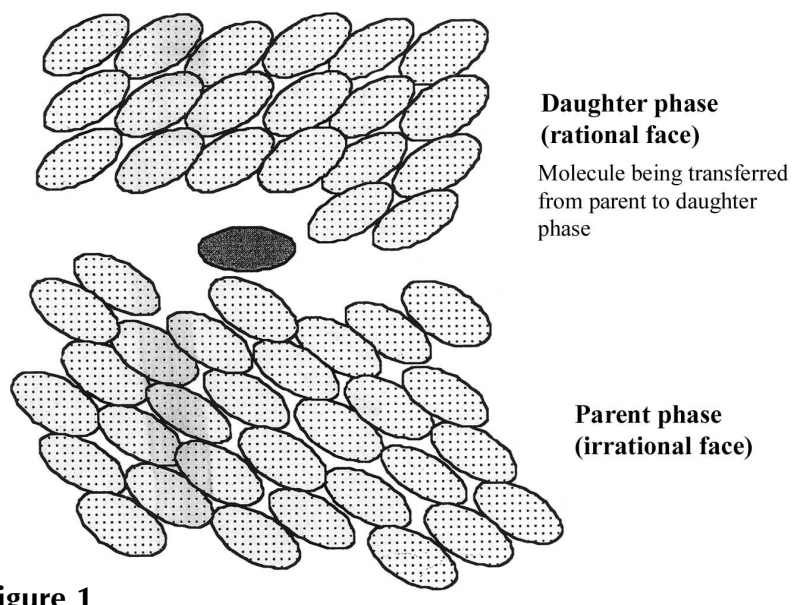

Figure 1

Schematic diagram of the molecular rearrangement at the contact interface between the parent phase (below) and the daughter phase (above); the width of the interface has been estimated as about half of a lattice spacing (Mnyukh (2001, pp. 63-77). The interface is a crystallographic face of the daughter phase, but not of the parent phase. The frame shows the transfer of a molecule from the parent to the daughter phase to build up a new layer of the daughter phase. The process repeats itself after completion of a layer. Adapted from Fig. 2.17 of Mnyukh (2001). pavlov (1972) showed the absence of a crystallographic relationship between the two phases, and this is supported by many experimental results (Mnyukh, 2001).

(iv) These conclusions, although based on many experiments with crystals of many different compounds, are neatly summarized in one photograph (Fig. 2), where a number of randomly oriented daughter crystals grow from a conglomeration of nuclei in an EII- $\alpha$ to EIII- $\beta$ transition in $p$ dichlorobenzene.

(v) When the structures of the parent and daughter phase are similar (this does not hold for $p$-dichlorobenzene), then interface growth is by an epitaxic mechanism i.e. both interfaces are rational planes (Mnyukh, 2001, pp. 121-143; Fig. 3).

[Ubbelohde (1962); p. 468: 'When the difference between unit cells becomes sufficiently small, well orientated domains of either form can coexist in the hybrid crystal at the transition... Conditions are now present for a transition which in appearance is thermodynamically continuous. But... X-ray methods leave no doubt about discontinuous jumps in structure between the domains of $\mathbf{1}$ and $\mathbf{2}$, provided sufficiently refined methods are used'.]

p-Dichlorobenzene EII to EIII heating transition

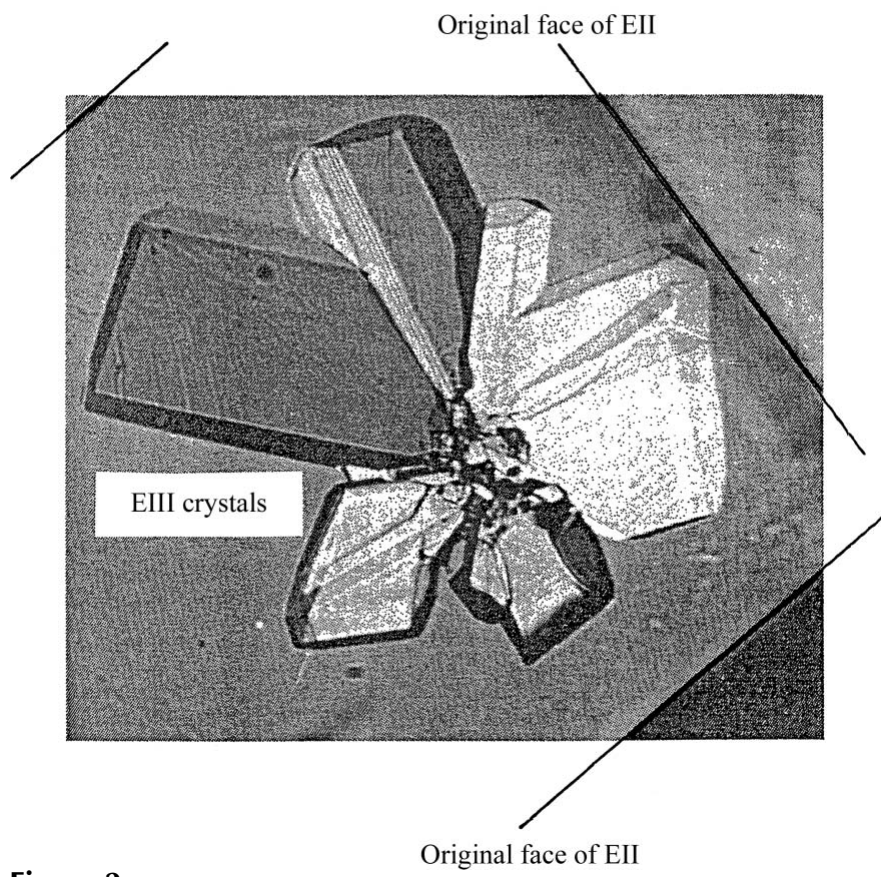

Figure 2

Original face of EII

Photomicrograph (partially polarized light) of an EII- $\alpha$ (monoclinic) to EIII- $\beta$ (triclinic) transition in $p$-dichlorobenzene. It was initiated by a slight prick of a needle in the parent (EII- $\alpha$ ) phase which created a local damaged area with nucleation sites for a cluster of EIII- $\beta$ crystals growing in different directions. Each crystal of the cluster has its own set of natural faces not appearing in others. The natural faces of the parent crystal are seen at both corners on the right. Reproduced with permission from Fig. 2.5 of Mnyukh (2001, p. 40). 
Smeared' or continuous transition

(following Ubbelohde, 1966)

\begin{tabular}{|c|c|c|}
\hline & $T_{0} \pm \Delta T$ & \\
\hline $\mathrm{L}$ & $\begin{array}{c}\text { Hybrid } \\
\mathrm{L}+\mathrm{H}\end{array}$ & $\mathrm{H}$ \\
\hline & & \\
\hline $\begin{array}{l}\text { Low temperature } \\
\text { single crystal }\end{array}$ & $\begin{array}{l}\text { Domains of both } \\
\text { structures coexist } \\
\text { within a strained } \\
\text { single crystal }\end{array}$ & $\begin{array}{l}\text { High temperature } \\
\text { single crystal }\end{array}$ \\
\hline & & \\
\hline
\end{tabular}

Scheme 3

\section{Some general remarks about experimentation}

\subsection{Definitions of various temperatures}

The only temperature that is invariant for a particular system is the temperature $T_{0}$ at which the two phases are in thermodynamic equilibrium. The transition has zero velocity at $T_{0}$, and the forward transition only proceeds with a degree of superheating dependent on the quality of the crystals; the more perfect the crystals, the greater the superheating required for nucleation and growth of the daughter phase (or supercooling, for the reverse transition). Various methods have been used for the determination of $T_{0}$ :

(i) Dilatometry to establish the temperature at which the conversion rate, in the presence of roughly equal amounts of the two phases, is zero. This has been applied to hexachloroethane (see below).

(ii) Determination of the temperature at which solubilities of the two phases are equal; this has been applied to thallium(I) picrate (discussed by Botoshansky, Ellern et al., 1998).

(iii) Visual determination of equilibrium temperature in the presence of solvent. This has been applied to $\mathrm{N}$-anilinephthalimide (Chattaway \& Lambert, 1915). ${ }^{\mathbf{8}}$

It should be noted that the transition temperature given by DSC (differential scanning calorimetry) measurements is, in general, not equal to $T_{0}$. The onset temperatures $\left(T_{H}, T_{L}\right.$ for heating and cooling, respectively) often given are operational values dependent on sample quality and history, and heating (or cooling) rates. On heating, the transition from the lowtemperature $(L)$ phase to the high-temperature $(H)$ phase begins at $T_{H}$, some degrees above $T_{0}$; on cooling the $H$ to $L$ transition begins at $T_{L}$, some degrees below $T_{0}$. A reversible DSC cycle would give values for $T_{H}$ and $T_{L}$; an approximation to $T_{0}$ is sometimes obtained by averaging heating and cooling onset temperatures. $T_{H}$ and $T_{L}$ are not parameters of the system; these temperatures are illustrated in Fig. 4 that has been adapted from Mnyukh's Fig. 2.30(a) and discussed by him on pp. $89-112$.

\footnotetext{
${ }^{\mathbf{8}}$ We quote from Chattaway \& Lambert 'Tubes containing a mixture of crystals... of the two forms, just covered with acetone, were sealed... and heated... At $55^{\circ}$ the pale yellow crystals [monoclinic], and at $55.5^{\circ}$ the orange crystals [triclinic] were unmistakably growing, although very slowly. Between these temperatures no definite alteration of either form could be observed. The transition point must therefore be between these temperatures, and lie in the neighbourhood of $55.25^{\circ}$.
}

The difference in the behavior of the system in heating and cooling regimens is the cause of hysteresis, defined as 'The dependence of the state of a system on its previous history, generally in the form of a physical effect lagging behind its cause' (definition from Parker, 1983). Here we have the value of, say, a cell dimension lagging behind its equilibrium value at a particular temperature.

\subsection{Individual-phase and combined-phase measurements}

Mnyukh (2001, ch. 3, pp. 165-204) has drawn attention to the fact that measurements referring to individual phases present during the phase transition (their amount and their properties) give information different in principle and practice from measurements on the system as a whole. Thus, measurement of the cell dimensions of the two phases as a function of temperature gives more information than dilatometric measurements of system volume. Among individualphase measurement techniques are cell dimensions, NMR frequencies for labeled atoms, NQR (nuclear quadrupole resonance) and other spectroscopies; among combined-phase measurement techniques are calorimetry, dilatometry, dielectric constant and other physical properties of the system as a whole. Although the distinction between the types of
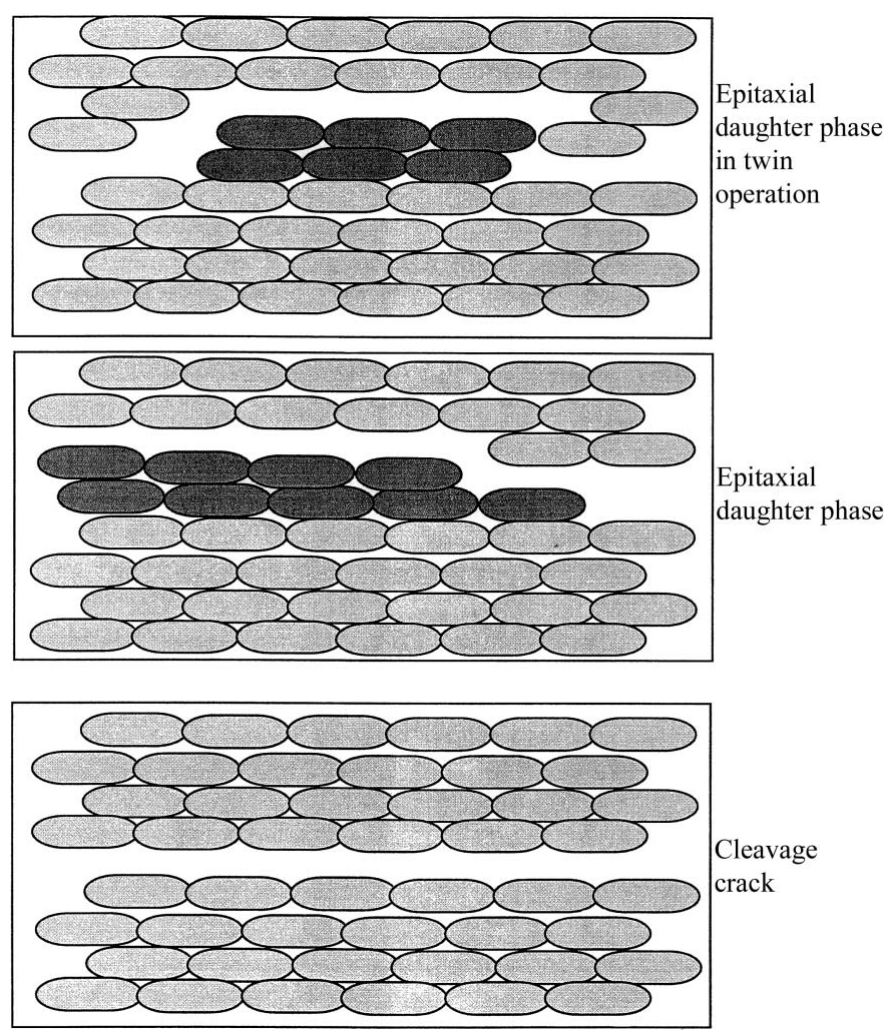

Figure 3

The initial stages of an epitaxial phase transition: (bottom) nucleation takes place in a microscopic crack parallel to the cleavage plane of the parent phase; (middle) oriented nucleus of the daughter phase (darkened) formed by the consecutive transfer of molecules from one side of the flat microcavity to the other; (top) equally probable nucleus in a twin orientation. Adapted from Fig. 2.43 of Mnyukh (2001, p. 137). 
measurement is surely obvious, it does not appear to have been adequately appreciated by many researchers.

\subsection{Determining whether a phase transition is first order}

We have noted above that Ehrenfest's (1933) definition of the order of a transition implies that, in a first-order transition, there will be discontinuities at $T_{0}$ in all the extensive physical properties of the system (such as volume, enthalpy and entropy) and that the heat capacity will become infinitely high at the transition. Volume would appear to be a convenient parameter for investigation, but there are not many measurements of the temperature dependence of cell dimensions. Two points need emphasis: firstly, $|\Delta V|$ is seldom more than a few percent of $V$ so precise measurements of $V_{L}(T)$ and $V_{H}(T)$ are needed, especially when one remembers that the variance of $|\Delta V|$ is the sum of the variances of $V_{L}$ and $V_{H}$ at $T_{0}$; secondly, a discontinuity in $V(T)$ requires, minimally, a discontinuity in only one of the cell dimensions. This situation, which seems likely in both 4,4'-dichlorobenzophenone and 2(2,4-dinitrobenzyl)-3-methylpyridine, may well hint at difficult-to-define complications. The occurrence of hysteresis is a strong indicator of a first-order transition, and this is illustrated for $\mathrm{NH}_{4} \mathrm{Cl}$, TTF-chloranil, and other systems given below. Similarly, the observation of an interface indicates that the transition is first order.

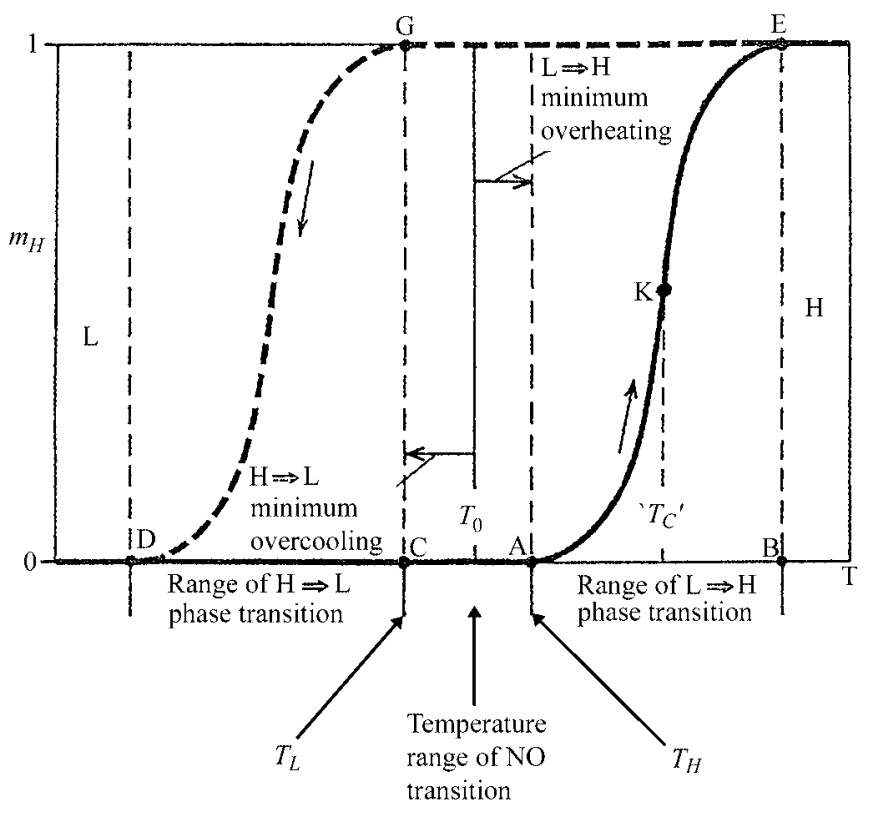

Figure 4

Definition of various temperatures. $T_{0}$ is the temperature at which the two phases are in thermodynamic equilibrium. $T_{H}$ is the temperature at which the transition in a particular crystal (or sample) begins on heating; $T_{L}$ is the corresponding value for cooling; $\left|T_{H}-T_{0}\right|<\left|T_{0}-T_{L}\right|$. The fraction transformed on heating is shown by the full curve AE on the right; the analogous curve for cooling is GD (broken line) on the left. ' $T_{C}$ ' is the 'transition temperature' recorded by DSC in a heating run. The schematic hysteresis loop DAEGD should be compared with the experimental loop for single-crystal $\mathrm{NH}_{4} \mathrm{Cl}$ determined by Dinichert (1942; see Fig. $7 b$ ). Adapted from Fig. 2.31 of Mnyukh (2001).
When $|\Delta V|$ is small, then other physical measurements may provide succor. This happens with both 4,4'-dichlorobenzophenone and 2-(2,4-dinitrobenzyl)-3-methylpyridine (see $\$ \S 9.1$ and 8.2.2).

\subsection{The paramount importance of (optical) microscopy}

Mnyukh's optical microscope studies have shown that the phase transitions in the eight compounds listed in Table 1 proceed by a nucleation and growth mechanism. Other methods may well add sophisticated embellishments to our knowledge of a transition, but their use cannot detract from the paramount importance of direct observation. Wherever possible, the first study of a phase transition should be by optical microscopy (and/or its offshoots), to be followed by complementary studies by other appropriate physical techniques.

[Ubbelohde (1957), p. 264]: 'Skilful use of the microscope can give useful supporting information about structural changes in transformations in solids, though the conclusions are necessarily more superficial'.]

A striking example of the power of enhanced microscopy is provided by the use made by the Dunitz group (Richardson et al., 1990; see $\$ 10$ ) of the device [developed by Wiedemann \& Bayer (1985) allowing simultaneous (DSC) and optical microscope (recorded by video camera) observations on heated samples]; extension to low temperatures would be most valuable. Optical observations often reveal thermal events that are not discernible by DSC.

\subsection{The temperature range of interest}

It is obvious that most attention will be given to a relatively narrow temperature range around $T_{0}$, but extension to a much broader range will often give essential information. An example of this approach is illustrated below for ammonium chloride, where Fig. 5 shows calorimetric and diffraction data over a wide temperature range, while Fig. 7 is concentrated on the interval immediately about the transition at $242 \mathrm{~K}$. The important premonitory features would not have been apparent if only a narrow temperature interval had been studied.

\section{Comparing the approaches of Ubbelohde and Mnyukh}

\subsection{Two (partly) different descriptions}

Ubbelohde (1962; see p. 468) considered three scenarios for transformation:

(i) Under conditions where the structural differences between low- and high-temperature phases are large, a single crystal of either form must transform with practically no correlation between crystallites [of the two phases];

(ii) when the difference between cells is only moderately large, the single crystal of one form may nucleate crystallites of the other at the surface or at dislocations, imposing some 


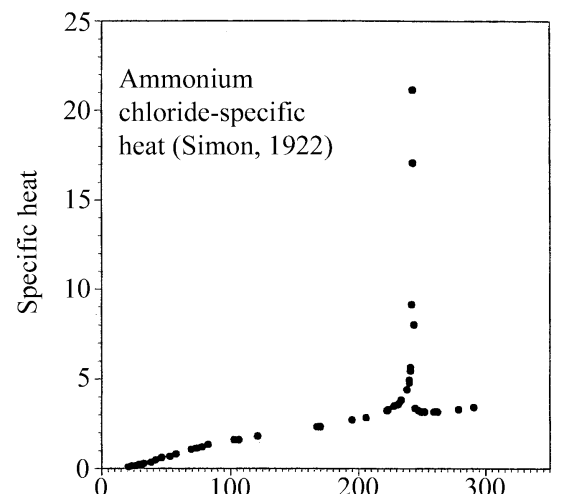

(a)

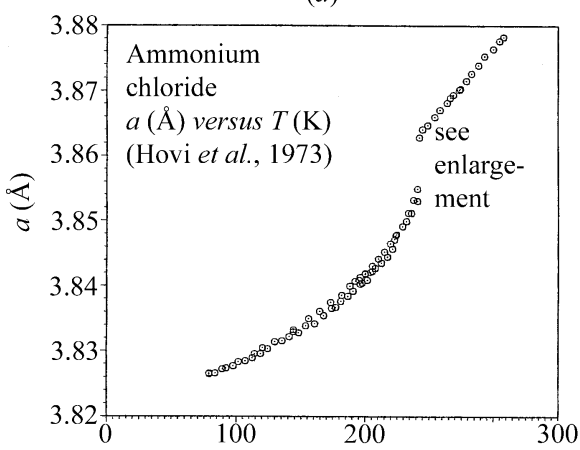

(b)

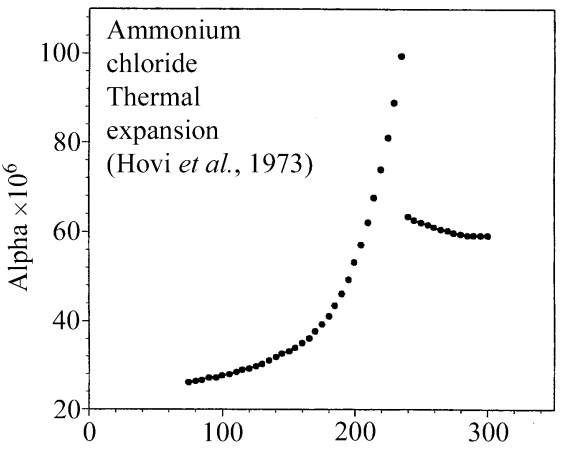

(c)

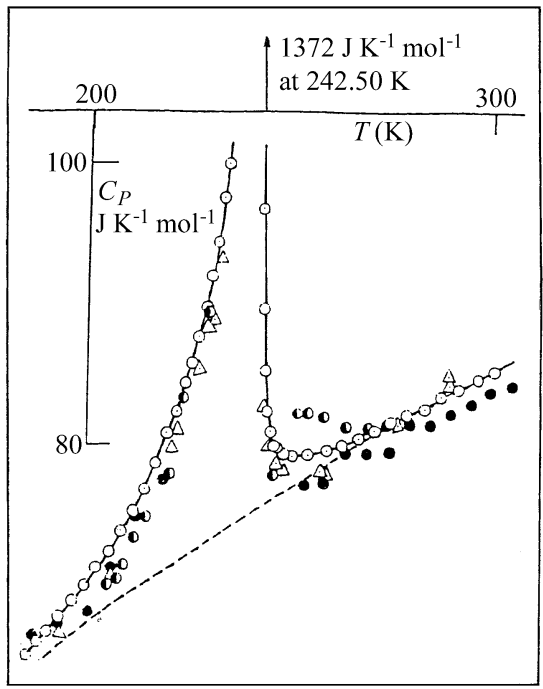

(d)

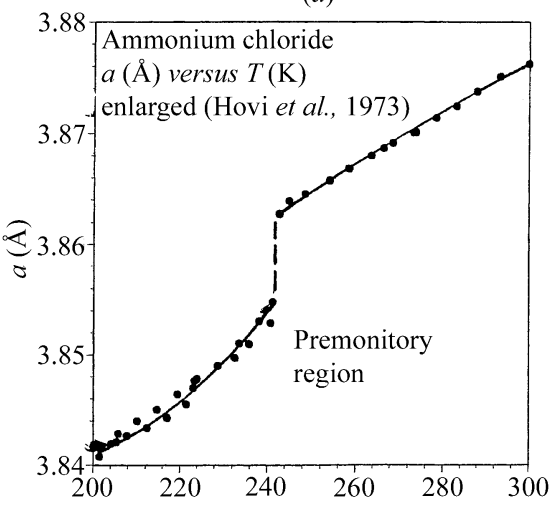

$(e)$

Figure 5

$\mathrm{NH}_{4} \mathrm{Cl}$ - a suite of experimental results for ammonium chloride. (a) Specific heat as a function of temperature for $\mathrm{NH}_{4} \mathrm{Cl}$ (Simon, 1922; values tabulated on pp. 256-257 of Simon's paper; see also his Fig. 3); (b) cell dimensions as a function of temperature (Hovi et al., 1973; values from Tables 2 and 3 of their paper; see also their Fig. 1). The spread of values below $242 \mathrm{~K}$ was considered to be indicative of hysteresis (see their Fig. 2), but this was not explained and has not been taken into account here; (c) thermal expansion as a function of temperature, calculated from (b) (Hovi et al., 1973; their Table 5 and Fig. 4); (d) central portion of $C_{p}-T$ curves given by Chihara \& Nakamura (1972) who give details of other experimental results included here. The excellent agreement between the results of Simon (1922) and those of Chihara \& Nakamura (1972) is noteworthy. The premonitory region found on heating is shown; $(e)$ central portion of cell dimension-temperature curve showing indications of a premonitory region. Curves are guides to the eye.

preferred orientation upon them but still producing a random assembly essentially independent of the parent; ${ }^{9}$

(iii) when the difference between the unit cells becomes sufficiently small, well oriented domains of either phase can

\footnotetext{
${ }^{9}$ The $\beta(H T)$ to $\alpha(L T)$ transition of resorcinol was used as an illustration of this situation; the two phases are enantiotropically related.
}

co-exist in the hybrid crystal... Conditions are now present for a transition that in appearance is thermodynamically continuous. However, X-ray methods leave no doubt about discontinuous jumps in structure between the domains of the two phases, provided sufficiently refined methods are used. The hybrid crystal was described in terms of the coexistence around a transition temperature of regions of two structures that are closely related... [there is an] association of sub-units that fulfils the characteristics of a single crystal on average. Every subunit has a structure and orientation closely related to the average structure; but the sub-units are distinguishable by sufficiently refined methods. The pseudo-single-crystal in which these sub-units are present is, in fact, a hybrid... As the temperature moves away from the transformation point, distinguishable sub-units disappear; apart from possible internal scars and cooperative defects, the hybrid single crystal becomes identical in every way with the conventional concept of a single crystal.

The first two situations described above match reasonably well with Mnyukh's emphasis on the 'nucleation and growth' character of the transition, but he (Mnyukh, 2001, see p.179) rejected the 'hybrid crystal'-'smeared transition' approach. His differences from Ubbelohde are summarized as follows: 'Ubbelohde, in divergence from the mainstream, criticized the contemporary theory for disregarding structural mechanism for phase transitions. He noticed and discussed the phase coexistence discovered by Dinichert [see below in the section on $\mathrm{NH}_{4} \mathrm{Cl}$ ], but failed to recognize independence of the phases and their representation with two separate plots. The $\lambda$ peaks in the amalgamated calorimetric plots were still taken for a true $C_{p}(T)$. Thermodynamics were declared to be inadequate to account for phase transitions. A 'hybrid crystal' concept was introduced. Inconsistence of that concept with thermodynamics is the reason not to discuss it further'. 


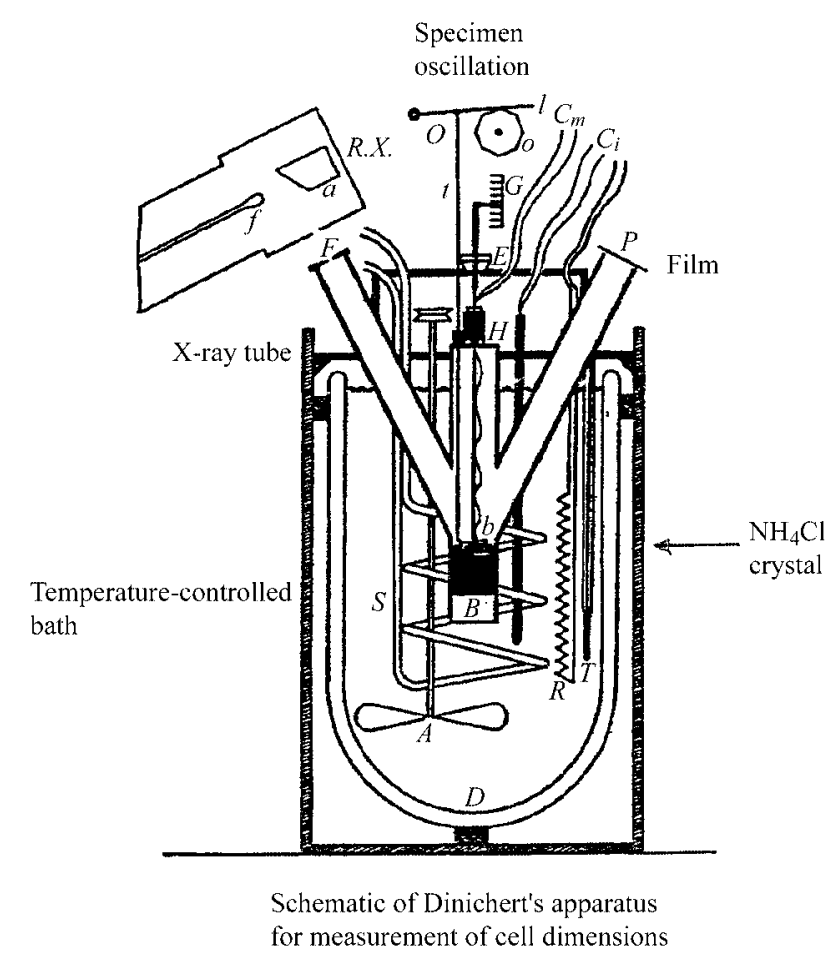

Figure 6

Dinichert's X-ray 'spectrograph', designed to record on film the diffracted (024) ray $\left(\mathrm{Cu} \mathrm{K \alpha _{1,2 } )}\right.$ from an ammonium chloride crystal held at varying temperatures controllable to $0.02^{\circ}$. Only the main features are indicated in this adaptation of Fig. 1 of Dinichert (1942).

\subsection{Using the Mnyukh approach to account for Ubbelohde's formulation}

In my view, Fig. 4 (from Mnyukh's Fig. 2.30) provides a simple explanation for most of Ubbelohde's observations. Consider a crystal of phase $L$ (the low-temperature phase) being heated from well below the thermodynamic transformation temperature $T_{0}$. Transformation to phase $H$ (the hightemperature phase) starts sensibly at some temperature above $T_{0}$ and proceeds with increasing velocity as the temperature departs further from $T_{0}$. For some period of time the original sample will contain both phases (in varying ratios). This mélange is what Ubbelohde called a hybrid but, in fact, it is just a non-equilibrium mixture of the two phases with a range of apparent 'stability' depending on the conditions of observation. Mnyukh explained 'the 'hybrid crystal' as a two-phase temperature range, which is an inevitable feature of every phase transition due to the specifics of nucleation as found in [the] investigations' (private communication, end of 1992). Such mixtures of the two phases are found, for example, in ammonium chloride and \{TTF...chloranil\}, as described below. Further heating leads to complete conversion of $L$ to $H$. Diffraction observations are not generally carried out under conditions of equilibrium; indeed, care to obtain equilibrium has been reported only for some dilatometer measurements, as noted below. Holding the two-phase system at a particular temperature gives a steady-state, but not an equilibrium, situation.
We have encountered one example where an Ubbelohde hybrid does indeed appear - this is 4,4'-dichlorobenzophenone (\$9.1). There is an intermediate phase, with a region of existence of about $10^{\circ}$ around $185 \mathrm{~K}$. However, this cannot be described as a 'continuous or smeared transition'.

\section{Two fundamental phase transitions - in ammonium chloride and \{TTF...chloranil\}}

Unexpected features of the phase transition at $\sim 242 \mathrm{~K}$ in ammonium chloride can be said to have triggered off the present line of investigation, leading to a spate of publications from 1922 onwards. We shall essentially confine ourselves to a review of the behavior of $\mathrm{NH}_{4} \mathrm{Cl}$ at atmospheric pressure, but extensions to higher pressures and to $\mathrm{ND}_{4} \mathrm{Cl}$ invite exploration. As many physical properties as possible should be measured over a wide range of temperatures, after which the investigation can be focused on the region of the transition. Fortunately such a suite of results has been accumulated for $\mathrm{NH}_{4} \mathrm{Cl}$. Our treatment complements that of Mnyukh (pp. 177187).

Our second fundamental example is $\{$ TTF...chloranil\}, which is the subject of a wide range of investigations by groups centered about the University of Rennes I, starting about 1994, with earlier papers, mainly from IBM laboratories, going back to around 1980. The studies were mainly directed towards the physics of the neutral to ionic transition (on cooling) and the nature of the two phases, but the published results can be used to provide a remarkably detailed picture of the transition itself, illustrating rather fully Mnyukh's description of an epitaxic transition.

\subsection{Ammonium chloride: transition at $242.5 \mathrm{~K}$}

The structural chemistry of ammonium chloride can be summarized as follows: at atmospheric pressure and below $242 \mathrm{~K}$ the space group is the non-centrosymmetric $P \overline{4} 3 m$ (No. $215)$; the ammonium ions are aligned parallel to one another with $\mathrm{N}-\mathrm{H}$ bonds along four of the $\{111\}$ directions [ordered tetrahedra; $\mathrm{H}$ atoms at Wyckoff positions 4(e), xxx etc., symmetry $3 m$ ]. At temperatures between 242 and $457.5 \mathrm{~K}$ the space group is the centrosymmetric $\mathrm{Pm} 3 m$ (the $\mathrm{CsCl}$ structure; No. 221) and the crystal is orientationally disordered with equal populations of the two possible orientations of the cation [H atoms at Wyckoff positions $8(g), x x x$ etc., symmetry $3 m$ ]. The use of the term 'order-disorder transition' stems from the difference in hydrogen arrangements in the two phases, as Mnyukh pungently remarks. ${ }^{\mathbf{1 0}}$ For both structures N is at the origin and $\mathrm{Cl}$ at the body center, $x_{H}=0.154$ (3). These results were given by Levy \& Peterson (1952), who determined the room-temperature structures of polycrystalline $\mathrm{ND}_{4} \mathrm{Cl}$ and of single-crystal $\mathrm{NH}_{4} \mathrm{Cl}$ by neutron diffraction (and who give references to earlier work). Above $457.5 \mathrm{~K}$ the

\footnotetext{
10 See p. 187: 'The fact that the $H$ phase is more 'disordered' than $L$ is merely another difference between them, bearing no relation to the mechanism of molecular rearrangement at the interface'.
} 


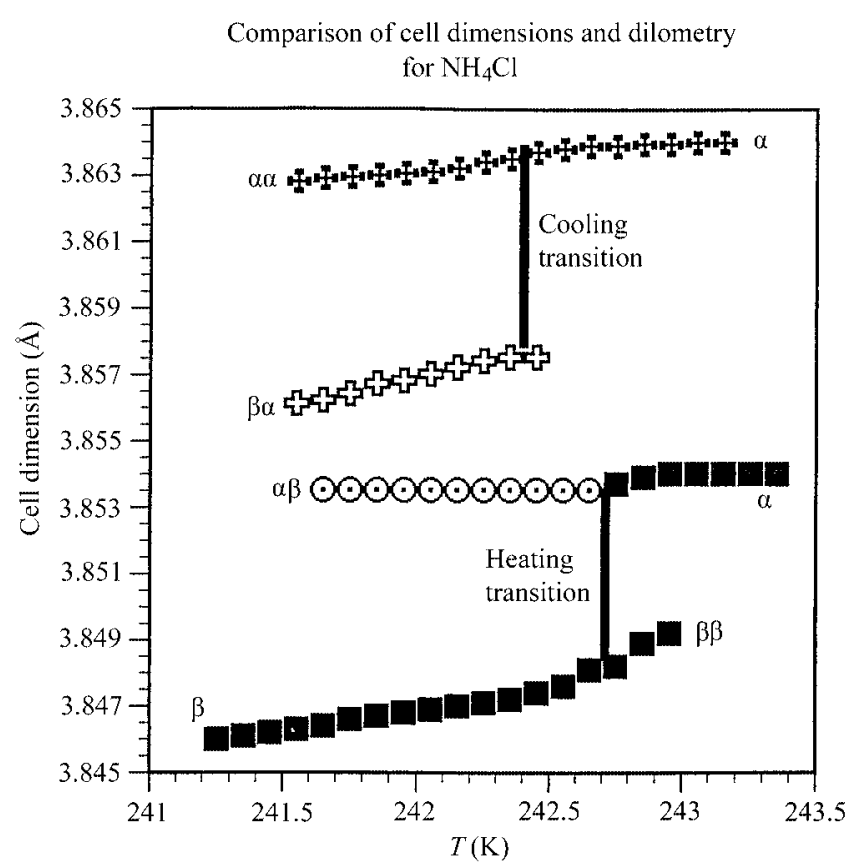

(a)

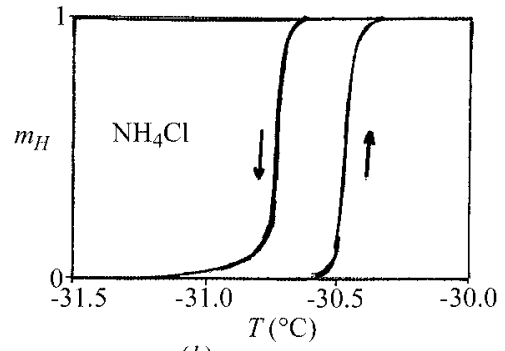

(b)

Figure 7

(a) $\mathrm{NH}_{4} \mathrm{Cl}$ dependence of the cell dimensions of $\mathrm{NH}_{4} \mathrm{Cl}$ on temperature in the region of the transition at $242 \mathrm{~K}$ (measurements made with $\mathrm{Cu} \mathrm{K \alpha}$ using the (024) plane of a single crystal). As numerical data are not given by Dinichert, enlargements of diagrams from his paper have been digitized and relabeled. Also, Dinichert's (diffraction) angle measurements were not on an absolute scale and had to be standardized by comparison with other measurements; it seems that Dinichert's values are in $\mathrm{kX}$ and should be multiplied by 1.00202 to place them on an $\AA$ scale. For clarity, the curves of the 'cooling transition' have been shifted vertically by $0.01 \AA$. Adapted from Fig. 8 of Dinichert (1942). (b) $\mathrm{NH}_{4} \mathrm{Cl}-$ dilatometry of $\mathrm{NH}_{4} \mathrm{Cl}$, values being taken from Table 1 of Smits et al. (1937; cf. their Fig. 4). In our diagram, molecular volumes have been converted into a mean cubic cell edge for comparison with Dinichert's results. We remind the reader that Dinichert gives separate results for each of the two phases, while dilatometry gives values for the system as a whole with varying proportions of the two phases as the transition progresses, thus the ordinate spread in the lower diagram is about twice as large as that in the upper diagram.

structure becomes that of $\mathrm{NaCl}$, but this high-temperature transition is not relevant here.

Our concern here is with the widely studied, so-called $\Lambda$ transition in $\mathrm{NH}_{4} \mathrm{Cl}$ at $\sim 242 \mathrm{~K}$, which we introduce by comparing atmospheric pressure ${ }^{\mathbf{1 1}}$ measurements over the range $0-350 \mathrm{~K}$ of specific heat (Fig. 5a; Simon, 1922), cell dimensions and thermal expansion (Figs. $5 b$ and $c$; Hovi et al.,

\footnotetext{
${ }^{11}$ Other measurements on $\mathrm{NH}_{4} \mathrm{Cl}$ not in the direct line of the present argument are summarized in Appendix 4.
}

1973). It is perhaps difficult to infer the order of the transition from the specific heat measurements, but the discontinuity in the cell dimensions (and hence in the volume) shows clearly that the transition is first order, as indeed had been established by earlier dilatometric measurements of Smits et al. (1937; Fig. $8 b$ ) (cf. Smits \& MacGillavry, 1933) and single-crystal X-ray diffraction measurements of Dinichert (1942; Fig. 7a).

The chronology of the calorimetric measurements is interesting. The $\Lambda$ transition was first measured in a heating regimen by Simon (1922; additional measurements for all four ammonium halides were reported by Simon et al., 1927), followed by measurements of Extermann \& Weigle (1942) in both heating and cooling regimens (but without distinction between endotherm and exotherm). A number of other calorimetric measurements followed. We reference only Chihara \& Nakamura (1972), who give references to earlier work. The decisive DSC measurements of Mnyukh (2001, Fig. 3 of his Appendix 2) show clearly that there is an endotherm on passing through the phase transition from lower to higher temperature, and an exotherm on cooling. This demonstrates that the enthalpy changes are latent heats associated with the transition, which is of first order, in agreement with the conclusions from the XRD measurements described immediately above and below. Conflicting values have been given for the enthalpy of transition: $1168 \mathrm{~J} \mathrm{~mol}^{-1}$ by Chihara \& Nakamura (1972); $466 \pm 15 \mathrm{~J} \mathrm{~mol}^{-1}$ at atmospheric pressure by Wirths \& Schneider (1981) and $351 \pm 42 \mathrm{~J} \mathrm{~mol}^{-1}$ by Mnyukh (see p. 182). The reasons for the differences are not known.

Dinichert's (1942) study of the transition was made using a single crystal, whereas most of the earlier studies (and many subsequent ones) were made on polycrystalline samples. The spacing of the 024 reflection $\left(\theta_{\text {Bragg }}\right.$ for $\left.\mathrm{Cu} K \alpha_{1}, \alpha_{2} \simeq 63^{\circ}\right)$ was measured as a function of temperature around $242 \mathrm{~K}$ using a custom-built apparatus with temperature control to $0.01 \mathrm{~K}$ (Fig. 6), which could be considered a precursor of the Bond (1960) diffractometer for precision measurement of lattice spacings. The cell dimension measurements (Fig. 7a) were

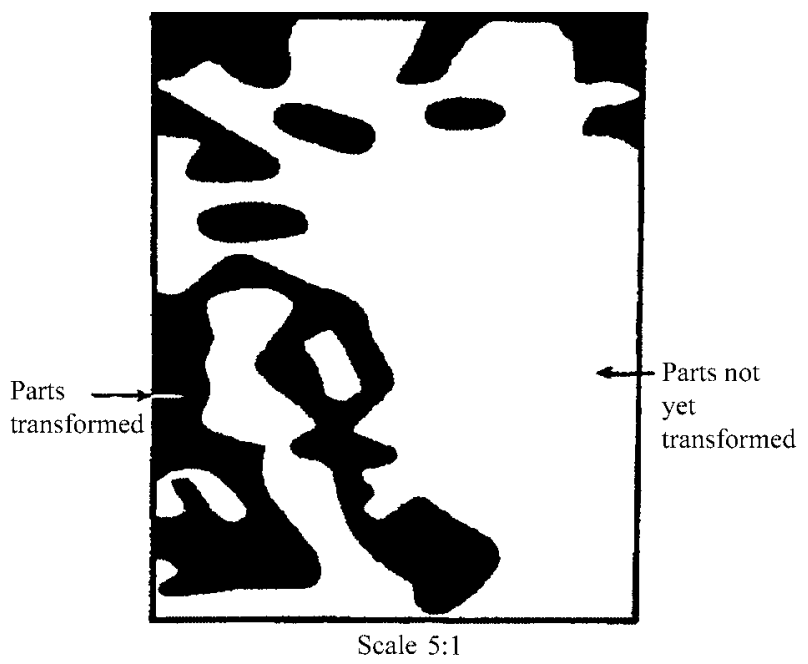

Figure 8

$\mathrm{NH}_{4} \mathrm{Cl}$ - photograph of the surface of the partially transformed $\mathrm{NH}_{4} \mathrm{Cl}$ single crystal. Adapted from Dinichert (1942). 
remarkably detailed. The width of the hysteresis is $0.24^{\circ}$ and the coefficients of linear expansion are $170 \times 10^{-6} \mathrm{deg}^{-1}$ for the low-temperature $[\mathrm{EI}(<242 \mathrm{~K})-\beta]$ phase and $82 \times$ $10^{-6} \mathrm{deg}^{-1}$ for the high-temperature [EII $(242<T<458 \mathrm{~K})-\alpha$ ] phase (calculated from Fig. 4 of Dinichert, 1942); values from Fig. 7(c) are 100 and $60 \times 10^{-6} \mathrm{deg}^{-1}$. The cell volume changes by $0.27 \AA^{3}$ at the transition (fractional change $4.7 \times 10^{-3}$ compared with $3.6 \times 10^{-3}$ from dilatometry). Dinichert states that a full explanation of all the details in this diagram require that there should be six separate phases $(\alpha, \beta, \alpha \alpha, \beta \alpha, \alpha \beta, \beta \beta)$, but it is difficult to assess this claim without knowing how the raw data were treated. Dinichert claimed that, in terms of the fine detail, the transformation is not reversible. In a simpler, but perhaps incomplete, picture the curve labeled $\beta$ (from lower left to the vertical line at $T=242.7 \mathrm{~K}$ ) followed by the curve in the middle right labeled $\alpha$ shows the progress of the EI to EII heating transition; the curve labeled $\beta \beta$ is from the EI phase that has not yet transformed. An analogous description applies to the cooling transition. The provenance of the curve labeled $\alpha \beta$ is not clear, but it possibly refers to the not-yet-transformed [EII- $\alpha$ ] phase. Measurements of cell dimensions as functions of temperature do not give the amounts of the two phases present; this must be obtained from intensity measurements and is given in Dinichert's Fig. 5. Dinichert's XRD results (Fig. 7a) show clearly that there is a discontinuity in the volume-temperature curve; thus, the transition is first order; the details receive a simple explanation in terms of the nucleation-and-growth model, and (our) Fig. 7(a) is compatible with (our) Fig. 4. These details were given explicitly by Mnyukh (1983) and are summarized on pp. 186187 of Mnyukh (2001). There would be considerable interest in repeating Dinichert's XRD results using $\mathrm{ND}_{4} \mathrm{Cl}$, particularly if this was coupled with a microscope study. In retrospect, Dinichert's experimental study was a remarkable achievement well ahead of its time, with implications for the mechanism of phase transitions that have taken many years to be appreciated.

It was also possible to examine the surface of the crystal at the transition point at a magnification of $5 \times$ (Fig. 8 ; this surely provides an incentive for emulation by atomic force microscopy). Characterization of $\mathrm{NH}_{4} \mathrm{Cl}$ as a non-epitaxic system is based on Fig. 8.

Dinichert (1942) gives 13 references to studies of the $242 \mathrm{~K}$ transition during the period 1922-1940. Particularly noteworthy are the dilatometric measurements of Smits and coworkers (Smits \& MacGillavry, 1933; Smits et al., 1937). Dinichert himself contributed three studies of the transition in $\mathrm{NH}_{4} \mathrm{Cl}$ - by single-crystal XRD (Dinichert, 1942), measurements of the dielectric constant at the transition point (Dinichert, 1944a) and a theoretical study of the hysteresis (Dinichert, 1944b); another theoretical study was by Thomas \& Staveley $(1951 b)$.

A considerable effort has been invested in establishing the details of the volume-temperature curves measured by dilatometry for ammonium chloride crystals of different provenance (isotope composition, method of preparation, crystallite size) and comparison of the dilatometer results for $\mathrm{NH}_{4} \mathrm{Cl}$ and
$\mathrm{ND}_{4} \mathrm{Cl}$ shows that these measurements can give useful information. However, when one takes into account more recent developments, one must reluctantly conclude that most of these careful measurements do not provide new insights. Different samples with different amounts of defects will inevitably give slightly different $V-T$ curves. This possibly tells us something about the samples, but very little about the transition.

[Ubbelohde was well aware of Dinichert's work; the following remarks appear in his 1956 paper (see p. 318), with similar remarks in the later papers: ' $I n \mathrm{NH}_{4} \mathrm{Cl}$ there is a jump in lattice spacing from $3.8540 \AA$ in structure 2 to $3.8480 \AA$ in structure 1 with a peak transition temperature at $-30.8^{\circ} \mathrm{C}$. Coexistence of subunits of crystal with each of these spacings, in a hybrid singlecrystal, has been verified [by Dinichert] in the transition region. As the temperature is changed from $-30.8^{\circ} \mathrm{C}$ in either direction, one form absorbs the other'.]

To summarize: the phase transition in $\mathrm{NH}_{4} \mathrm{Cl}$ at $242 \mathrm{~K}$ is first order based on the occurrence of hysteresis and the form of the cell dimension-temperature curves; according to the little evidence available, the transition is non-epitaxic. The premonitory effects in specific heats and cell dimensions appear to be the source of the ' $\Lambda$ ' nomenclature.

\subsection{Tetrathiafulvalene ‥chloranil (TTF...CA) - the neutral to ionic transition at $82 \mathrm{~K}$}

The first study of this molecular compound (needles along [100] crystallized from acetonitrile) showed a mixed stack, neutral ground-state crystal structure at $300 \mathrm{~K}\{a=7.411$ (1), $b$ $=7.621$ (2), $c=14.571$ (3) $\AA, \beta=99.20$ (1) $)^{\circ} P 2_{1} / n, Z=2$; stack axis [100]; degree of charge transfer 20\%; Mayerle et al., 1979; TTFCAN\}. In parallel studies, powder patterns (temperature range $10-300 \mathrm{~K}$ at 1 bar) were indexed in terms of the same unit cell throughout; no additional reflections appeared on cooling to $4 \mathrm{~K}$ nor was there evidence for a triclinic distortion. There were also cell dimension measurements, from single crystals at $300 \mathrm{~K}$, over the pressure range 0-20 kbar. Distinct changes of slope were seen at $84 \mathrm{~K}$ and 1 bar, which was identified as the 1 bar neutral $\Leftrightarrow$ ionic transformation temperature, and at $11 \mathrm{kbar}$ and $300 \mathrm{~K}$, identified as the $300 \mathrm{~K}$ neutral $\Leftrightarrow$ ionic transformation pressure. This work was followed, some 15 years later, by a detailed neutron diffraction study using co-sublimed crystals (Le Cointe, 1994: ${ }^{\mathbf{1 2}}$ Le Cointe, Lemée-Cailleau et al., 1995); other techniques $\left(C_{P}-T,{ }^{35} \mathrm{Cl}\right.$ NQR, IR and Raman spectroscopy) have also been used in concurrent and subsequent studies. We shall refer to this body of work as coming from the University of Rennes I Group (URennes I), but it actually comes from a wider interlaboratory and international collaboration. The cell dimensions at various temperatures and pressures (up to $5 \mathrm{kbar}$ ) are shown in Fig. 9 (Le Cointe, 1994). At atmospheric pressure there are abrupt changes in [010] and [001] around $81 \mathrm{~K}$, and to a lesser extent in $\beta$ and $V$, while [100] is continuous; the effects of pressure will be discussed later. This demonstrates

\footnotetext{
${ }^{12}$ I am grateful to Dr Marylize Buron-Le Cointe for a copy of her doctoral thesis (University of Rennes I).
} 

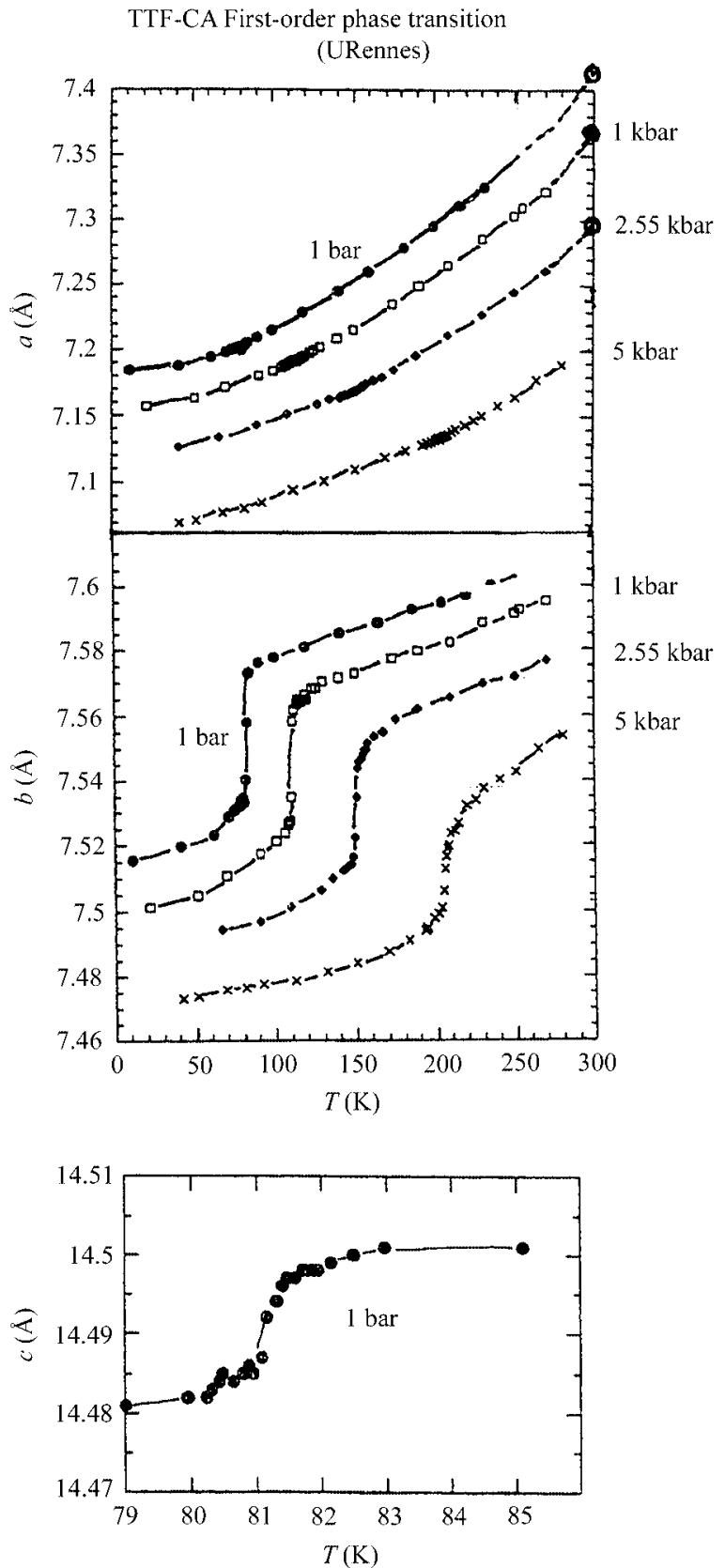

Figure 9

TTF...CA - the temperature and pressure dependence of the cell dimensions of TTF-CA (values for [001] were given only for the temperature range shown); $\beta$ is $99.1^{\circ}$ at $300 \mathrm{~K}$ and $98.6^{\circ}$ at $50 \mathrm{~K}$ (both at 1 bar). These (and other) results show that there is a neutral (N) to ionic (I) phase transition on cooling. This is first order at $1 \mathrm{bar}$, but appears to change towards second order as the pressure increases to $5 \mathrm{kbar}$. It is shown later that cell dimension values between 7.54 and $7.58 \AA$ on the [010] 1 bar curve are artifacts; this probably also holds for [001] between 14.485 and $14.500 \AA$ A. This figure is taken from Figs. 5, 6 and 4(c) of Le Cointe (1994). The 1 bar curves are given in Fig. 3 of Le Cointe, LeméeCailleau et al. (1995).

the occurrence of a first-order phase transition at atmospheric pressure $\left(\Delta V \simeq 5 \AA^{3}\right)$, but also shows that at least one of the cell dimensions ([100]) is continuous through the transition. The principal interest of the URennes I group appears to have been in the nature of the two phases and the driving force for

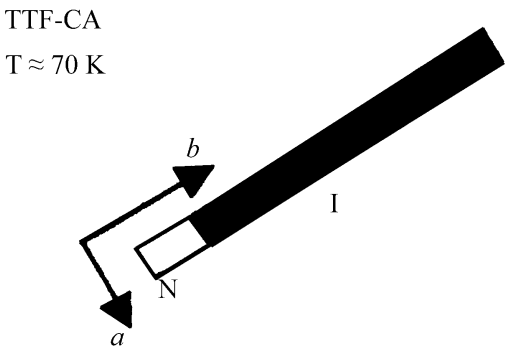

$100 \mu \mathrm{m}$

Figure 10

TTF...CA - the epitaxic relation between $\mathrm{N}$ and I phases at $70 \mathrm{~K}$ and their coexistence as observed by optical microscopy with unpolarized light. This is adapted from Fig. 6 of Buron-Le Cointe et al. (2003).

the transition, although many measurements were made to establish and illustrate the occurrence of hysteresis. Their excellent and detailed set of measurements provide outstanding material for testing Mnyukh's description of a first-order enantiotropic epitaxic phase transition; we shall find that overall there is excellent agreement between experiment and description, but that some discrepancies remain.

We first illustrate the overall behavior of the TTF...CA system over a range of temperatures and pressures (Fig. 9) and show that the two phases can coexist and are in an epitaxic relation (Fig. 10). We then show the experimental evidence for two essential facets of first-order phase transitions - coexistence of the higher and lower temperature phases over a range of temperatures (Figs. 14 and 15) and hysteresis (Figs. 16, 17 and 18). All these diagrams are from the URennes I group.

The epitaxic growth of $\mathrm{N}$ and I phases and their coexistence at $70 \mathrm{~K}$ is shown visually in Fig. 10. This microphotograph was evidently taken during cooling of a crystal to below the transition temperature, but not enough time had elapsed for complete conversion of the (metastable) neutral phase to the (stable) ionic phase. The interface between the two phases passes down the crystal ( $c f$. Fig. 3); there are many examples in the literature of such interfaces traversing a crystal during a phase transformation.

The space group below $84 \mathrm{~K}$ is inferred from the behavior of the 030 reflection which is systematically absent above $84 \mathrm{~K}^{\mathbf{1 3}}$ The intensity of this reflection increases abruptly below $84 \mathrm{~K}$ (Fig. 11); similar behavior is found over the range $0-5 \mathrm{kbar}$. Thus, the transition involves a change of space group from $P 2_{1} / n, Z=2$ ( $N$ phase) to $P n, Z=2$ ( $I$ phase). In the $N$ phase the TTF and chloranil molecules are located at centres of symmetry, but this requirement is removed in the $I$ phase. Confirmation of the loss of centrosymmetry comes from the ${ }^{35} \mathrm{Cl}$ NQR spectra - two independent resonances in the $N$

\footnotetext{
${ }^{13}$ Le Cointe, Lemée-Cailleau et al. (1995; see \#2, ionic phase) remark that 'only the (070) superstructure reflection was clearly extracted from the background'; however, it is the temperature dependence of (030) that is shown in their Fig. 2(a) (our Fig. 11).
} 
phase and four in the $I$ phase (Gourdji et al., 1991; Gallier et al., 1993; Le Cointe, Gallier et al., 1995).

An apparently similar transition takes place in Naphthazarin $C$ at $110( \pm 1) \mathrm{K}$ (Herbstein et al., 1985). The space group changes from $P 2_{1} / c, Z=4$ above $110 \mathrm{~K}$ to $P c, Z=4$ below $110 \mathrm{~K}$. There are only minor differences between the cell dimensions of the two phases; the space groups are distinguished by the appearance of reflections $0 k 0, k$ odd, below the transition temperature. Thus, the situation in Naphthazarin C is formally analogous to that in TTF..CA; however, the temperature dependence of 070 in naphthazarin C (Fig. 12) is quite different from that of 030 in \{TTF . . chloranil\} (Figs. 11 and 13). The sharp change in the (neutron diffraction) intensity of the space-group determining reflection 030 in TTF...CA is evidence for a first-order change; the gradual change in the (neutron diffraction) intensity of 070 in Naphthazarin $\mathrm{C}$ shows that transition to be second order. A number of $\pi$-molecular compounds also show second-order transitions with a similar temperature dependence of the superlattice reflections (Herbstein, 1996). Microscope studies have not been made for any of these second-order transitions.

However, life is seldom simple, as is shown by the temperature dependence of $I(030)$ of TTF . . CA over a wide range of temperatures and pressures (Fig. 13). Proceeding from the lowest temperatures, these curves start out as though the transition was second order ( $c f$. Fig. 12) and then fall abruptly to zero, as one would expect for a first-order transition. The overall shape, which appears to be qualitatively the same up to at least $5 \mathrm{kbar}$, is somewhat reminiscent of that

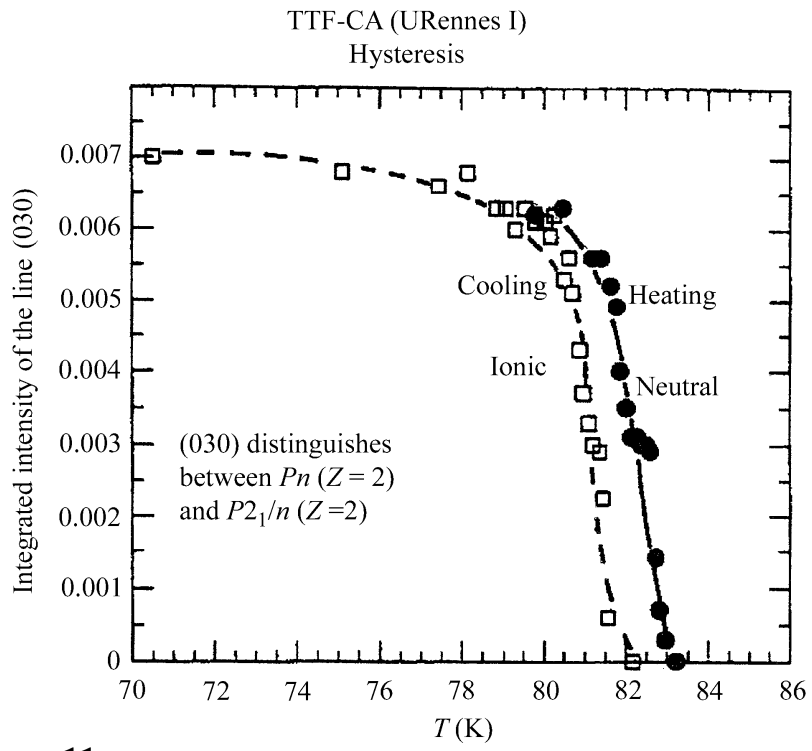

Figure 11

TTF-CA - the intensity of the (030) reflection is shown as the temperature is raised and lowered around the transition temperature of $\sim 81 \mathrm{~K}$. The (030) reflection distinguishes between the neutral-phase space group $P 2_{1} / n$ [((030) absent] and the ionic phase space group $P n$ [(030) allowed]. Note the hysteresis. The cooling curve is Fig. 2(a) from Le Cointe, Lemée-Cailleau et al. (1995) or Fig. 4 from Le Cointe et al. (1996); the complete hysteresis curve is Fig. 2 of Buron-Le Cointe et al. (2003). found for long-range order in $\mathrm{Cu}_{3} \mathrm{Au}$ ( $c f$. Fig. 12.4 of Warren, 1990).

The coexistence of the neutral and ionic phases over a narrow range of temperatures is demonstrated through the behavior of the 020 reflection. There is no evidence for an intermediate phase (Fig. 14). The distinction between spacings and intensities is emphasized in Fig. 14. The spacings (upper diagram) identify a particular phase, while the intensities (lower diagram) give its amount.

An alternative demonstration of the coexistence of the two phases is shown in the reciprocal space representation of Fig.

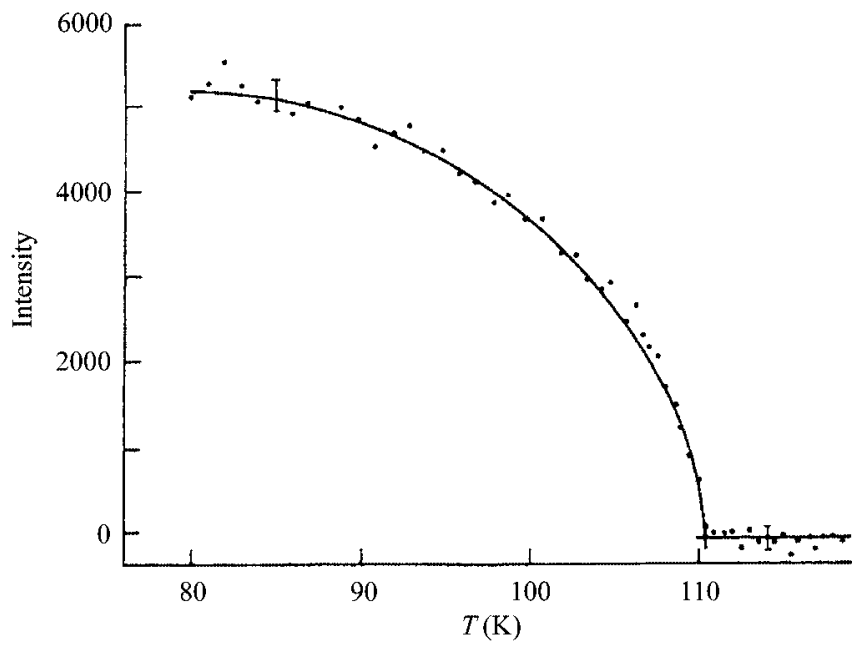

Figure 12

Naphthazarin C: the variation of the integrated intensity as a function of temperature of the 070 reflection, which distinguishes between the disordered phase [stable above $110 \mathrm{~K}$; space group $P 2_{1} / c$, (070) absent] and the ordered phase $[P c,(070)$ allowed $] ..$ Neutron diffraction measurements $(\lambda=0.895 \AA)$ were made for 15 min periods on the D9 reactor at ILL Grenoble. There was no indication of hysteresis. Comparison of Figs. 11 and 12 shows the different behavior of distinguishing reflections in first- and second-order transitions. Reproduced with permission from Herbstein et al. (1985).

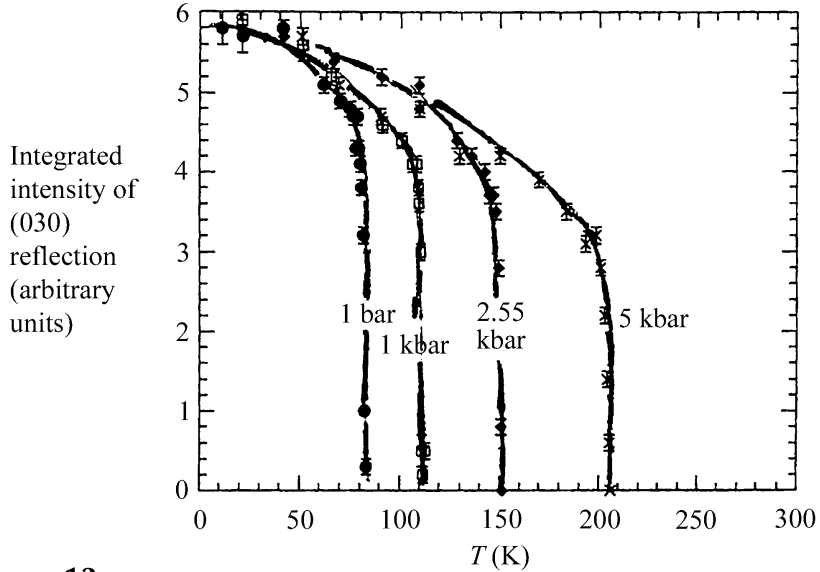

Figure 13

TTF ...CA - temperature dependence of the integrated intensity of the (030) reflection at various pressures showing how the phase-transition temperature changes with increasing pressure. Adapted from Fig. 3 of Le Cointe (1994). 
15. The two peaks in Fig. 15 would be equal at $81.20 \mathrm{~K}$ and this is taken as the transition temperature $\left(T_{0}\right)$. This value is in good agreement with the temperature of intersection of the two (integrated) intensity curves in the lower panel of Fig. 14. Temperatures in these measurements are claimed to be precise to $0.03 \mathrm{~K}$. Vertical lines showing $T_{0}$ have been inserted in other diagrams less suited to the precise determination of $T_{0}$.

The lower panel of Fig. 14 should be compared with Mnyukh's depiction of the changes in the amounts of the two coexisting phases over the region of the transition (Fig. 4). It must be remembered that the ordinate in Fig. 4 is the fraction of the high-temperature phase $\left(m_{H}\right) ; m_{H}$ increases with rising temperature and decreases with falling temperature, whereas in Fig. 14 the ordinate is proportional to the amount of each of
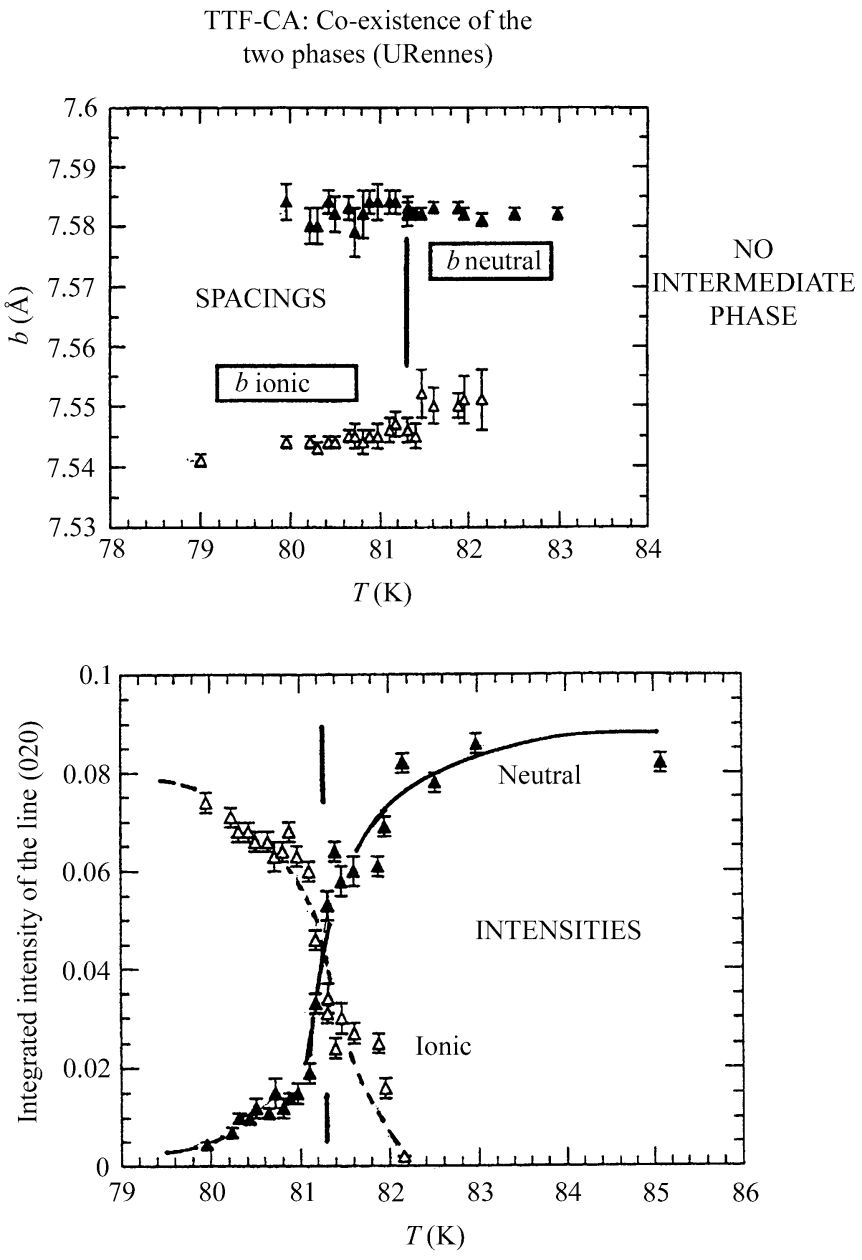

Figure 14

TTF ... CA - co-existence of the $\mathrm{N}$ and I phases in the transition region. The cell dimensions in the upper panel (an embellished view of the lower panel in Fig. 12) show the existence of the two phases. Although there appears to be a small increase in the 020 spacing of the ionic phase at temperatures above the transition temperature, this seems unlikely to be significant because there is much less of the ionic phase and hence the cell dimension measurements are likely to be less precise. The integrated intensity measurements in the lower panel show their relative amounts. The measurements were made at increasing temperatures - the ionic phase diminishes and the neutral phase grows. This is Fig. 4 of Buron-Le Cointe et al. (2003). the coexisting phases. The lack of symmetry in Fig. 4 contrasted with the approximately symmetrical disposition of the two curves about $T_{0}$ in Fig. 14 follows from this usage. However, there appears to be a real difference between the two figures (in addition to the 'nomenclature' difference) in that in Fig. 4 the growth and decay curves are separated along the temperature axis, whereas in Fig. 14 (lower panel) the two intensity (amount) curves intersect, showing the coexistence

TTF-CA (URennes I) co-existence of neutral and ionic phases

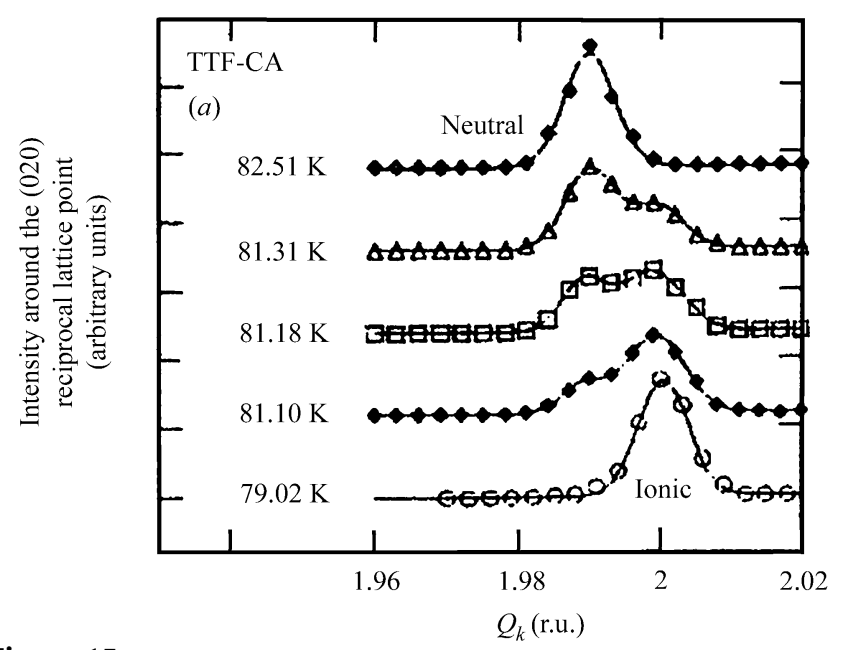

Figure 15

TTF ...CA - a reciprocal space representation of the dependence of the intensity and position of the $(020)$ reflection as a function of temperature. The information given here is actually a combination of that in the two panels of Fig. 14. Adapted from Fig. 3(a) of Buron-Le Cointe et al. (2003) and Fig. 12 of Le Cointe (1994).

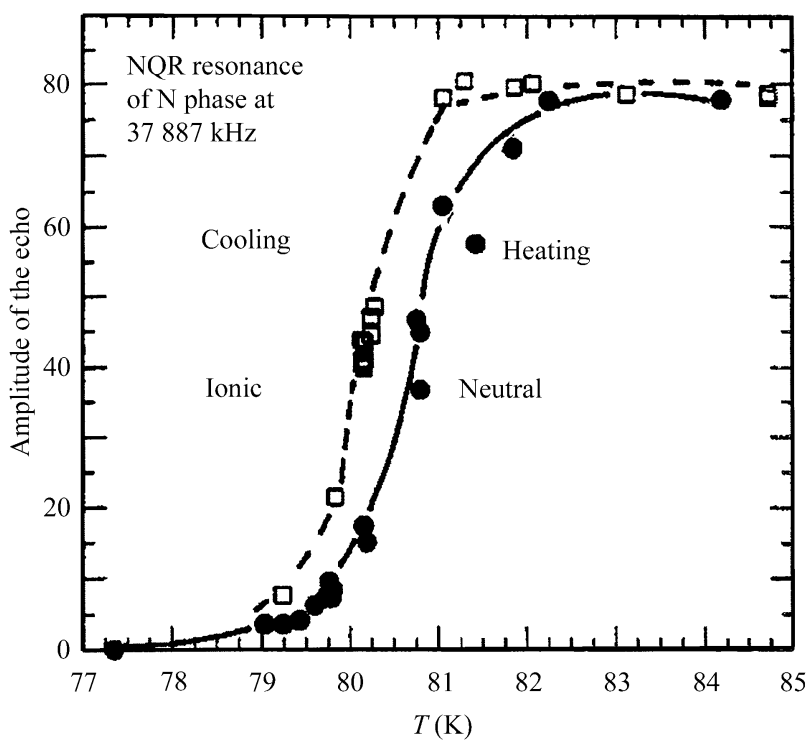

Figure 16

TTF ...CA - the intensity of the high-frequency NQR resonance of the neutral phase $(37887 \mathrm{kHz}$ at $81 \mathrm{~K}$ ) as a function of temperature around the transition temperature. Note the hysteresis. Adapted from Fig. 4 of Le Cointe et al. (1995). 
of the two phases in the transition region. A sample heated from well below $T_{0}$ has an $N$ phase present below $T_{0}$ (a premonitory effect). This is not found in Fig. 4. A possible explanation is that, because of the constraints of the experiment, the neutron diffraction samples had not attained equilibrium (or even a steady state).

Hysteresis is shown by diffraction (Figs. 11 and 18) and other techniques such as ${ }^{35} \mathrm{Cl}$ NQR (Fig. 16) and calorimetric measurements (Fig. 17). As already noted, there is a distinction between the different kinds of measurement. Dilatometry (not reported for TTF...CA) and $C_{p}$ give values for the sample as a whole, while the diffraction measurements and evolution of the amplitude of a particular ${ }^{35} \mathrm{Cl} \mathrm{NQR}$ resonance show the behavior of a particular phase. Diffraction measurements of hysteresis have an advantage over other measurements - they can show the effects of anisotropy (Fig. 18). Thus, the upper panel of Fig. 18 shows no hysteresis in the [100] direction, in accordance with the fact that there is no spacing discontinuity in this direction (upper panel in Fig. 9), but there is hysteresis in the [010] direction (mutual shift of heating and cooling curves) and this matches the discontinuity found in this parameter (centre panel of Fig. 9). Hysteresis apparently could not be studied for [001] and $\beta$.

\section{TTF-CA (URennes)}

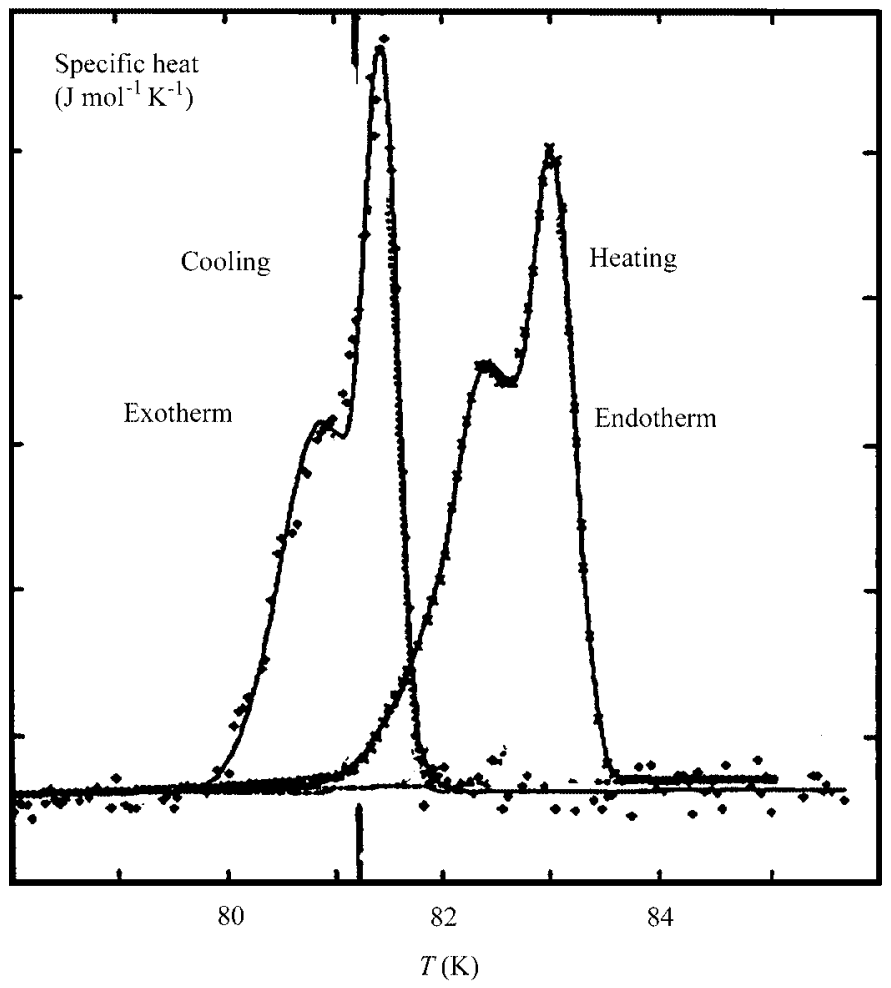

Figure 17

TTF...CA - specific heat anomaly (i.e. background subtracted) for heating on the right and cooling on the left. The heating anomaly is an endotherm and the cooling anomaly an exotherm; this distinction would be shown by a DSC study which appears not to have been reported. $T_{0}$ is shown by a vertical line at $81.20 \mathrm{~K}$; the heating curve shows superheating of $\sim 2^{\circ}$, while the supercooling appears negligible. Adapted from Fig. 5(a) of Le Cointe (1994) and Fig. 5 of Buron-Le Cointe et al. (2003).
There is a curious contradiction between the upper panel of Fig. 14 on the one hand and the lower panel of Fig. 18 on the other. The absence in Fig. 14 of cell dimensions between [010] $=7.545$ and $7.58 \AA$ means that there is no intermediate phase between neutral and ionic. However, in Fig. 18 (and also in the centre panel of Fig. 9), we see a continual series of cell dimensions between 7.525 and $7.570 \AA$. This is presumably an artifact of the method of measurement. If the resolution between peaks was poorer than that shown in Fig. 15 (perhaps at an early stage of the experiment), then overlapped peaks could have been interpreted as showing a continuous change in [010] and thus, erroneously, the occurrence of an intermediate phase.

The ${ }^{35} \mathrm{Cl}$ NQR measurements shown in Fig. 16 are for one of the two independent lines of the neutral phase. The temperature dependence of the amplitude shows hysteresis with a distinct separation between heating and cooling curves. Indeed, the form of the curves is more or less what would be expected from Fig. 4.

TTF-CA First-order phase transition (URennes)
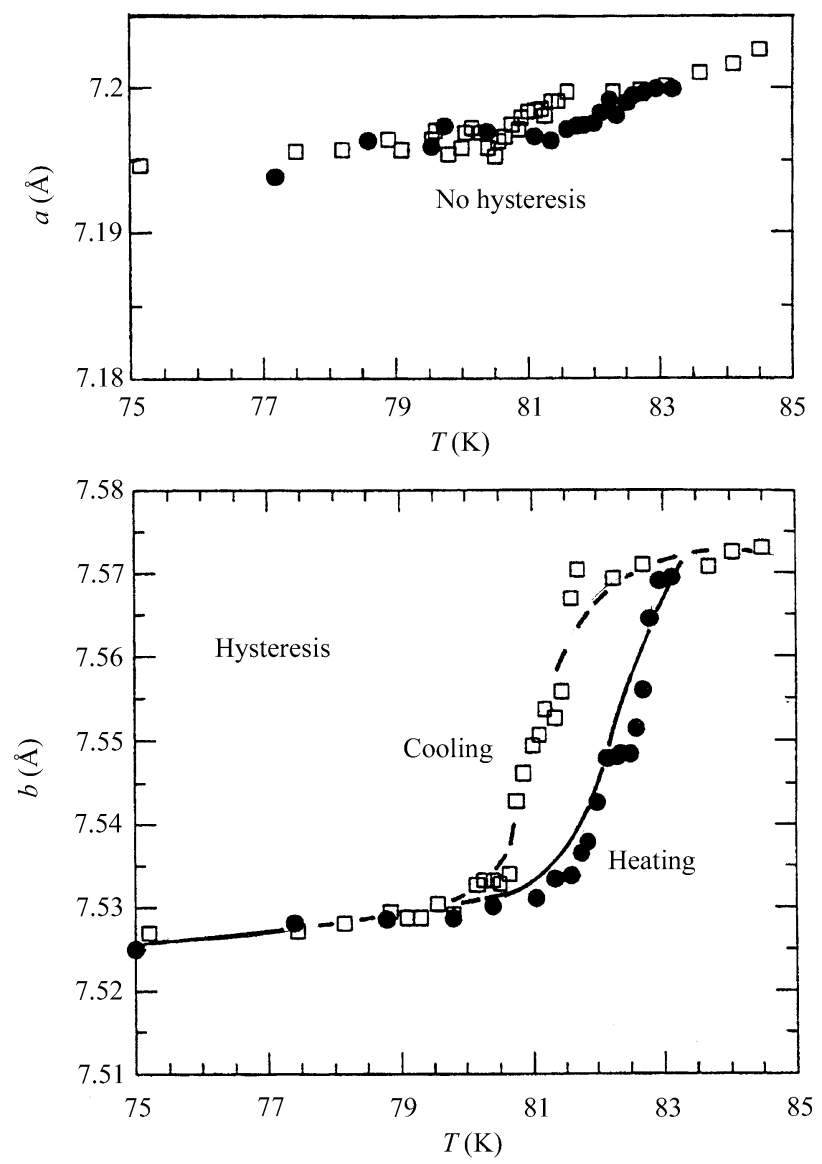

Figure 18

TTF ...CA - values of the [100] and [010] cell dimensions as a function of temperature in the region of the neutral to ionic first-order phase transition. The heating curve is shown by filled circles and the cooling curve by open squares. This figure shows the anisotropy in the hysteresis. Curves are guides to the eye. Adapted from Fig. 7 of Le Cointe (1994). 
Table 2

Cell dimensions ( $\AA{ }^{\circ}{ }^{\circ}$; reduced cells) for the three phases of $p$-dichlorobenzene.

Comparison of EII and EIII phases shows similarity if $b$ and $c$ (and the corresponding angles) are interchanged.

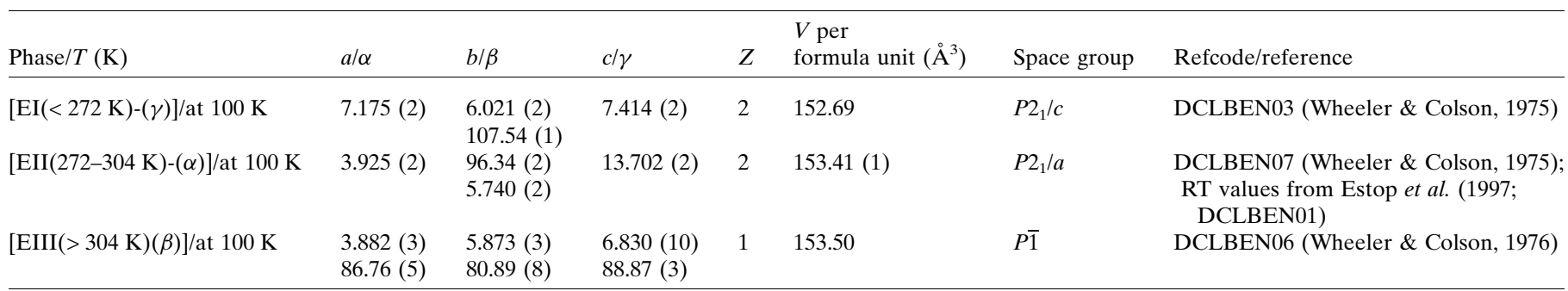

Calorimetric measurements have been made by two groups, with overall agreement but differences of detail. Buron-Le Cointe et al. (2003) show results for both heating and cooling measurements, obtaining split peaks in both directions (Fig. 17). The peak obtained on heating must be an endotherm and that obtained on cooling an exotherm. Hysteresis is clearly shown. A DSC measurement would distinguish between the kinds of peak; this has been shown for ammonium chloride by Mnyukh (2001; see p. 291 and elsewhere), but not reported for TTF...CA. Kawamura et al. (1997) gave results for the temperature range $8-300 \mathrm{~K}$ and over the range $80-86 \mathrm{~K}$ (samples heated). In the present context we need only note that a single peak was found in the $C_{p}-T$ curve at $\sim 82 \mathrm{~K}$. There were complications with sample preparation, described in detail in the original paper. Both sets of calorimetric measurements would appear to require reconsideration.

Finally, we contrast the hysteresis found for [010] at 1 bar with the absence of hysteresis at 5 kbar (Fig. 19). This indicates that the transition is first order at 1 bar and second order at 5 kbar. If so, the tricritical point in the phase diagram (Fig. 4 of Lemée-Cailleau et al., 1997) must be shifted.

To summarize: the phase transition in TTF. . CA at $82 \mathrm{~K}$ is first order based on the occurrence of hysteresis and the form of the cell dimension-temperature curves; the transition is epitaxic. The experimental results reported, although mostly designed for other purposes, are perhaps the most detailed available for study of a first-order phase transition. Nevertheless, some details remain unresolved.

\section{Mnyukh's examples}

\section{1. $p$-Dichlorobenzene}

There are three phases and two transitions, of which only that at $304 \mathrm{~K}$ is immediately relevant here. The crystal structures of all three phases at $100 \mathrm{~K}$ have been reported (Table 2; Wheeler \& Colson, 1975, 1976). A calorimetric study gave transition temperatures at 271.77 and $304.35 \mathrm{~K}$ (Dworkin et al., 1976).

The differences between the (volumes per formula unit) for the three phases at $100 \mathrm{~K}$ are small, especially between EII- $\alpha$ and EIII- $\beta$. However, the molecular arrangements in the EII$\alpha$ and EIII- $\beta$ phases are not interconvertible by displacement (even in a strictly formal, geometrical sense) as that in the monoclinic EII- $\alpha$ phase is of the herring-bone type, while all the molecules are translationally equivalent in the triclinic EIII- $\beta$ phase. Such a lack of interconvertibility by displacement is a feature of many systems; here it is strikingly illustrated by an optical microscope study (Fig. 2). Comparison of cell dimensions suggests that the EI to EII transition is also of the nucleation and growth type, but a detailed study does not appear to have been made. In essence, we have here just rephrased Buerger's (1951) classic classification of phase transitions into 'reconstructive' (not interconvertible by displacement) and 'displacive'. This corresponds to the distinction made in mathematics between topologically inequivalent and equivalent systems. Whether a formally possible displacement process is realised in practice or whether such systems also transform by nucleation-andgrowth remains an open question that requires investigation for each system.

$\Delta H$ for the EII- $\alpha$ to EIII- $\beta$ transition has been measured by micro-calorimetry (van Miltenburg \& Berg, 1989) giving $100.8 \mathrm{~J} \mathrm{~mol}^{-1}$ (to be compared with the DSC value of $200 \mathrm{~J} \mathrm{~mol}^{-1}$ given by Petropavlov et al., 1988; their Table 1).

The EI- $\gamma$ to EII- $\alpha$ and EII- $\alpha$ to EIII- $\beta$ transitions have been studied by a simulation technique. The transition was first envisaged to be nucleated by a concerted and coordinated local rearrangement of molecules. Calculations using atom-toatom potentials gave a potential barrier of $\sim 54 \mathrm{~kJ} \mathrm{~mol}^{-1}$ separating the EII- $\alpha$ and EIII- $\beta$ phases, considered sufficiently low to permit such nucleation (Royer et al., 1990). An analogous calculation (Royer et al., 1993) for the EI- $\gamma$ to EII- $\alpha$ transition gave an enormous barrier of $\sim 20000 \mathrm{~kJ} \mathrm{~mol}^{-1}$, completely ruling out such a process. When microcavities were introduced, the parent crystal became unstable, allowing the transition. These results could be interpreted as providing support for the nucleation process proposed by Mnyukh.

\subsection{Hexachloroethane}

This compound has an orthorhombic to monoclinic ${ }^{\mathbf{1 4}}$ transition at $317.4 \mathrm{~K}\left(\Delta H=2565 \mathrm{~J} \mathrm{~mol}^{-1} ; \Delta V=0.0097 \mathrm{~cm}^{3} \mathrm{~g}^{-1}\right)$, and monoclinic to cubic transition at $344.6 \mathrm{~K}[\Delta H=$ $8220 \mathrm{~J} \mathrm{~mol}^{-1} ; \Delta V=0.028 \mathrm{~cm}^{3} \mathrm{~g}^{-1}$ (Seki \& Momotani, 1950; Rahkmenkulov et al., 1975) give $\Delta H=2644$ (8) and

\footnotetext{
${ }^{14}$ Possibly triclinic crystal data have not been reported for this phase.
} 


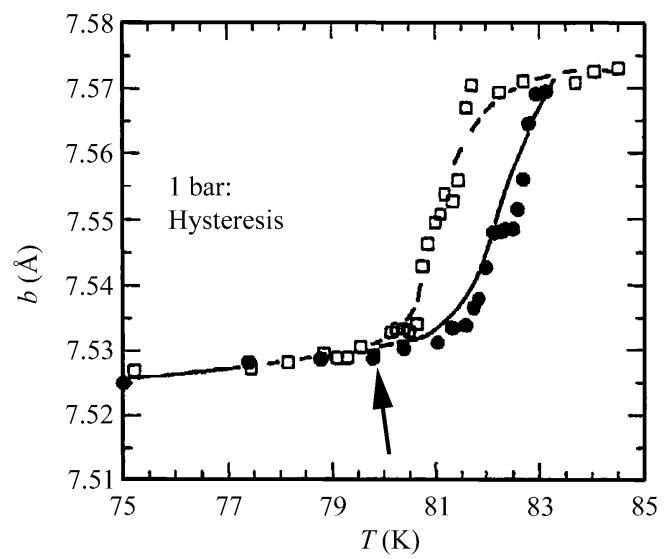

TTF-CA (URennes)

Effect of pressure

on hysteresis

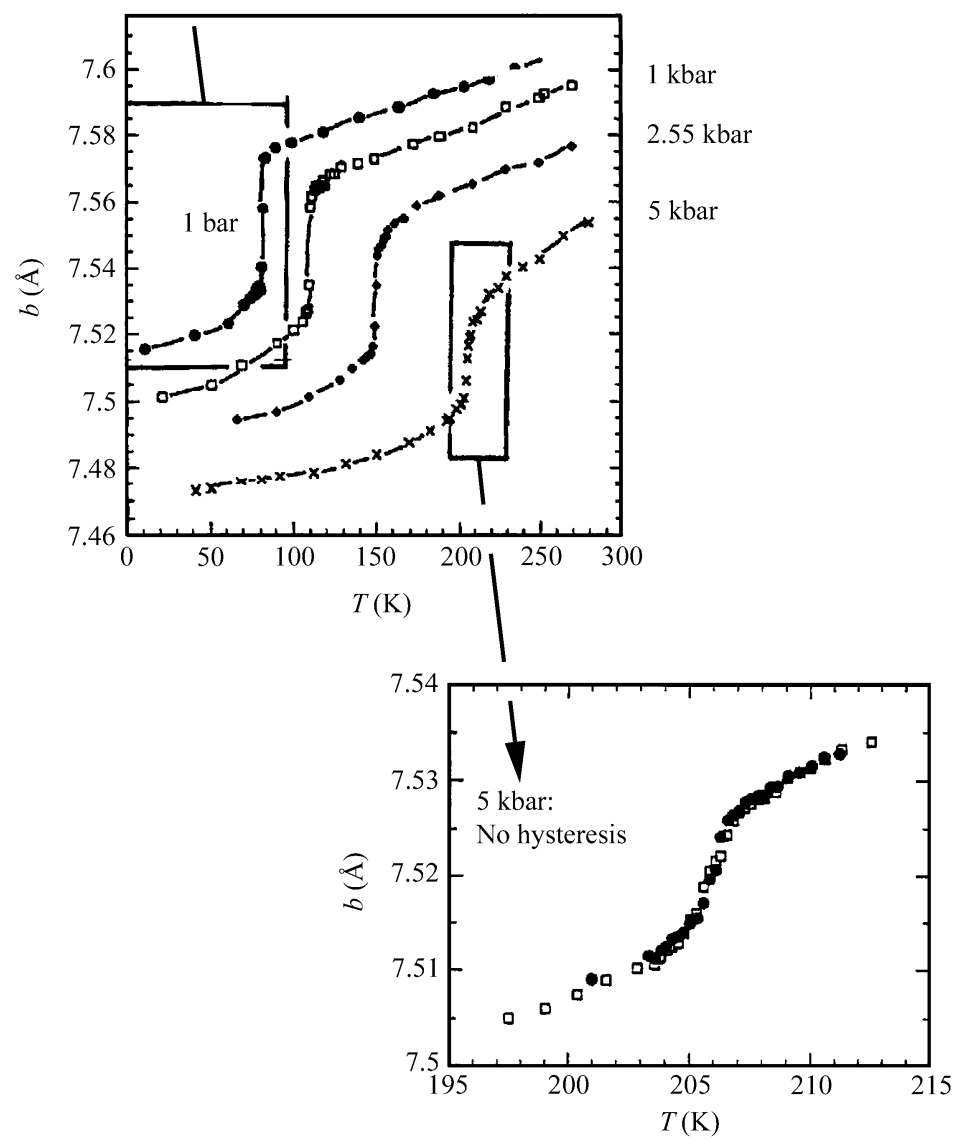

Figure 19

TTF ...CA - the effect of pressure on the temperature-induced neutral to ionic (TINI) transition. The central panel is taken from the central panel of Fig. 9, while the upper panel is the lower panel of our Fig. 18 (Le Cointe, 1994; thesis, Fig. 7) and the lower panel is from Le Cointe (1994; thesis Fig. 16). The filled circles are for the heating regimen and the open squares for cooling.

is marked diffuse scattering; the cubic phase appears to be plastic.

The orthorhombic to monoclinic and monoclinic to cubic transitions were studied dilatometrically by Wiebenga (1935), using highly purified samples. A sample of $65.69 \mathrm{~g}$ was used to study the $317 \mathrm{~K}$ transition. The capillary was $1 \mathrm{~m}$ in length and had a diameter of $1.36 \mathrm{~mm}$; water was used as the dilatometer fluid; temperatures were given to $0.01 \mathrm{~K}$. Only relative changes of volume were reported. Dilatometry of the reversible orthorhombic to monoclinic transition is shown in Fig. 20; the waiting periods to ensure constant temperature varied from 4 to $70 \mathrm{~h}$ and the total time spent on the measurements was $605 \mathrm{~h}$. The transition temperature was determined by measuring the transition rate for a sample containing roughly equal amounts of the two polymorphs as a function of temperature, and extrapolating to zero rate. The transitions were found at 316.75 and $344.25 \mathrm{~K}$, in good agreement with earlier measurements of Steinmetz (1905) and Pascal (1913). Koga \& Miura (1978) used a similar dilatometric technique for the determination of a zero conversion rate, and obtained $T_{0}=316.74$ (3) K; Wiebenga was not referenced. Perhaps surprisingly, the coefficients of volume expansion are similar for the orthorhombic and monoclinic phases. The hysteresis width of the orthorhombic to monoclinic transition was $\sim 1.8 \mathrm{~K}$. The hysteresis width of the monoclinic to cubic transition is $\sim 0.8 \mathrm{~K}$ and the time spent on this experiment was $\sim 29 \mathrm{~h}$, with waiting periods of $\sim 1 \mathrm{~h}$.

Kinetics of nucleation were measured (by dilatometry) for the transition from EII to EI as a function of undercooling (Koga, 1987). A sample that had been swept through the phase boundary

6916 (36) $\mathrm{J} \mathrm{mol}^{-1}$, respectively]. The orthorhombic phase $[(\mathrm{EI}(<317 \mathrm{~K})-(\mathrm{II})]$ was studied by neutron diffraction at 140 and $294 \mathrm{~K}$ (HEXCET02; Hohlwein et al., 1979; at $294 \mathrm{~K}: a=$ 11.568 (4), $b=10.198$ (3), $c=6.409$ (2) $\AA$; volume $/$ molecule = $189.02 \AA^{3}$ at $294 \mathrm{~K}, 181.28 \AA^{3}$ at $140 \mathrm{~K}$, Pnma, $Z=4$; molecule on a mirror plane perpendicular to [010]) and the cubic phase ([(EIII(> $344 \mathrm{~K})]$; HEXCET04; $a=7.51 \AA$ A, $Z=2$; Im3m; Atoji et al., 1953). There is no record of the monoclinic phase [(EII(317-344 K)-(III)] in the CSD. There is no indication of rotational disorder in the orthorhombic phase, although there more than 100 times was found to give reproducible results. After annealing at $323 \mathrm{~K}$ for periods of up to weeks in order to ensure complete conversion to EII, the sample was cooled by $5 \leq T \leq 2.5 \mathrm{~K}$ below $T_{0}$. The induction period ranged from $0.06 \mathrm{~h}$ for $\Delta T=4.83 \mathrm{~K}$ to $1487 \mathrm{~h}(\sim 50 \mathrm{~d})$ for $\Delta T=2.49 \mathrm{~K}$. Koga \& Miura (1978) measured kinetics of growth for the orthorhombic to monoclinic transition on both sides of the transition temperature [growth rate proportional to $\left(|\Delta T|^{3}\right)$ for small conversions]. We shall not reproduce the theoretical analyses of these results. 
Table 3

Thermodynamic data for the phase transitions in malonic acid and perdeuteromalonic acid.

Data from Fukai et al. (1991).

\begin{tabular}{lllll}
\hline Transition & Compound & $T_{\text {trans }}(\mathrm{K})$ & $\begin{array}{l}\Delta H_{\text {trans }} \\
\left(\mathrm{J} \mathrm{mol}^{-1}\right)\end{array}$ & $\begin{array}{l}\Delta S_{\text {trans }} \\
\left(\mathrm{J} \mathrm{mol}^{-} \mathrm{K}^{-1}\right)\end{array}$ \\
\hline $\operatorname{EI}(\gamma)$ to $\operatorname{EII}(\beta)$ & $\mathrm{C}_{5} \mathrm{H}_{8} \mathrm{O}_{4}$ & 47.3 & 14.86 & 0.313 \\
& $\mathrm{C}_{5} \mathrm{D}_{8} \mathrm{O}_{4}$ & 60.0 & 23.86 & 0.40 \\
$\operatorname{EII}(\beta)$ to $\operatorname{EIII}(\alpha)$ & $\mathrm{C}_{5} \mathrm{H}_{8} \mathrm{O}_{4}$ & 352.2 & 1837 & 5.217 \\
& $\mathrm{C}_{5} \mathrm{D}_{8} \mathrm{O}_{4}$ & 348.0 & 1810 & 5.201 \\
\hline
\end{tabular}

A monoclinic crystal was heated through the transition to the cubic (plastic) phase and returned to the monoclinic phase. Comparison of Laue photographs of the original single crystal with those from the product of the cycling process showed that the transition is 'single crystal to textured polycrystal' (Mnyukh, 2001, p. 120).

Hexabromoethane has at least two phases: an orthorhombic phase [HEXBME11; Mandel \& Donohue, 1972; at $295 \mathrm{~K}: a=$ 12.043 (2), $b=10.674$ (2), $c=6.705$ (1) $\AA$; Pnma, $Z=4$ ] that is isomorphous with the orthorhombic phase of hexachloroethane, and a cubic phase (HEXBME03; $a=7.800 \AA$, $Z$ $=2$; space group not given; Koide et al., $1974 ; T_{\text {trans }}=450 \mathrm{~K}$ on heating and $441 \mathrm{~K}$ on cooling; $\Delta H_{\text {trans }}=1.3 \pm 0.1 \mathrm{~kJ} \mathrm{~mol}^{-1}$ ). There is no mention of a monoclinic (or triclinic?) phase in the CSD. The study of possible hysteresis in the phase transition does not appear to have been reported.

Evidence is lacking whether the transitions in hexachloroethane and hexabromoethane are epitaxic or nonepitaxic. The times required to attain equilibrium have been given in some detail for comparison with other (particularly diffraction) experiments.

\subsection{Malonic acid ( $\left.\mathrm{HOOC}-\mathrm{CH}_{2}-\mathrm{COOH}\right)$}

There are three ambient pressure phases in malonic acid, and in perdeuterated malonic acid; the two systems are similar, but there are differences of detail. The triclinic $[\mathrm{EI}(<47 \mathrm{~K})-(\gamma)]$ phase of $\mathrm{C}_{5} \mathrm{H}_{8} \mathrm{O}_{4}$ transforms to a second triclinic phase [EII $(47-352 \mathrm{~K})-(\beta)]$ at $47 \mathrm{~K}$ and this triclinic phase transforms to orthorhombic [EIII $(>352 \mathrm{~K})-(\alpha)$ ] at $352 \mathrm{~K}$. The thermodynamic data (Table 3; Fukai et al., 1991) show that there are appreciable differences of kind between the two transitions. There is unpublished neutron diffraction data for the EI- $\gamma$ and EII- $\beta$ phases (R. K. McMullan \& H.-P. Weber, quoted by Krzystek et al., 1995; Table 4).

The early structural work of Morrison \& Robertson (1949) and Goedkoop \& MacGillavry (1957) on the $\mathrm{C}_{5} \mathrm{H}_{8} \mathrm{O}_{4}$ EII- $(\beta)$ phase was followed by precise studies by Gopalan et al. (2000; MALNAC04; $140 \mathrm{~K}$ ) and Thalladi et al. (2000; MALNAC05; $130 \mathrm{~K})$. The averaged crystal data at $135 \mathrm{~K}$ are given in Table 4. The perdeuterated EIII- $(\alpha)$ phase (powder neutron diffraction at $373 \mathrm{~K}$; MALNAC03; Delaplane et al., 1993) is orthorhombic (Table 4).

The (unpublished) neutron diffraction measurements (on $\mathrm{C}_{5} \mathrm{D}_{8} \mathrm{O}_{4}$ ) also show the EI to EII transition at $60 \mathrm{~K}$ to be first
Dilatometry of hexachloroethane; orthorhombic to monoclinic (Wiebenga, 1935)

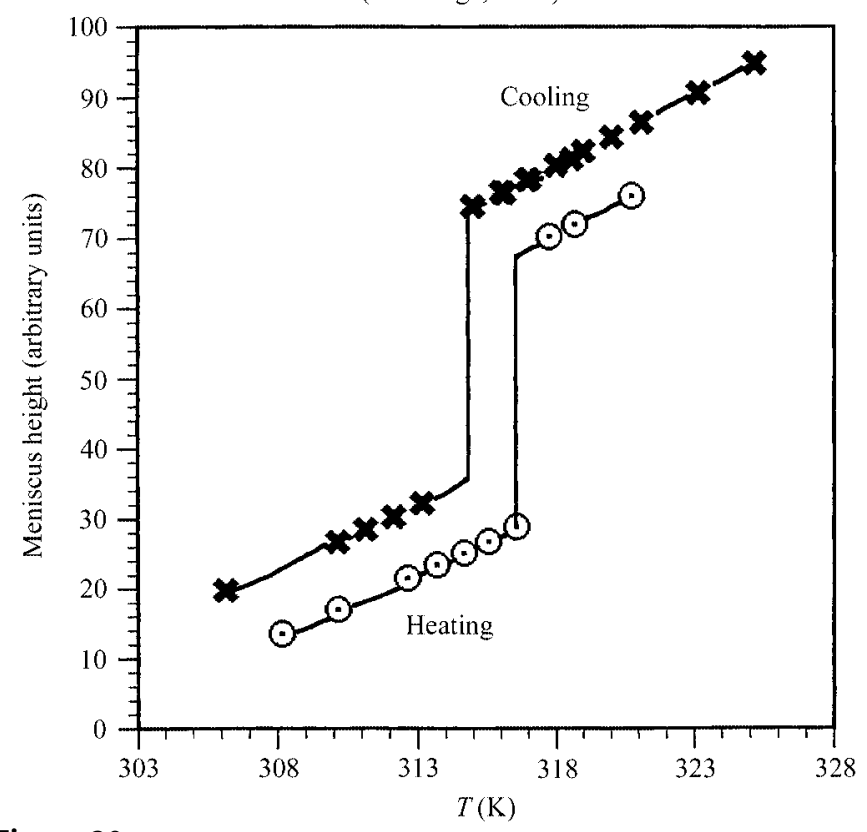

Figure 20

Hexachloroethane - dilatometry of the reversible orthorhombic to monoclinic (triclinic?) transition showing the hysteresis. The cooling curve has been displaced upwards by 10 units for clarity. The width of the loop is $1.8 \mathrm{~K}$. Curves are guides to the eye. Data from Wiebenga (1935).

order, although there are resemblances between cell dimensions and structures ${ }^{15}$ of the two phases. A comprehensive study of this transition in perdeuterated malonic acid has been made by the techniques of electron-nuclear double resonance (ENDOR) and ENDOR-detected nuclear magnetic resonance (EDNMR; Krzystek et al., 1995). These authors suggest that the transition is 'martensitic' and that there may be differences in the time scales of diffraction and resonance measurements. It is possible that the EI to EII transition proceeds by an epitaxic mechanism, as illustrated in Fig. 3, but there is no direct evidence for this.

The EII to EIII transition at $352 \mathrm{~K}$ proceeds by a nucleation-and-growth mechanism (Mnyukh, 2001, Fig. 2.9). There is a conformational change in the molecule; in the EII phase the two cyclic hydrogen-bonded dimer units are almost orthogonal and not symmetry-equivalent. Accordingly, the two dimers have significantly different Raman and IR spectra (Rao et al., 1982). Above $360 \mathrm{~K}$ only one set of vibrational frequencies, attributable to a single type of cyclic hydrogenbonded dimer, is found, and this is confirmed by a ${ }^{13} \mathrm{C}$ NMR study (Jagannathan \& Rao, 1987). The diffraction results showing twofold symmetry for the molecule in the EIII phase are in agreement. The small structural differences between EI and EII phases agree well with the small enthalpy and entropy differences between these two phases; the structural differences between EII and EIII phases are appreciably larger and so are the differences in the thermodynamic parameters.

\footnotetext{
${ }^{15}$ Atomic coordinates for the EI phase are not available.
} 
Table 4

Cell dimensions $\left(\AA{ }^{\circ}{ }^{\circ}\right.$; reduced cells $)$ for the three phases of malonic acid.

A comparison of EI and EII phases shows their similarity if $b$ and $c$ (and corresponding angles) are interchanged.

\begin{tabular}{|c|c|c|c|c|c|c|c|}
\hline Phase/T (K) & $a / \alpha$ & $b / \beta$ & $c / \gamma$ & $Z$ & $V\left(\AA^{3}\right)$ & $\begin{array}{l}\text { Space } \\
\text { group }\end{array}$ & Refcode \\
\hline \multirow[t]{2}{*}{ Perdeuterated EI- $(\gamma) / 56 \mathrm{~K}$} & $5.152(1)$ & $8.070(1)$ & $10.675(1)$ & \multirow[t]{2}{*}{4} & \multirow[t]{2}{*}{407.87} & \multirow[t]{2}{*}{$P \overline{1}$} & \multirow[t]{2}{*}{ ND; quoted by Krystek et al. (1995) } \\
\hline & $107.84(1)$ & $94.93(1)$ & $102.00(1)$ & & & & \\
\hline \multirow[t]{2}{*}{ Perdeuterated $\operatorname{EII}(\beta) / 153 \mathrm{~K}$} & $5.158(3)$ & $5.333(3)$ & $8.157(14)$ & \multirow[t]{2}{*}{2} & \multirow[t]{2}{*}{$206.34(15)$} & \multirow[t]{2}{*}{$P \overline{1}$} & \multirow[t]{2}{*}{ ND; quoted by Krystek et al. (1995) } \\
\hline & $107.99(9)$ & $101.45(8)$ & $95.25(3)$ & & & & \\
\hline Perdeuterated EIII- $(\alpha) / 373 \mathrm{~K}$ & $7.64800(1)$ & $5.02111(1)$ & $11.55803(1)$ & 4 & 443.84 & $P \underline{P b n}$ & ND; MALNAC03 \\
\hline \multirow[t]{2}{*}{ Perprotonated EII $(\beta) / 135 \mathrm{~K}$} & $5.1604(6)$ & $5.3319(5)$ & $8.1838(9)$ & \multirow[t]{2}{*}{2} & \multirow[t]{2}{*}{$207.12(4)$} & \multirow[t]{2}{*}{$P \overline{1}$} & \multirow[t]{2}{*}{ MALNAC04, 05} \\
\hline & $108.083(2)$ & $101.280(2)$ & $95.230(2)$ & & & & \\
\hline
\end{tabular}

\subsection{Glutaric acid [HOOC- $\left.\left(\mathrm{CH}_{2}\right)_{3}-\mathrm{COOH}\right]$}

Glutaric acid has a phase transition at $348 \mathrm{~K}\left(\Delta H_{\text {trans }}=\right.$ $2.3 \mathrm{~kJ} \mathrm{~mol}^{-1}$; Cingolani \& Berchiesi, 1974). The early work of Morrison \& Robertson (1949) on the [EI(?-340 K)- $(\beta)$ ] polymorph has been followed by two precise studies at $130 \mathrm{~K}$ by Gopalan et al. (2000; GLURAC02) and Thalladi et al. (2000; GLURAC03). The averaged crystal data are $a=$ 12.979 (12), $b=4.752$ (2), $c=9.700$ (2) $\AA$, $\beta=98.29(1)^{\circ}, Z=4$, $C 2 / c$, volume per molecule $=148.0(1) \AA^{3}$. The molecule has a twofold axis, with the dimeric rings inclined at $32.5^{\circ}$ to the carbon chain. Cell dimensions were reported for the [EII(340$371 \mathrm{~K})-(\alpha)$ ] polymorph $(a=25.57, b=5.08, c=10.34 \AA$, $\beta=$ $90.02^{\circ}, Z=8, C 2 / c$, volume per molecule $=167.9 \AA^{3}$; m.p. 371 K; Dupré La Tour, 1932), but the crystal structure does not appear to have been determined. The IR spectra of glutaric acid have been recorded across the phase transition (Rao et al., 1982). The bands associated with the bending vibrations of $\mathrm{C}=\mathrm{O}, \mathrm{C}^{\prime} \mathrm{CO}$ and $\mathrm{COO}$ groups show the most change between polymorphs. Mnyukh (2001, Table 2.1) gave the transition temperature as $337 \mathrm{~K}$ and showed micrographs (p. 49, Fig. 2.10) and diffraction patterns (p. 56, Fig. 2.13) interpreted as showing a 'single-crystal to textured polycrystal' transition. This agrees with expectations from a comparison of the cell dimensions of the two phases and the value of $\Delta H_{\text {trans. }}$

\subsection{1,2,3,4,5,6,7,8-Octahydroanthracene}

Two phases are known; the transition occurs somewhere between 318 and $336 \mathrm{~K}$ with $\Delta H_{\text {trans }}=2.2 \mathrm{~kJ} \mathrm{~mol}^{-1}$ (Tseneva \& Godovskii, 1967). The transition has been described in somewhat different ways. Vatulev \& Prikhot'ko (1965) describe the transition at $318 \mathrm{~K}$ as martensitic, KühnertBrandstätter \& Moser (1981) report 'Die R-Form wandelt sich ab ca $60^{\circ} \mathrm{C}$ in die $\mathrm{H}$-Form um, wobei die meist gerade Umwandlungsfront über den Kristall hinweg zu laufen scheint'. They also note that the IR spectra of the two phases are essentially identical. This could suggest epitaxic growth. However, Mnyukh's photomicrographs (2001, p. 46; Mnyukh \& Petropavlov, 1972) show 'a cluster of rod-like $H$ crystals growing in divergent directions in the rhombus-shaped $L$ single-crystal', indicating a nucleation and growth mechanism, which is also indicated by the value of $\Delta H_{\text {trans }}$.
Two structure determinations at $110 \mathrm{~K}$ and room temperature, respectively, appear to be in good agreement (van Koningsveld \& Baas, 1984; CEKWEU at $110 \mathrm{~K}$; Wilson et al., 1986; CEKWEU01 at room temperature; Table 5), but comparison of the data sets shows a difference of $\sim 0.3 \AA$ in $c$, $1.3^{\circ}$ in $\beta$ and different space groups. The structure determinations show that the two phases are indeed different; this is illustrated by comparison of the projections down [001] (Figs. 21 and 22). The CEKWEU crystals were grown from acetone at $278 \mathrm{~K}$; details were not given for CEKWEU01. The difference in structures suggests that Mnyukh's description is correct, but further investigation into the transition itself seems desirable.

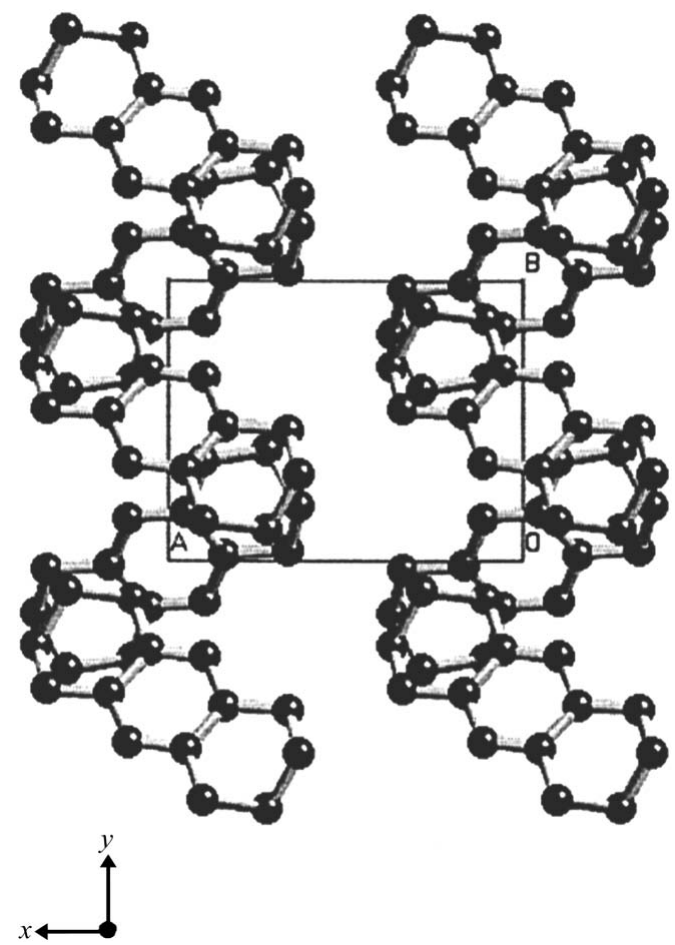

Figure 21

Octahydroanthracene - crystal structure of the low-temperature EI phase (CEKWEU) projected down [001]. $\mathrm{H}$ atoms omitted for clarity. Data from van Koningsveld \& Baas, 1984. 
Table 5

Cell dimensions $\left(\AA \AA^{\circ}\right.$; reduced cells) for the two phases of octahydroanthracene.

Cell shapes are similar, but space groups differ as do packing arrangements (see Figs. 21 and 22).

\begin{tabular}{lllllllll}
\hline Phase $/ T(\mathrm{~K})$ & $a / \alpha$ & $b / \beta$ & $c / \gamma$ & $Z$ & $V\left(\AA^{3}\right)$ & $\begin{array}{l}\text { Space } \\
\text { group }\end{array}$ & $R$ & Refcode \\
\hline EI (?-332 K)/110 K & $9.354(3)$ & $\begin{array}{l}6.550(2) \\
116.99(2)\end{array}$ & $9.622(3)$ & 2 & 525.32 & $P 2_{1} / c$ & 0.038 & CEKWEU \\
EII (332-? K)/RT & $9.437(2)$ & $\begin{array}{l}6.624(2) \\
118.29(2)\end{array}$ & $9.937(3)$ & 2 & 546.98 & $P 2_{1} / n$ & 0.047 & CEKWEU 01 \\
\end{tabular}

Table 6

Thermodynamic data for the transitions of HMB- $h_{18}$ and $-d_{18}$.

Data from Fujiwara et al. (1992).

\begin{tabular}{llllll}
\hline & $\begin{array}{l}T(\mathrm{~K}) \\
\text { (trigonal } \\
\text { to triclinic) }\end{array}$ & $\begin{array}{l}\Delta H \\
\left(\mathrm{~kJ} \mathrm{~mol}^{-1}\right)\end{array}$ & $\begin{array}{l}\Delta S \\
\left(J \mathrm{~K}^{-1} \mathrm{~mol}^{-1}\right)\end{array}$ & $\begin{array}{l}T(\mathrm{~K}) \\
\text { (triclinic } \\
\text { to orthorhombic) }\end{array}$ & $\begin{array}{l}T(\mathrm{~K}) \\
\text { (melting) }\end{array}$ \\
\hline HMB- $h_{18}$ & $117.5 \pm 0.1$ & $1.12 \pm 0.02 \dagger$ & 9.3 & 382 & 439 \\
HMB- $d_{18}$ & $132.4 \pm 0.1$ & $1.73 \pm 0.5$ & $13.1 \pm 0.5$ & 381 & 437 \\
\hline
\end{tabular}

$\dagger$ In good agreement with the value given by Frankosky \& Aston (1965).

\subsection{Hexamethylbenzene (HMB)}

Calorimetric measurements on HMB- $h_{18}(13-340 \mathrm{~K}$; Frankosky \& Aston, 1965) and HMB- $d_{18}(10-300 \mathrm{~K}$; Fujiwara et al., 1992) show two phases and one transition (Table 6, Fig. 23). An additional high-temperature phase found by XRD (Watanabe et al., 1949) is beyond the range of the calorimetric

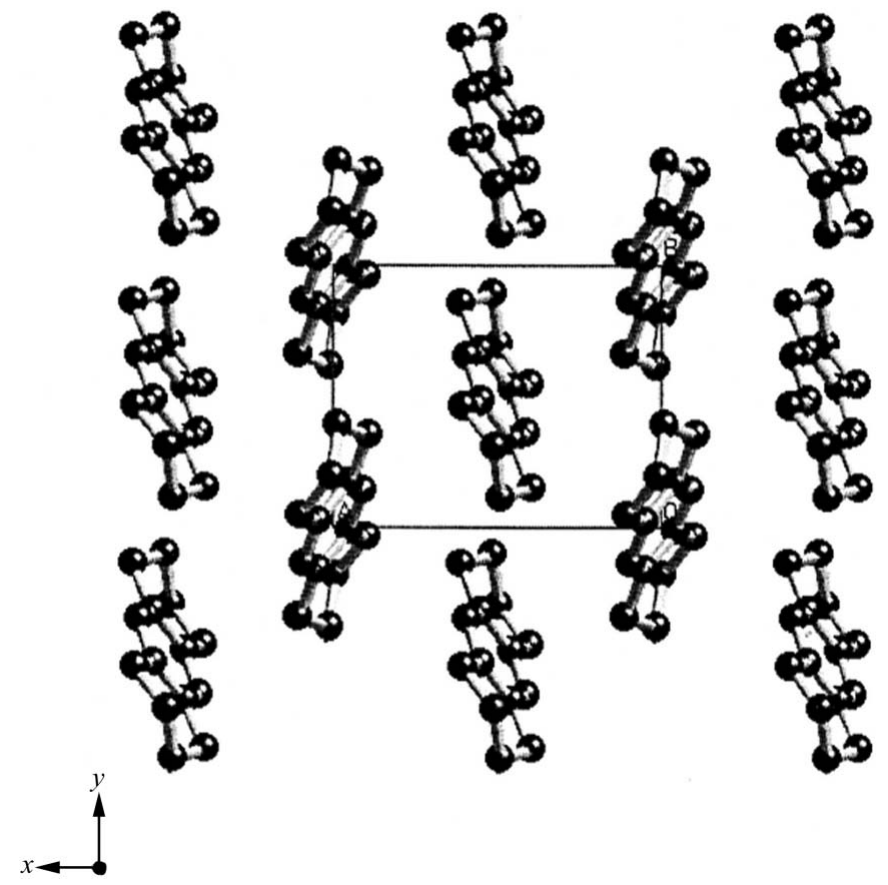

Figure 22

Octahydroanthracene - crystal structure of the low-temperature EI phase (CEKWEU01) projected down [001]. H atoms omitted for clarity. The unit-cell axes are in the same orientation as for Fig. 21. Data from Wilson et al. (1986). measurements. Although the heat capacity measurements (Frankosky \& Aston, 1965) have been classified as showing a $\Lambda$ transition (Westrum \& McCullough, 1963), this does not appear to be supported by the evidence (Fig. 23). A DSC study (KühnertBrandstätter \& Moser, 1981) shows a phase-transition endotherm at $391 \mathrm{~K}$ and a melting endotherm at $431 \mathrm{~K}$; there was some hysteresis on cooling. These authors note that identical IR spectra were obtained for the two phases; they mention 'Lamellierung' of thin crystalline films on cooling. Further evidence for a first-order transition at $\sim 383 \mathrm{~K}$ comes from measurements of the optical path differences in (100) and (001) faces, where abrupt changes occur at $383 \mathrm{~K}$ (Kusto, 1981). The transition at $383 \mathrm{~K}$ has been followed by microscopy using polarized light (Mnyukh, 2001, pp. 122128, Figs. 2.34 to 2.37). The (001) face is the interface between triclinic and orthorhombic phases; on heating through the transition faceted orthorhombic crystals grow by an edgewise mechanism into the parent triclinic phase.

Crystal data for the three polymorphs of HMB- $h_{18}$ have been recorded (Table 6); structures have been reported for the lowest temperature phase $[\mathrm{EI}(T \leq 117 \mathrm{~K})-(\mathrm{III})]^{\mathbf{1 6}}$ at $19 \mathrm{~K}$ (Santarsiero et al., 1985, 2005; Stride, 2005) and for the triclinic [EII (117 $\leq T \leq 382 \mathrm{~K}$ )-(II)] phase at 123 and $293 \mathrm{~K}$ (Table 7). We note early but inconclusive studies of the structure of the EI phase by optical (Bertinelli \& Stremmenos, 1973) and crystallographic techniques (Celotti et al., 1975). There are also as-yet unpublished neutron diffraction measurements on powder samples of all three phases (David, 2005), while Fujiwara et al. (1992) show powder patterns that establish that the $h_{18}$ and $d_{18}$ EI phases (and their solid solutions) are isomorphous, as are the pair of EII phases. The EI phase is described as 'pseudo-cubic' and it is noted that high-resolution neutron diffraction studies were carried out, but details were not given.

One could expect that the layer nature of the three HMB polymorphs would favour 'displacive' transitions; observation contradicts this seemingly attractive prediction. The crystal data can be combined to give a plot of volume per molecule as a function of temperature (Fig. 24). This plot, with its two distinctive $\Delta V$ values, confirms an earlier categorization of the transitions as first order. Hamilton et al. (1969) reported that cooling single crystals of the triclinic phase below $117 \mathrm{~K}$ always resulted in their shattering; this is why powder samples of the EI phase have been studied. However, Santarsiero et al. $(1985,2005)$ were able to obtain single crystals, albeit twinned,

\footnotetext{
$\mathbf{1 6}$ The phase stable below $117 \mathrm{~K}$ is generally designated phase III in the literature.
} 
Table 7

Crystal data $\left(\AA,{ }^{\circ}, \AA^{3}\right)$ for the three polymorphs of hexamethylbenzene.

Stride's results are for perdeuterated samples, while the others are for perhydrogenated samples.

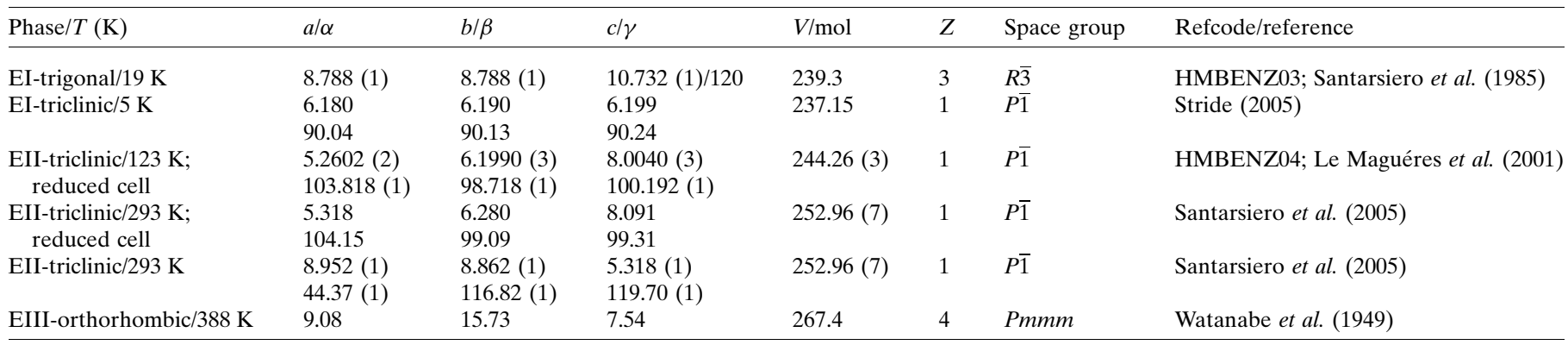

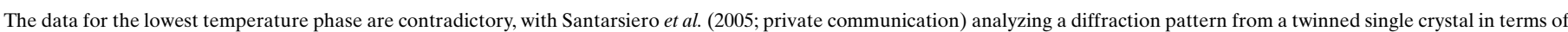

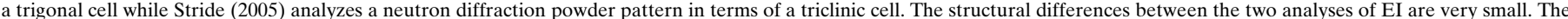

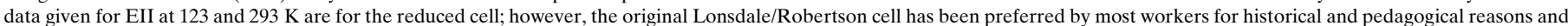
this cell is also given in Table 7 .

of the EI phase and, after correcting for the effects of twinning, carried out a single-crystal analysis on the basis of a trigonal cell (space group $R \overline{3} ; Z=3$ ). The EI phase of HMB$d_{18}$ has been treated as triclinic by Stride (2005) on the basis of a neutron diffraction powder pattern and its structure determined at $5 \mathrm{~K}$. Stride notes that the low temperature HMB- $h_{18}$ cell volumes are about $1 \%$ larger than those of HMB- $d_{18}$. All three polymorphs have layer structures; the arrangements of HMB molecules within the layers being quasi-hexagonal and

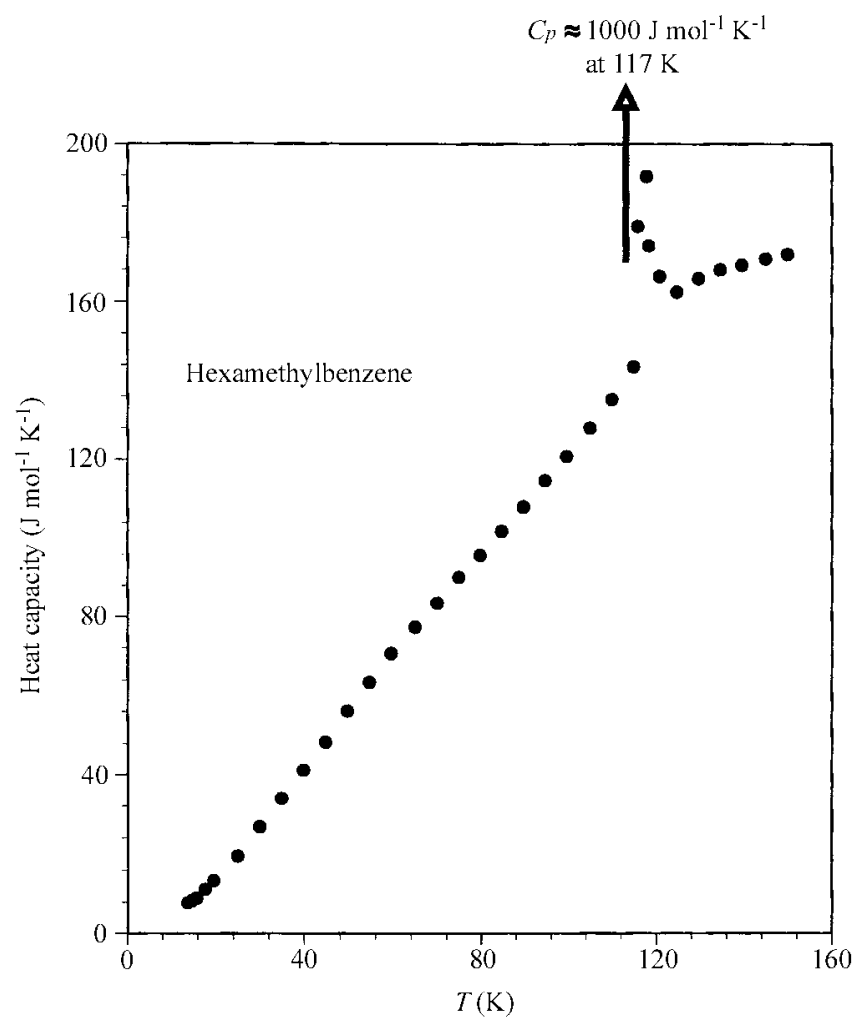

Figure 23

Hexamethylbenzene (HMB) - specific heat as a function of temperature up to $160 \mathrm{~K}$. There do not appear to be premonitory effects in the region 10-115 K. Data from Frankosky \& Aston (1965). similar in all three phases, but the layer stackings differ from one phase to the next. In the EI phase adjacent layers follow the hexagonal close packed ...ABAB... sequence to a good

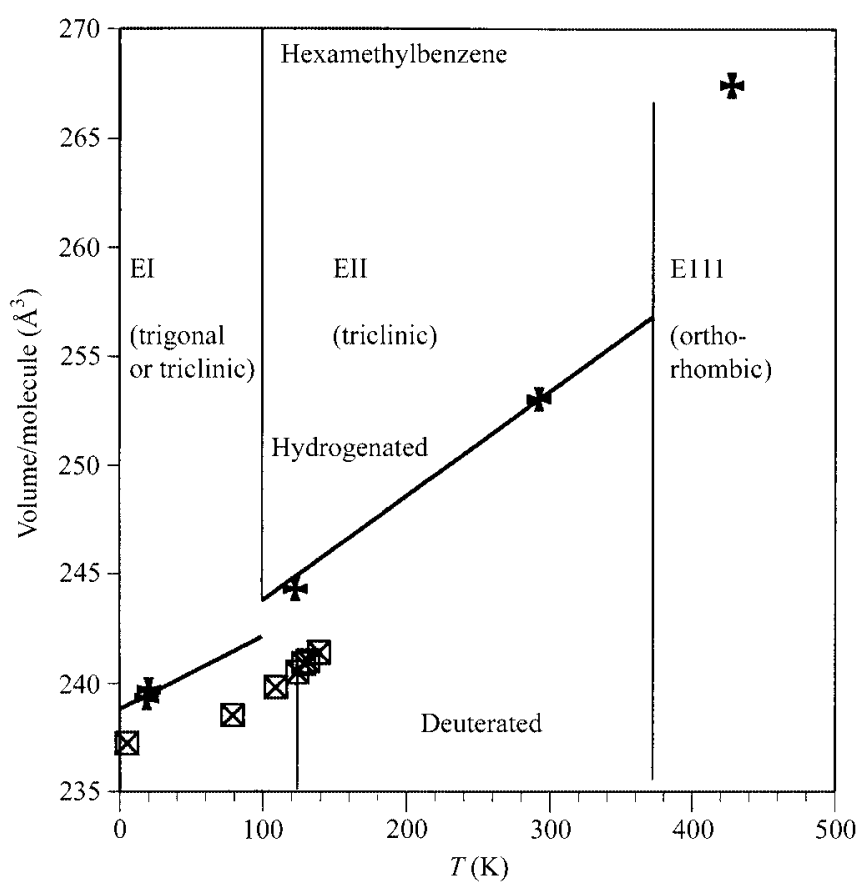

Figure 24

Hexamethylbenzene - plot of volume per molecule in the three phases. The regions of stability of the three polymorphs are shown. The crosses show measured values (XRD) for the hydrogenated compound (at 19 and $293 \mathrm{~K}$ from Santarsiero et al., 2005; at $20 \mathrm{~K}$ from Stride, 2005; at $123 \mathrm{~K}$ from Le Maguéres et al., 2001; at $428 \mathrm{~K}$ from Watanabe et al., 1949). The crossed squares show measured values for the deuterated compound (Stride, 2005). The Stride values are by neutron diffraction on polycrystalline samples except for the $20 \mathrm{~K}$ XRD value. The slopes of the $V / T$ curves are taken as linear; we calculate from Stride's results that $d V / d T$ (phase EI, d18) is $0.0253 \AA^{3} \mathrm{~K}^{-1}$ and, for phase II (h18) $0.051 \AA^{3} \mathrm{~K}^{-1}$ (from Le Maguéres et al., 2001 and Santarsiero et al., 2005). These values are in good agreement with those given by Santarsiero -0.025 and $0.057 \mathrm{~A}^{3} \mathrm{~K}^{-1}$, respectively. The volume change at the EI/EII transition is $0.4 \mathrm{~A}^{3}$ per molecule (from Table 2 of Stride, 2005), while that for the triclinic/orthorhombic transition was measured as $6.1 \AA^{3}$ (Chihara \& Seki, 1948). 
Table 8

Crystal data for the low- and high-temperature phases of D,L-norleucine and D,L-methionine.

\begin{tabular}{|c|c|c|c|c|c|c|c|}
\hline Compound/T (K) & $a$ & $b / \beta$ & $c$ & $Z$ & $V / \mathrm{mol}$ & Space group & Refcode/reference \\
\hline \multicolumn{8}{|l|}{$\mathrm{D}, \mathrm{L}-$ Norleucine } \\
\hline $\mathrm{EI}-(\beta) / 120 \mathrm{~K}$ & $31.067(5)$ & $\begin{array}{l}4.717(1) \\
91.37(2)\end{array}$ & $9.851(2)$ & 8 & $180.4(1)$ & $C 2 / c$ & DLNLUA02/Dalhus \& Görbitz (1996) \\
\hline $\mathrm{EII}-(\alpha) / 296 \mathrm{~K}$ & $9.907(1)$ & $\begin{array}{l}4.737(2) \\
104.68(1)\end{array}$ & $16.382(2)$ & 4 & $185.95(8)$ & $P 2_{1} / a$ & DLNLUA01/Harding et al. (1995) \\
\hline \multicolumn{8}{|l|}{ D,L-Methionine } \\
\hline $\mathrm{EI}-(\beta) / 293 \mathrm{~K}$ & $9.912(5)$ & $\begin{array}{l}4.700(7) \\
106.3(3)\end{array}$ & $33.13(2)$ & 8 & 185.2 & $I 2 / a$ & DLMETA03/Taniguchi et al. (1980) \\
\hline $\mathrm{EII}-(\alpha) / 333 \mathrm{~K}$ & $9.89(2)$ & $\begin{array}{l}4.70(2) \\
102.3(7)\end{array}$ & $16.74(3)$ & 4 & 190.1 & $P 2_{1} / a$ & DLMETA02/Taniguchi et al. (1980) \\
\hline $\operatorname{EIII-}(\gamma)$ & 9.90 & $\begin{array}{l}4.70 \\
90.98\end{array}$ & 31.76 & 8 & 184.7 & $C 2 \dagger$ & Matsuoka et al. (1999) \\
\hline
\end{tabular}

$\dagger$ Probably $C 2 / c$ (see caption to Fig. 25)

approximation, while in the triclinic (EII) phase the layers are displaced along [010]. Although the molecular arrangement in the orthorhombic phase is not known, Mnyukh (his Table 2.6) suggests that the layer sequence is again approximately ...ABAB... hexagonal close packed. We do not pursue this point. The structure of the EIII phase remains to be reported.

The EI-EII transition at $117 \mathrm{~K}$ has been studied by optical techniques, suggesting that $\mathrm{EI}$ is trigonal or hexagonal; the small value of $\Delta V_{\text {transition }}\left(0.4 \AA^{3}\right)$ seems at variance with the shattering of the crystals on cooling below $117 \mathrm{~K}$.

Evidence (for HMB- $h_{18}$; Yoshimoto et al., 1985) for HMB$d_{18}$ and the 1:1 $h_{18}-d_{18}$ solid solution (Fujiwara et al., 1992) has been obtained from calorimetric measurements, showing that each crystallite of a powdered specimen has a specific and different transition temperature or, in other words, each crystallite has a built-in memory as to where it should begin its phase transition. This matches remarks by Mnyukh on nucleation (Mnyukh, 2001, pp. 77-89).

\subsection{Tetrabromomethane}

There are two phases with a monoclinic to cubic transition at $320 \mathrm{~K}$ (Mnyukh, 2001, p. 34). The monoclinic [EI(<320 K)(II)] phase has $a=21.43$ (4), $b=12.12$ (2), $c=21.02$ (4) $\AA$, $\beta=$ $110.88(3)^{\circ}, Z=32$, space group $C 2 / c$, volume per molecule $=$ $159.4 \AA^{3}$ (More et al., 1977a; CTBROM; Powers \& Rudman, 1977; CTBROM02, 03). The cubic [EII(> $320 \mathrm{~K})-(\mathrm{I})]$ phase has $a=8.82$ (1) $\AA, Z=4$, space group $F m 3 m$ at $325 \mathrm{~K}$ (neutron diffraction; More et al., 1977b; CTBROM01); similar results were given by Dolling et al. (1979; CTBROM04, 05). There is orientational disorder in the cubic phase, which is described as plastic. Mnyukh (2001, Section 2.7.2, pp. 114-121) has studied the mechanism of the transition by microscope examination and by diffraction (Laue photographs). A monoclinic crystal was heated through the transition to the cubic phase and returned to the monoclinic phase. The microscope study of the monoclinic to cubic transition showed the growth of orientationally disordered faceted single crystals of the cubic phase from the matrix of the monoclinic phase (his Fig. 2.32). Comparison of Laue photographs of the original single crystal with the product of the cycling process showed that the transition is 'single crystal to textured polycrystal' (Mnyukh, 2001, p. 120). The plastic nature of the cubic phase does not have any influence on the transition itself.

\section{8. $\mathrm{D}, \mathrm{L}-\mathrm{Norleucine}$ [2-aminohexanoic acid $\mathrm{H}_{3} \mathrm{C}\left(\mathrm{CH}_{2}\right)_{3} \mathrm{CH}\left(\mathrm{NH}_{2}\right)\left(\mathrm{CO}_{2} \mathrm{H}\right)$ ] and D,L-methionine [2-amino- 4-methylthiobutanoic acid, $\mathrm{H}_{3} \mathrm{CS}\left(\mathrm{CH}_{2}\right)_{2} \mathrm{CH}\left(\mathrm{NH}_{2}\right)\left(\mathrm{CO}_{2} \mathrm{H}\right)$ ]}

These two compounds are conveniently discussed together as there are marked similarities in their behavior, but also subtle differences. The first crystallographic studies were by Mathieson $(1952,1953)$ with more recent work by Taniguchi et al. (1980; D,L-methionine), Harding et al. (1995) and Dalhus \& Görbitz (1996; both on D,L-norleucine), confirming and extending Mathieson's results. There are three phases and two (solid-state) transitions in both systems. Structural features (summarized in Fig. 25) have been discussed in some detail with less attention paid to thermodynamic aspects. In Mathieson's original studies there was concomitant crystallization of two polymorphs, so-called $\beta$ \{low-temperature phase; in our nomenclature [EI (120-300 K?)-( $\beta$ )] $\}$ and $\alpha$ \{room-temperature phase; in our nomenclature [EII (>300 K?)- $(\alpha)]\}$. The $\operatorname{EII}(\alpha)$ forms of both $\mathrm{D}, \mathrm{L}-$ norleucine and $\mathrm{D}, \mathrm{L}-\mathrm{methionine}$ undergo a further phase transition at $\sim 390 \mathrm{~K}$ to a $\gamma$ polymorph $\{$ in our nomenclature [EIII $(>390 \mathrm{~K})-(\gamma)]$ ]. The crystal structures of the EI and EII phases of both systems have been determined, but only that of the EIII phase of $\mathrm{D}, \mathrm{L}-$ methionine has been reported. The high-temperature EII $\Leftrightarrow$ EIII transition in D,L-norleucine has been discussed by Mnyukh. Crystal data for the various phases are given in Table 8 and are discussed below.

(i) D,L-Norleucine. Crystals of the EI- $\beta$ (low-temperature) form were grown at room temperature, but their structure was determined at $120 \mathrm{~K}$ (Dalhus \& Görbitz, 1996). The EI- $\beta$ phase transforms reversibly ('single crystal to single crystal') on heating to room temperature, but the temperature of the transition has not been reported, nor its nature. The structure of the [EII (> $300 \mathrm{~K}$ ?)- $(\alpha)$ phase was determined at 296 (2) K (Harding et al., 1995). Molecular geometries are almost 


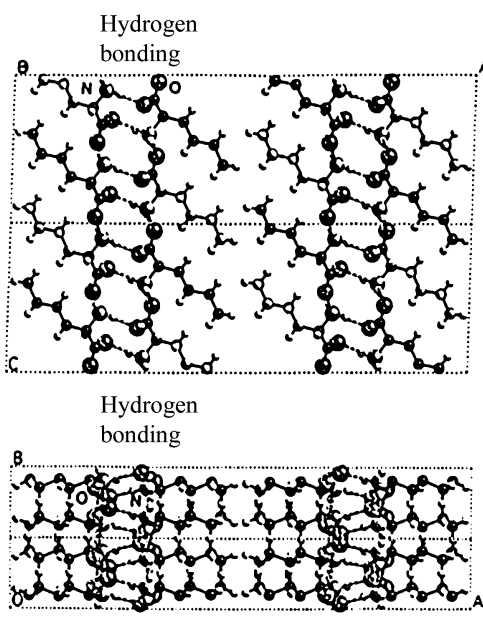

(a)
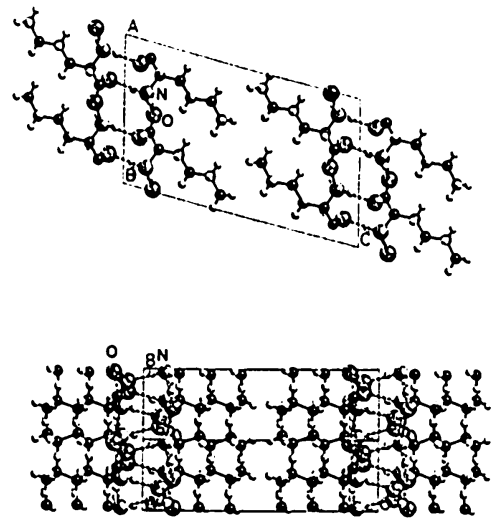

(b)
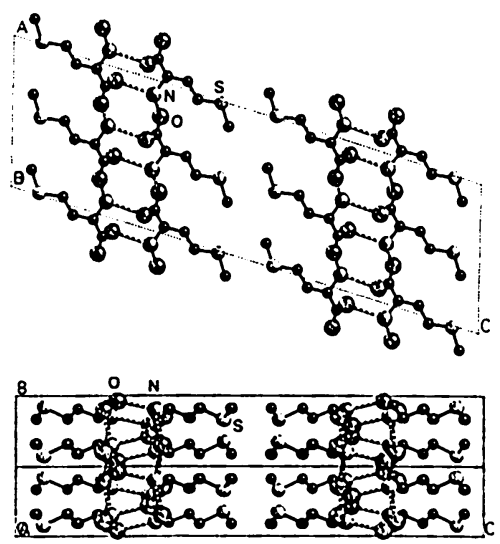

(c)
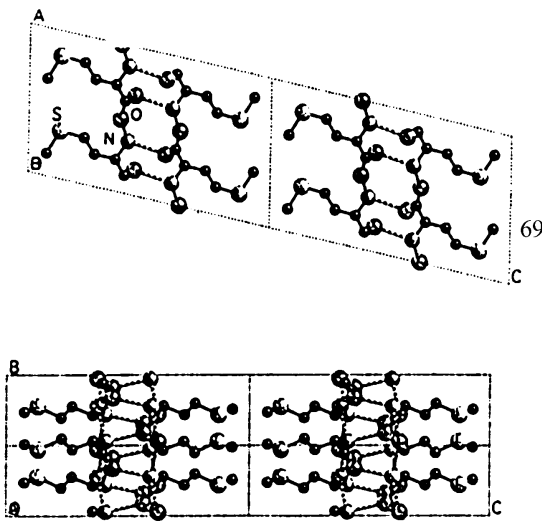

(d)
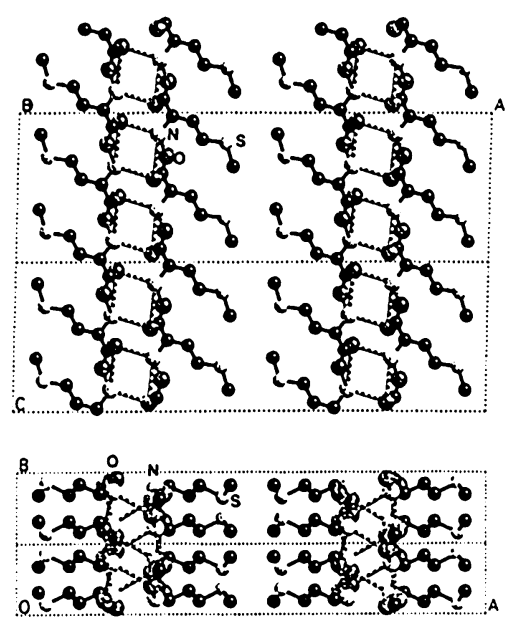

(e)
Figure 25

Projections down [010], and in perpendicular directions, of the various phases of D,Lnorleucine and D,L-methionine: Left: D,L-norleucine $(a) \operatorname{EI}(\beta)$ and $(b) \operatorname{EII}(\alpha)$; the structure of the $\gamma$ phase has not been reported. Right: D,L-methionine $(c) \operatorname{EI}(\beta),(d) \operatorname{EII}(\alpha)$ and $(e) \operatorname{EIII}(\gamma)$. A full report of the $\operatorname{EIII}(\gamma)$ structure has not appeared but the preliminary atomic coordinates kindly made available by Professor Matsuoka (Matsuoka et al., 1999) suggest that the correct space group is $C 2 / c$ and not $C 2$, and this change has been made in $(e)$. The structural unit in all these phases is the hydrogen-bonded ribbon marked in $(a)$ and shown in the other diagrams. The similarity of the cells would be even more apparent if axes alternative to those in the literature were used, but this has not been done to avoid confusion. Data references in Table 8. identical in the EI- $\beta$ and EII- $\alpha$ phases of $\mathrm{D}, \mathrm{L}-$ norleucine, the side chains being fully extended. The double layer arrangements in the two phases and the resemblances between the $\mathrm{D}, \mathrm{L}-$ norleucine and $\mathrm{D}, \mathrm{L}-\mathrm{methionine}$ systems are described in some detail by Mathieson and by Dalhus \& Görbitz and we shall give only an abbreviated account here. Reports of streaking in the diffraction patterns serve as a reminder that the real nature of transitions may be more complicated than the simple models discussed here.

The transition EII- $\alpha$ to EIII- $\gamma$ was first studied by optical microscopy. Mnyukh et al. (1975; see also Mnyukh, 2001, pp. 128-141) reported that there was a transition at $390 \mathrm{~K}$ accompanied by cracking of the crystals. Mnyukh also shows, in his Fig. 2.41, diffraction lines (from a polycrystalline sample) of a lower temperature phase at $388 \mathrm{~K}$, of a higher temperature phase at $393 \mathrm{~K}$, and from both phases at $390 \mathrm{~K}$. This matches in principle Dinichert's results for $\mathrm{NH}_{4} \mathrm{Cl}$. Kühnert-Brandstätter \& Moser (1981) reported confirmatory microscopy and DSC measurements and there have since been a number of DSC (Matsumoto et al., 1987; $\left.\Delta H_{\text {trans }}=4.4 \mathrm{~kJ} \mathrm{~mol}^{-1}\right)$ and spectroscopic (Sonoyama et al., 2000) studies, as well as synchrotron radiation Laue diffraction studies by Harding et al. (1995) and even positron lifetime studies (Srivastava et al., 1986). All these studies confirm the occurrence of a firstorder transition of EII- $\alpha$ to EIII- $\gamma$ at $390 \mathrm{~K}$, although diffraction-quality single crystals do not appear to have been obtained.

Mnyukh (2001, pp. 128-135) has studied the EII- $\alpha$ to EIII- $\gamma$ transition by XRD, measuring (from powder photographs) the dependence of $d(200)$ and $d(020)$ on temperature over the ranges $290-453 \mathrm{~K}$ and $290-403 \mathrm{~K}$, respectively. Both vary linearly with temperature with abrupt changes at $391 \mathrm{~K} ; \Delta a / a=0.9 \%$ and $\Delta b / b=$ $1.0 \%$. Single-crystal Laue photographs below and above $391 \mathrm{~K}$ are virtually identical and indicate a 'single crystal to single crystal' transition. Micrographs (Mnyukh's Fig. 2.42) show an epitaxic growth mechanism. The structure of the EIII- $\gamma$ phase remains to be determined.

(ii) D,L-Methionine. The original XRD study was by Mathieson (1952) and in fact preceded that of D,L-norleucine. Later work (Taniguchi et al., 1980) confirmed the earlier results. The reversible 'single crystal to single crystal' EI- $\beta$ to EII- $\alpha$ transition occurred on heating to room temperature, but the temperature of the transition has not been reported, nor its nature. The transition EII- $\alpha$ to EIII- $\gamma$ occurs at $380 \mathrm{~K}$ 
(Grunenberg et al., 1984) and the crystal structure of EIII- $\gamma$ (Table 9) has been briefly reported (Matsuoka et al., 1999).

(iii) Comparison of the crystal structures of the various phases of D,L-norleucine and D,L-methionine. Projections of the crystal structures down [010] and in perpendicular directions are shown in Fig. 25; as the [010] axis is $4.7 \AA$ for all the structures, the projections are very similar and differences are shown up by views in directions normal to [010]. The basic structural motif is the group of four hydrogen-bonded molecules shown in the outline of the EII cell in the centre of Fig. 25 and this is repeated in all the structures. Small differences in the arrangement of this motif both in the (010) plane and perpendicular to it are found in the different phases. In addition, one notes that the aliphatic side chain is extended in the EI and EII phases of D,L-norleucine and the EI and EIII phases of D,L-methionine, but crimped in the EII phase of the latter. Thus, one could anticipate differences in detail in the reversible 'single crystal to single crystal' EI- $\beta$ to EII- $\alpha$ transitions in the two compounds, and also in the EII- $\alpha$ to EIII- $\gamma$ transitions. The cell dimensions of the various phases are remarkably similar, especially in view of the somewhat different molecular arrangements and this illustrates that one cannot rely on cell dimensions alone - molecular arrangements must also be considered.

\section{Other studies of first-order transitions without intermediate phases}

In addition to the transitions in the phases described above, there are a number of other systems that have been studied by a variety of methods. Our aim is to correlate earlier results with current perspectives and, for some examples, to point out, with the benefit of hindsight, possible contradictions and remediable omissions. It is convenient to distinguish between transitions without (\$8) and with (\$9) intermediate phases.

\subsection{Acetonitrile - the phase transition at $216.9 \mathrm{~K}$}

Heat capacity measurements (Putnam et al., 1965) showed a transition at $216.9 \mathrm{~K}\left(\Delta H_{\text {trans }}=898 \mathrm{~J} \mathrm{~mol}^{-1}\right)$, with the melting point at $229.3 \mathrm{~K}\left(\Delta H_{\text {fusion }}=8167 \mathrm{~J} \mathrm{~mol}^{-1}\right)$. A region of high heat capacity was found around $217 \mathrm{~K}$, but not defined in detail; Putnam et al. commented 'Due to the complicating effects of solid solution, premelting, and slow approach to equilibrium, it does not appear possible to make a clear decision on the basis of the data presented as to whether this region of high heat capacity is an isothermal transition, a sharp lambda-type transition, or merely a hump in the heat capacity shaped like an error function'. Nevertheless, it can be concluded from the volume change of $3 \%$ on transition (see below) and the observed hysteresis that the transition is first order.

Lattice parameters as a function of temperature were measured by powder neutron diffraction (EI phase from 12 to $220 \mathrm{~K}$; EII phase at $229 \mathrm{~K}$; Torrie \& Powell, 1992; not in CSD); the volume of the EI phase has an approximately linear dependence on temperature. The crystal data for the two phases are:

(i) EI [at 206 (2) K]: 6.187 (1), 5.282 (3), 7.887 (4) $\AA, C m c 2_{1}$, $Z=4$; molecular volume $64.44 \AA^{3}$; QQQCIV04;

(ii) EII [at 201 (2) K]: $4.102(3), 8.244$ (7), 7.970 (7) , $100.1(1)^{\circ}, P 2_{1} / c, \quad Z=4$; molecular volume $66.34 \AA^{3}$; QQQCIV05 (Enjalbert \& Galy, 2002).

(iii) The crystal data for the transition can be summarized as follows: [EI $<216.9 \mathrm{~K}-(\beta)$ (orthorhombic, $C m c 2_{1}, Z=4$ )] to [EII $\left(>216.9 \mathrm{~K}-(\alpha)\right.$ (monoclinic, $\left.\left.\left.P 2_{1} / c, Z=4\right)\right)\right]$.

Single-crystal XRD studies of the structures of both phases have been made at temperatures around $200 \mathrm{~K}$ (Enjalbert \& Galy, 2002), complementing the earlier calorimetric and ND studies. The $\operatorname{EII}(\alpha)$ high-temperature cell can be expressed in terms of the $\operatorname{EI}(\beta)$ low-temperature cell as

$$
\begin{aligned}
\mathbf{a}(\alpha) & =(-\mathbf{a}(\beta)+\mathbf{b}(\beta)) / 2 \\
\mathbf{b}(\alpha) & =1.045 \mathbf{c}(\beta) \\
\mathbf{c}(\alpha) & =\mathbf{a}(\beta)+\mathbf{b}(\beta) .
\end{aligned}
$$

This is an example where comparison of the two structures is facilitated by the use of non-reduced cells. Enjalbert \& Galy (2002) propose a mechanism for the $\operatorname{EI}(\beta)$ to the $\operatorname{EII}(\alpha)$ structural transformation 'based on a $90^{\circ}$ rotation of every double slab of molecules packed in layers'. While this description is undoubtedly correct, its reconstructive nature makes it seem unlikely as a vehicle for single-crystal to singlecrystal transformation, and a nucleation and growth mechanism would appear preferable. In their Fig. 4 Enjalbert \& Galy (2002) show single-crystal diffraction patterns for the EI and EII phases just below and above the transition temperature, and for material in transition between them; presumably the 'transition' pattern is the sum of EI and EII patterns, but this was not stated explicitly.

\subsection{Three isostructural phase transitions}

Our definition is quoted from Chernyshov et al. (2003; footnote 24): 'The commonly used term 'isostructural' phase transition does not imply equal structures, but rather equal space groups and equal Wyckoff positions. The unit-cell volumes and atomic coordinates are generally different and their changes with temperature discontinuous as expected for a first-order phase transition'. We have chosen three examples for illustration - the first from an early stage in the author's career, the second more recent and chosen because of its unusual experimental methodology, NMR and spectroscopy making important contributions in addition to diffraction. The third is a comprehensive diffraction study from the very recent current literature.

8.2.1. 1,2,4,5-Tetrabromobenzene. A phase transformation was first observed by hot-stage microscopy (Schaum et al., 1916) and the transition temperature determined by ${ }^{81} \mathrm{Br}$ NQR to be $320 \mathrm{~K}$ (Johnson, 1956). Structures of the EI- $(\beta)$ phase at $298 \mathrm{~K}$ and the EII- $(\gamma)$ phase at $342 \mathrm{~K}$ were reported by Gafner \& Herbstein $(1960,1964)$. The two phases had the same space group $\left(P 2_{1} / a, Z=2\right)$ and similar cell dimensions [EI: $10.323(1), \quad 10.705(1), 4.018(4) \AA, \quad 102.3(1)^{\circ}$; $\quad$ EII: 
Table 9

Crystal data for the two enantiotropic phases of 2-(2,4-dinitrobenzyl)-3methylpyridine that have very similar cell dimensions but differences in molecular positions and conformations.

\begin{tabular}{lll}
\hline & $\begin{array}{l}\text { Phase }(\mathrm{EI} ;<318 \mathrm{~K})(A) \\
(\text { at } 293 \mathrm{~K})\end{array}$ & $\begin{array}{l}\text { Phase }(\mathrm{EII} ;>318 \mathrm{~K})(B) \\
(\text { at 343 K) }\end{array}$ \\
\hline$a(\AA)$ & $11.333(4)$ & $11.617(3)$ \\
$b(\AA)$ & $15.386(4)$ & $15.355(5)$ \\
$c(\AA)$ & $7.639(3)$ & $7.641(3)$ \\
$\beta\left({ }^{\circ}\right)$ & 106.07 & $105.97(3)$ \\
$V /$ mol $\left(\AA^{3}\right)$ & $320.0(2)$ & $327.6(2)$ \\
Space group & $P 2_{1} / c$ & $P 2_{1} / c$ \\
$Z$ & 4 & 4 \\
\hline
\end{tabular}

10.00 (1), 11.18 (1), 4.07 (2) $\left.\mathrm{A}, 103.8(4)^{\circ}\right]$ and molecular arrangements. The volume change at $T_{\text {trans }}$ was reported as less than $0.1 \%$ (Everett \& Edwards, 1958). Gafner and I noted that the phase transition was accompanied by twinning and by shattering and hopping of the crystals, in apparent contradiction to a zero volume change. A state of the art experimental study would be most desirable. The only intermolecular interactions are due to van der Waals forces so this system should be attractive for theoretical study.

8.2.2. 2-(2,4-Dinitrobenzyl)-3-methylpyridine. The transition around $315 \mathrm{~K}$ in 2-(2,4-dinitrobenzyl)-3-methylpyridine (Scheme 4) has been studied by ${ }^{13} \mathrm{C}$ and ${ }^{15} \mathrm{~N}$ solid-state NMR, by XRD and by spectroscopy in the visible range (Schmidt $e t$ al., 1999). DSC studies (Fig. 26) show that this compound is found in three phases - an enantiotropic pair $([\mathrm{EI}(<318 \mathrm{~K})]$; $[\mathrm{EII}(>318 \mathrm{~K})])$ and a monotropic phase, which does not concern us here. Spectroscopy showed that the apparently first-order phase transition at $\sim 320 \mathrm{~K}$ had unanticipated features, and this transition was then studied by ${ }^{15} \mathrm{~N}$ and ${ }^{13} \mathrm{C}$ CPMAS NMR and by spectroscopy in the visible region, the

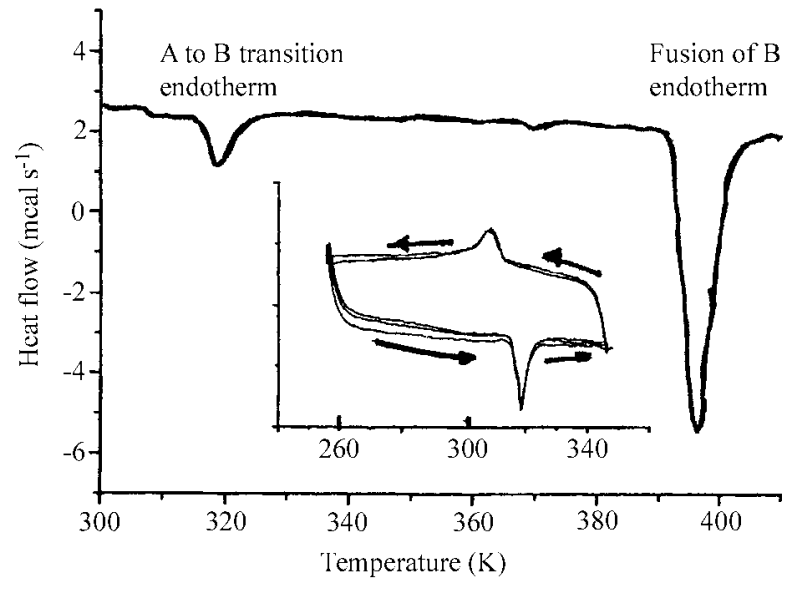

Figure 26

2-(2,4-Dinitrobenzyl)-3-methylpyridine (formula in Scheme 4): DSC of the enantiotropic pair, with inset showing reversible cycling of (EI; $<320 \mathrm{~K})(A)$ and $(\mathrm{EII}>320 \mathrm{~K})(B)$ phases and the associated hysteresis of $\sim 3 \mathrm{~K}$. The behavior of the monotropic phase is not shown as it is not relevant in the present context. Adapted from Schmidt et al. (1999). relationship between the phases being determined in parallel by single-crystal XRD.

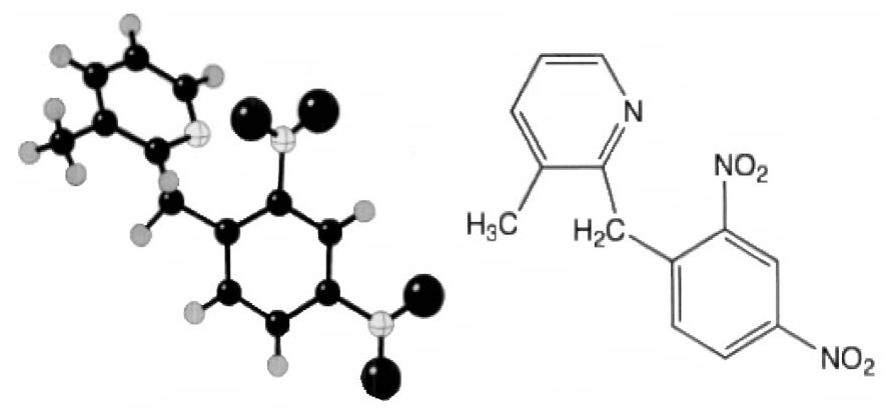

Scheme 4

Crystal data have been obtained for all three phases (Table 9, where the monotropic phase is omitted). Crystals of EI were grown from ethanol solutions in the dark. Crystals of EII were obtained by heating a single crystal of EI at $343 \mathrm{~K}$ for $7 \mathrm{~d}$ in a single crystal to single crystal transformation. Crystals heated at 318 and $323 \mathrm{~K}$ did not give soluble data sets, a finding to be discussed later. Phases EI and II have very similar cell dimensions, the only marked difference being in [100], and the same space group, with the phase transition consequently being classified as 'isostructural'. The volume change on transition at $318 \mathrm{~K}$ seems likely to be very small, but was not measured directly. The crystal structures of EI and EII are similar (Fig. 27), but perhaps not as similar as might have been expected from the resemblance in cell dimensions. The prin-
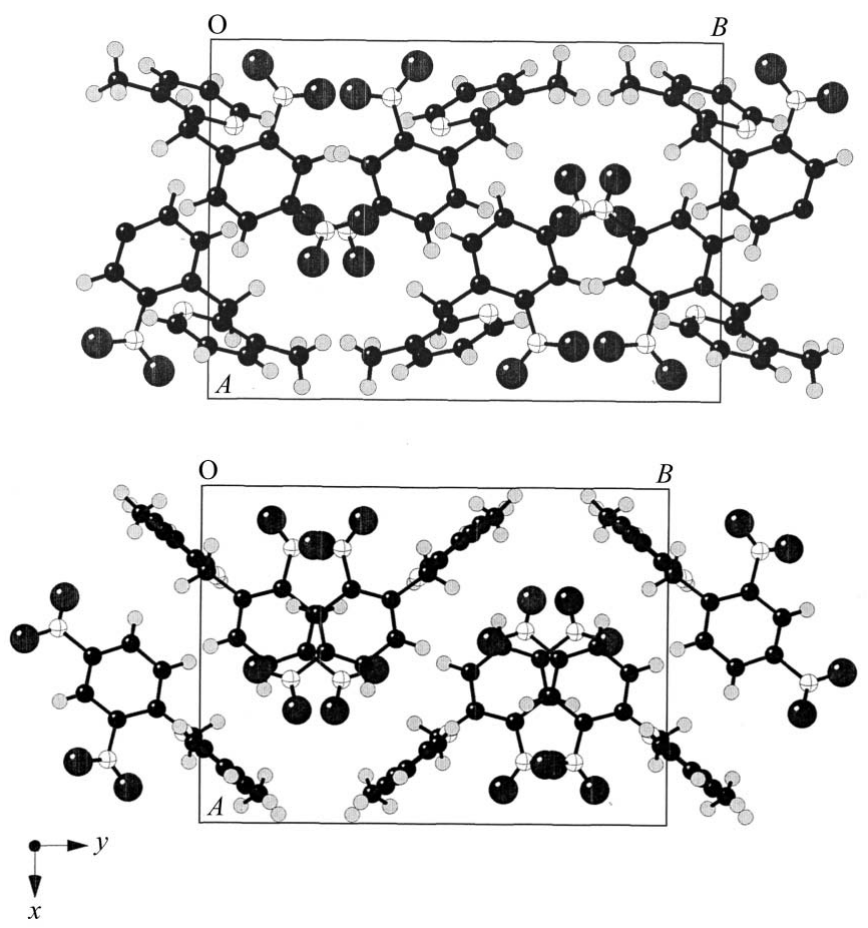

Figure 27

2-(2,4-Dinitrobenzyl)-3-methylpyridine - crystal structures of the two enantiotropic phases projected down [001]. The molecular arrangements differ rather more than might be expected from the resemblance of the cell dimensions. Adapted from Schmidt et al. (1999). 
cipal differences are in the inclination of the pyridine ring to the dinitrobenzyl portion of the molecule; the interplanar angles are $56^{\circ}$ (EI) and $68^{\circ}$ (EII) and in the positioning of the molecules in the two phases (Schmidt et al., 1999).

The EI to EII transition was not studied directly by diffraction because of the experimental difficulties noted above, but was studied extensively by ${ }^{15} \mathrm{~N}^{17}$ and ${ }^{13} \mathrm{C}$ CPMAS NMR (Fig. 28; Schmidt et al., 1999). For reasons of brevity we concentrate here on the ${ }^{15} \mathrm{~N}$ study, but entirely compatible results were obtained from the ${ }^{13} \mathrm{C}$ spectra. The ${ }^{15} \mathrm{~N}$ spectra were recorded as a function of temperature with increments smaller than $1 \mathrm{~K}$ over the entire transition range. The selected group of six spectra in Fig. 28 show that the conversion of EI to EII is continuous, and both phases coexist over a temperature range of almost $10 \mathrm{~K}$. Mole fractions of the two phases as a function of temperature were obtained from integrated intensities of all the NMR peaks (Fig. 29), not just the selection shown in Fig. 28. The absence of line broadening over the entire phase-transition temperature range (width

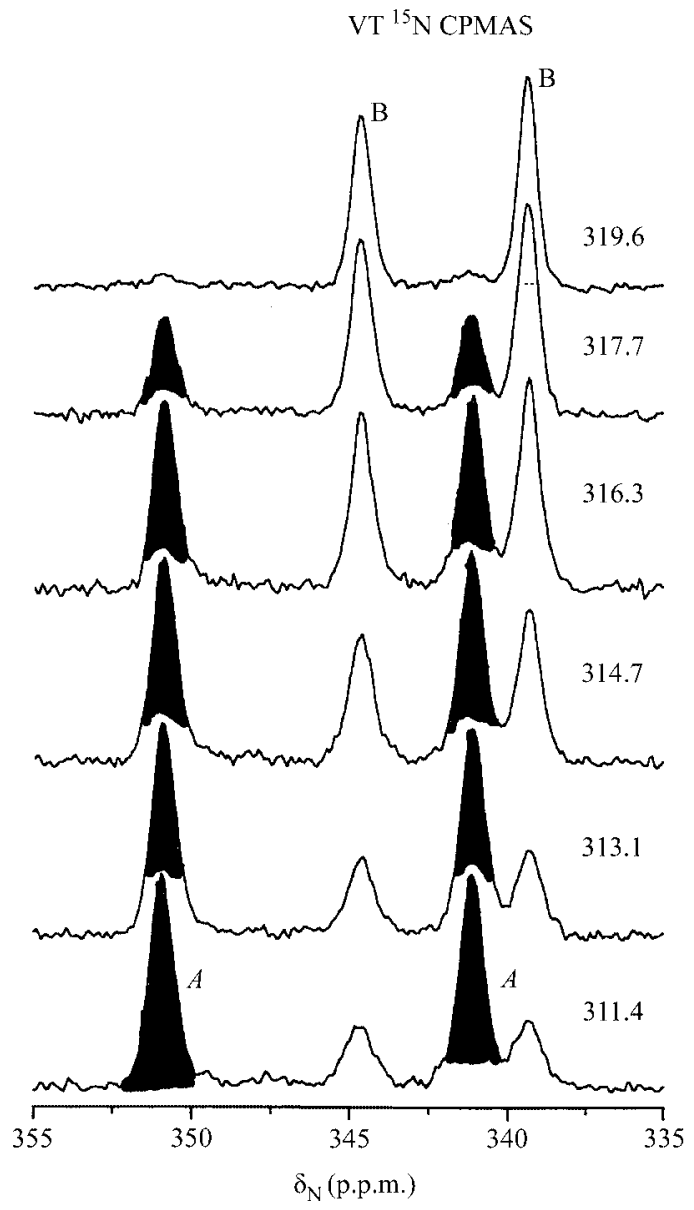

Figure 28

2-(2,4-Dinitrobenzyl)-3-methylpyridine-CPMAS ${ }^{15} \mathrm{~N}$ NMR spectra (centreband regions only) for the enantiotropic EI- $A$ and EII- $B$ phases of 2-(2,4-dinitrobenzyl)-3-methylpyridine over a range of temperatures, increasing from bottom to top. The two independent lines originate from ${ }^{15} \mathrm{~N}$ substitution in the two independent nitro groups. Parallel ${ }^{13} \mathrm{C}$ spectra, which are not shown, led to the same conclusions. Adapted from Schmidt et al. (1999). constant at $22 \mathrm{~Hz}$ ) excludes the possibility of dynamic processes (e.g. hopping of molecules between phases) with correlation times less than one minute. As there was no loss of total integrated peak intensity during the transition, the presence of ill-defined phases such as mobile glass or melt zones is excluded. [EII $(>318 \mathrm{~K})$ ] transforms to [EI $(<318 \mathrm{~K})$ ] even at $293 \mathrm{~K}$, but the process takes some months; it was not noted whether this was a single crystal to single crystal transition.

The $\mathrm{N}$ atoms of the two nitro groups were substituted by ${ }^{15} \mathrm{~N}$; thus the ${ }^{15} \mathrm{~N}$ CPMAS NMR spectrum has two lines for each of the EI and EII phases (both $P 2_{1} / c, Z=4$ ).

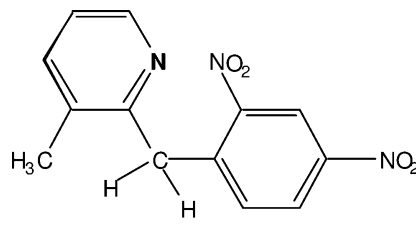

Stable state

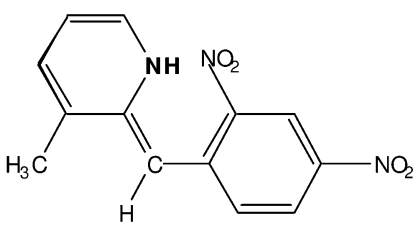

Tautomer after UV irradiation
The results shown in Fig. 29 were corroborated from an optical measurement (Fig. 30). Both phases of 2-(2,4-dinitrobenzyl)-3-methylpyridine grown from ethanol develop a blue-green colour $\left(\lambda_{\max }=611 \mathrm{~nm}\right)$ upon UV irradiation $(\lambda<$ $430 \mathrm{~nm}$ ) because of the formation of the phototautomer obtained by transfer of benzyl $\mathrm{H}$ to pyridine $\mathrm{N}$ (Scheme 5). This colour decays exponentially at different rates in the two

\section{2-(2,4-Dinitrobenzyl)-3-methylpyridine}

$\mathrm{A} \rightleftharpoons \mathrm{B}$ Phase transition

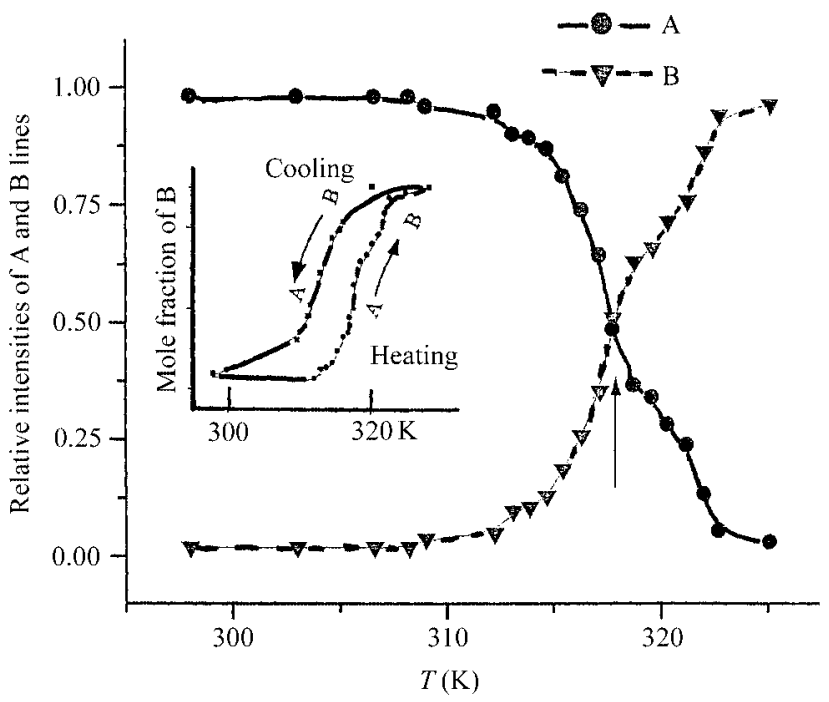

Figure 29

2-(2,4-Dinitrobenzyl)-3-methylpyridine - mole fractions of the EI- $A$ and EII- $B$ phases obtained from the integrated intensities of peaks from the entire set of ${ }^{15} \mathrm{~N}$ CPMAS NMR lines as a function of increasing temperature. Note the resemblance to the lower portion of Fig. 14 (coexistence of neutral and ionic phases of TTF …CA). Inset: Mole fraction of phase $B$ through the heating-cooling cycle. Adapted from Schmidt et al. (1999). 
phases because the phototautomers are located in different sites. As the concentration of phototautomer is $\sim 10^{-6}$, the crystal as a whole will hardly be affected by its presence, although there could be greater effects in regions of nucleation. The activation energies for decay in the EI and EII phases are 108 and $78 \mathrm{~kJ} \mathrm{~mol}^{-1}$, respectively. Determination of the decay kinetics at different temperatures in the phasetransition range provides an independent measure of phase concentration. The biexponential decay system has the same activation energies as those found in the single phase materials. These results imply that if there are interphase exchange processes in the system, their rates are at least one order of magnitude slower than the detected lifetimes (minutes to hours at ambient temperature). An analogous spectroscopic method was used by Shigenari et al. (1991) in their study of polymorphism in resorcinol.

Schmidt et al. (1999) summarize their conclusions as follows: 'Solid-state NMR... [reveals] the coexistence of two phases over at least 8-9 $\mathrm{K}$ and their gradual interconversion, thus manifesting the nonclassical nature of the phase transition (my italics). The slowly evolving intensities of (X-ray) reflections above $T_{c}$ are attributed to annealing of domains into a longrange ordered system. These observations imply that, in addition to the fast response of the system to temperature changes, much slower processes occur, probably within the multidomain structure. These observations are rationalized in terms of two different processes having very different time scales. The first process constitutes a fast redistribution of the mole ratio of the coexisting phases, while a much slower second process involves macroscopic relaxation of the system'. In assessing these results, one should remember that solidstate NMR provides evidence on the immediate surroundings of the probed nucleus, while (Bragg) X-ray diffraction requires domains of at least some hundreds of $\AA$. That the 318 and $323 \mathrm{~K}$ data sets were not soluble could suggest some sort

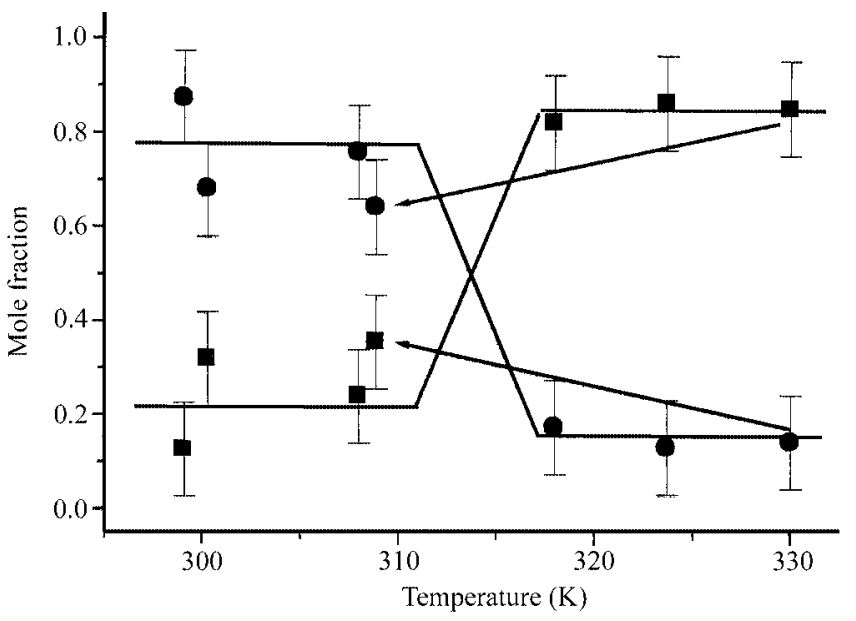

Figure 30

2-(2,4-Dinitrobenzyl)-3-methylpyridine - mole fractions of EI and EII phases as a function of temperature in a single crystal, as obtained from the decay of the phototautomer (Scheme 5) produced by irradiation below $430 \mathrm{~nm}$ and monitored at $\lambda_{\max }=611 \mathrm{~nm}$. Adapted from Schmidt $e t$ al. (1999).
Table 10

Crystallographic data $\left(\AA,{ }^{\circ}, \mathrm{g} \mathrm{cm}^{-3}\right)$ at $300 \mathrm{~K}$ for the $\mathrm{D}, \mathrm{L}$-homocysteine thiolactone hydrochloride polymorph cluster.

\begin{tabular}{llllll}
\hline $\begin{array}{l}\text { Crystal and } \\
\text { space group }\end{array}$ & $a$ & $b / \beta$ & $c$ & $D_{\text {meas }}$ & $Z$ \\
\hline HTL-hybrid & $19.55(3)$ & $9.29(2)$ & $7.23(2)$ & $1.535(3)$ & - \\
HTL-Pbc2 1 & $9.806(3)$ & $9.321(2)$ & $7.321(2)$ & $1.519(1)$ & 4 \\
HTL-Pbca & $19.512(2)$ & $9.296(3)$ & $7.272(1)$ & $1.543(2)$ & 8 \\
\hline
\end{tabular}

of intermediate structure, but this is not supported by the NMR results that show no such evidence.

What is the order of the transition? Schmidt et al. (1999) emphasize the 'gradual interconversion', and this would appear to negate a first-order change; however, the endotherm on heating and exotherm on cooling in the DSC measurement (Fig. 26) strongly suggests that the transition is first order. Such diffraction evidence as is available points to an epitaxic transition. A more extended diffraction study would be most useful. Optical microscopy is sorely lacking, especially as the transition is in a convenient temperature range.<smiles>Nc1cccc(C(=O)O)c1</smiles>

$\mathrm{HPO}_{2}(\mathrm{OH})$

Scheme 6

8.2.3. $m$-Carboxyphenylammonium monohydrogen phosphite. This compound (Scheme 6) has a reversible first-order transition at $T_{0}=246$ (2) with a hysteresis of $3.6 \mathrm{~K}$ (Bendeif $e t$ al., 2005). The cell dimensions at $100 \mathrm{~K}$ are $12.1405(7)$, 12.4273 (9), 6.3851 (4) $\AA, 100.122(5)^{\circ}, 948.35 \AA^{3}$ and at $298 \mathrm{~K}$ 13.036 (3), $11.538(2), 6.6366(13) \AA, 104.73(3)^{\circ}, 965.4 \AA^{3}$. The space group is $P 2_{1} / c, Z=4$ over the $95-335 \mathrm{~K}$ range, and hence the phase transition is classified as 'isostructural'. DSC scans showed an exotherm of $1346 \mathrm{~J} \mathrm{~mol}^{-1}$ at $246.0 \mathrm{~K}$ and an endotherm of $1346 \mathrm{~J} \mathrm{~mol}^{-1}$ at $249.6 \mathrm{~K}$. All cell parameters showed abrupt changes at 246 (2) K, $a, c$ and $\beta$ expanding and $c$ contracting. The volume expanded by $1.77 \%$. An illustration is given in Fig. 31 (Fig. 4 of Bendeif et al., 2005), where the hysteresis is clearly shown. There are striking similarities to our Fig. $8\left(\mathrm{NH}_{4} \mathrm{Cl}\right)$.

\subsection{Is $\mathrm{D}, \mathrm{L}$-homocysteine thiolactone hydrochloride another example?}

This compound (abbreviated as HTL) was studied by Freer \& Kraut (1965) and found to crystallize in two polymorphic forms and as a 'hybrid' of the two polymorphs. All crystals were grown from methanol-nonsolvent mixtures at room temperature; all three crystal structures (Table 10) were determined at room temperature. 
<smiles></smiles>

Homocysteine thiolactone hydrochloride: the chiral carbon is marked by an asterisk

Scheme 7

There is an extensive network of strong $\mathrm{N}-\mathrm{H} \cdots \mathrm{Cl}$ hydrogen bonds in both polymortphs, with $d(\mathrm{~N} \cdots \mathrm{Cl})$ ranging from 3.15 to $3.23 \AA$ and each chloride ion being linked to three ammonium groups. In both polymorphs the molecules lie in layers at $z=1 / 4$ and $3 / 4$, with the plane of the thiolactone group approximately normal to [001]. The projections of the $P b c a$ and $P b c 2_{1}$ structures down [100] are barely distinguishable, but there is a clear difference between the projections down [010] (Fig. 32). The O, N ends of adjacent molecules are staggered on opposite sides of the $a$ glide plane in HTL-Pbca (HOCYSL01), while they are directly opposed in HTL-Pbc2 (HOCYSL).

There is no hint in the paper as to which polymorph is the more stable at room temperature nor whether they are
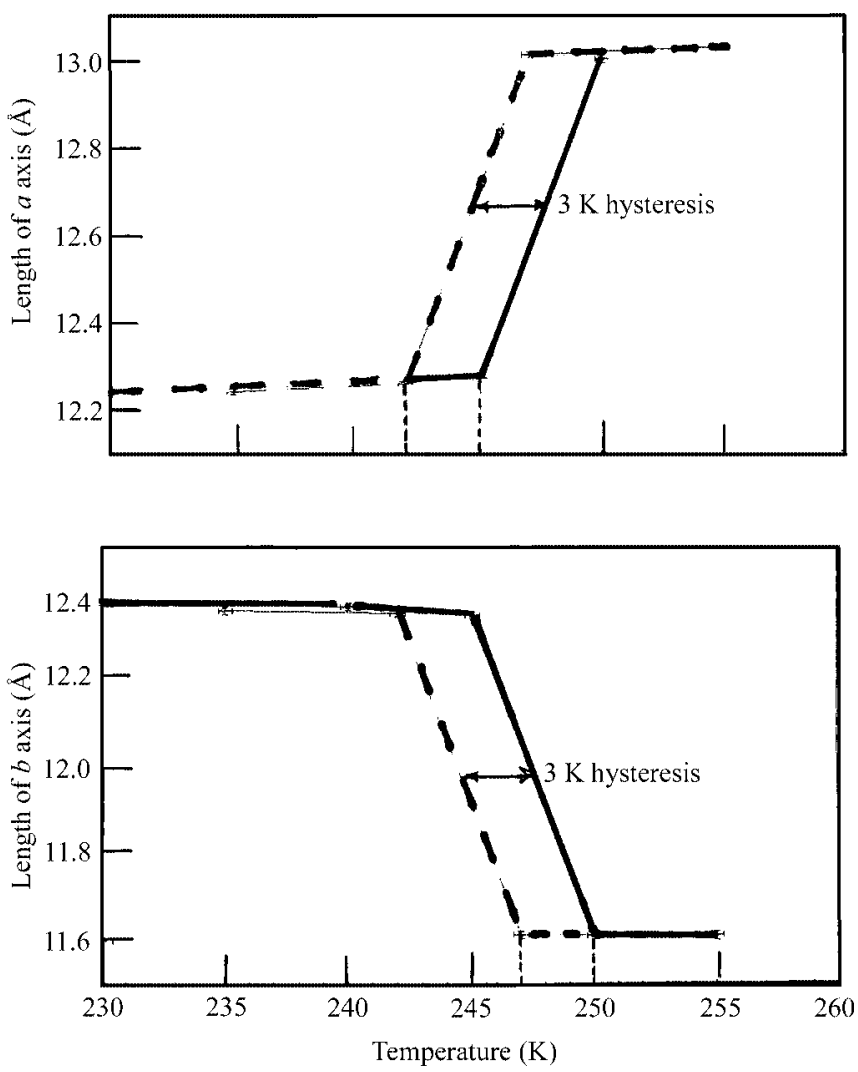

Figure 31

$m$-Carboxyphenylammonium monohydrogenphosphite - detail of the variation of the $a$ and $b$ axes with temperature in the region of the phase transition at 246 (2) K. The heating and cooling curves are separated by a hysteresis of $3 \mathrm{~K}$, in agreement with the DSC results (not shown). Adapted from Bendeif et al. (2005). enantiotropically related, nor whether there is a phase transition. If density is the criterion, then the Pbca structure is more stable than the $P b c 2_{1}$ structure. The so-called HTLhybrid was considered to be "composed of separate domains of HTL-Pbca and HTL-Pbc2 $2_{1}$ which scattered X-rays independently but had their unit-cell axes oriented in the same directions'. It seems that the HTL-hybrid is really a composite crystal in the sense used by Boonstra \& Herbstein (1963). Similar situations of agglomeration appear to occur in the EIII $(>304 \mathrm{~K})-(\beta)$ phase of $p$-dichlorobenzene (Reynolds, $1977)$ and with an enantiomorph and a racemate in 5-oxatricyclo[5.1.0.01,3] octane-4-one (Yufit et al., 2002). One can speculate that there is a first-order phase transition in $\mathrm{D}, \mathrm{L}-$ homocysteine thiolactone hydrochloride which proceeds by an epitaxic mechanism. DSC measurements and an optical microscope study are needed to check this guess.

\section{Two recent studies of reversible single crystal to single crystal transitions with intermediate phases}

\subsection{4,4'-Dichlorobenzophenone}

Early indications of a phase transition in $4,4^{\prime}$-dichlorobenzophenone came from Raman spectroscopy (Peretti \& Ranson, 1979), followed by DSC measurements (Ecolivet et al., 1987), which were interpreted as showing two first-order transitions at $185.0(5)$ and $189.0(5) \mathrm{K}$, with enthalpies of transition of 146 and $251 \mathrm{~J} \mathrm{~mol}^{-1}$. Determinations of the room-temperature structure (Shields \& Kennard, 1977; Granger \& Coillot, 1985) were followed by determination of

D, L-Homocysteine thiolactone hydrochloride - $\mathrm{Pbca}$

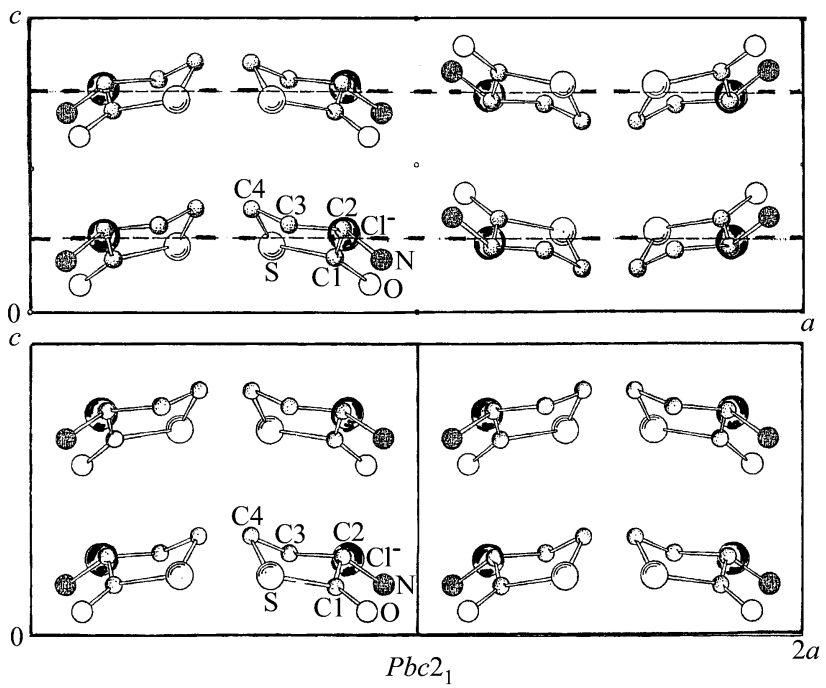

Figure 32

D,L-Homocysteine thiolactone hydrochloride: there is a clear difference between the projections of the $P b c a$ and $P b c 2_{1}$ phases down [010], while those down [100] (not shown) are barely distinguishable. The $\mathrm{O}, \mathrm{N}$ ends of adjacent molecules are staggered on opposite sides of the $a$ glide plane in HTL-Pbca, while they are directly opposed in HTL- $P b c 2_{1}$. The chloride ions are the large darkened partially obscured circles. Adapted from Freer \& Kraut (1965). 
Table 11

4,4'-Dihalobenzophenone, where halo- = chloro- or fluoro-.

Structures of the $\mathrm{F}, \mathrm{Cl}$ pair are isomorphous at $295 \mathrm{~K}, Z=4$, molecular symmetry $C_{2}-2$.

\begin{tabular}{|c|c|c|c|c|c|c|}
\hline$T(\mathrm{~K}) /$ refcode/reference & $a$ & $b / \beta$ & $c$ & $\begin{array}{l}\text { Molecular } \\
\text { volume }\end{array}$ & $\begin{array}{l}\text { Space } \\
\text { group }\end{array}$ & $\begin{array}{l}\text { Angle between } \\
\text { phenyl rings }\end{array}$ \\
\hline \multicolumn{7}{|c|}{ 4,4'-Dichlorobenzophenone } \\
\hline $295 / \mathrm{CBENPH} /(a)$ & $25.161(11)$ & $\begin{array}{l}6.128(3) \\
102.05(3)\end{array}$ & $7.586(3)$ & 285.97 & $C 2 / c$ & 47.1 \\
\hline 295/CBENPH01/(b) & $25.161(9)$ & $\begin{array}{l}6.104(2) \\
101.98(9)\end{array}$ & $7.535(8)$ & 283.01 & $C 2 / c$ & 48.3 \\
\hline 164/CBENPH03/(c) & $24.527(6)$ & $\begin{array}{l}6.064(1) \\
100.10(2)\end{array}$ & $7.457(4)$ & 272.98 & $I 2 / c$ & 49.7 \\
\hline 140/CBENPH02/(d) & $24.620(10)$ & $\begin{array}{l}6.091(1) \\
104.14(3)\end{array}$ & $7.476(2)$ & 272.90 & $I 2 / c$ & 49.3 \\
\hline \multicolumn{7}{|c|}{ 4,4'-Difluorobenzophenone } \\
\hline 295/HATXIJ/(e) & $23.184(7)$ & $\begin{array}{l}6.17(1) \\
79.87(1)\end{array}$ & $7.409(9)$ & 260.8 & $C 2 / c$ & $47.1(1)$ \\
\hline
\end{tabular}

References: (a) Shields \& Kennard (1977); (b) Granger \& Coillot (1985); (c) Mitkevich et al. (1999); (d) Zuniga \& Criado (1995); (e) Maginn \& Davey (1994). the structure of the low-temperature phase at $140 \mathrm{~K}$ and lattice dynamical calculations applied to the stabilities of the two phases and interpretation of the Raman spectra over the range 293-296 K (Zuniga \& Criado, 1995); these authors also discussed the structure of the intermediate phase, to which we return later. A consolidated quantitative picture of the behavior of the system comes from the XRD study of Mitkevich et al. (1999) to which other studies, although earlier in point of time, add complementary detail (structure first, with properties and behavior illuminated in terms of structure). The later luminescence spectroscopy study of Mitkevich et al. (2001) also fits into this scheme. At room temperature the structure can be described in the space group $C 2 / c, Z=4$. The molecule has a twofold axis down the $\mathrm{C}=\mathrm{O}$ bond and these are arranged in sheets in (100) with alternate dipoles along [001] pointing in opposite directions. The angle between the planes of the phenyl rings is $50.6^{\circ}$ (Fig. 33). The $140 \mathrm{~K}$ structure is based on the same sheets (along [001]) found at room temperature, but now displaced to conform to the space group $12 / \mathrm{c}$ (using the same unit cell at both temperatures). Crystal data for $4,4^{\prime}$ dichlorobenzophenone and some related compounds are summarized in Table 11.

The cell dimension- $T$ curves change slope on cooling at $c a$ $190 \mathrm{~K}$ ( $a$ and $c$ contract, $b$ expands, $V$ contracts (Fig. 34), There are intensity changes and at $164 \mathrm{~K}$ the systematic absences show that the space group has changed to $I 2 / c$ in terms of the room-temperature cell axes. The low-temperature structure is formally derived from the room-temperature structure by displacement of alternate (100) sheets by $c / 2$. The alternation of the directions of the $\mathrm{C}=\mathrm{O}$ dipoles and the angle between the planes of the phenyl rings (now $49.7^{\circ}$ ) remain essentially unchanged. On heating, the converse changes start at $190 \mathrm{~K}$. The diagrams of cell dimensions versus temperature show what appear to be typical hysteresis loops.

The structure of the intermediate phase has been studied by both Zuniga \& Criado (1995; see pp. 881 and 887) and Mitkevich et al. (1999; see p. 804) with generally concordant results that still, however, require some amendment; our description is based on an amalgamation of their reports. The dependence of intensities on temperature is shown in Fig. 34. In the 'intermediate' region between 192 and $186 \mathrm{~K}$ (cooling regimen), the intensities of the reflections 111 and 031, representative of the $C 2 / c$ and $I 2 / c$ structures, respectively, are very weak. The conclusion drawn (Mitkevich et al., 1999, p. 804 ) is that the intermediate state must be a mixture of the quasi- $C$ and quasi- $I$ lattices in order that both absences be almost rigorously observed experimentally'. Zuniga \& Criado (1995; see p. 881) showed (from precession photographs and sequential diffractometer traces) that the intermediate phase was monoclinic but primitive; new superlattice reflections 
appear at $\mathbf{H}+0.53 \mathbf{a}^{*}$, slightly displaced from the basic lattice. An equivalent description invokes the introduction of stacking faults (shifts of adjacent $C$ areas by c/2) into the initial $C$ phase. A shift of every second sheet would bring about transformation from $C$ to $I$; half these shifts (i.e. c/4) would give a primitive monoclinic cell with four $\mathrm{Cl}$ atoms in the asymmetric unit, i.e. two 4,4'-dichlorobenzophenone molecules. This would give 'a sort of coexistence of the high- and low-temperature structures' (Zuniga \& Criado, 1995; see p. 887). These authors (loc. cit.) write that 'a plausible explanation... [for the diffraction effects]... would be the coexistence of... domains of $I$ - and $C$-centring with zones of alternate centred cells CICICI... When decreasing temperature the domains of $C$-centring would gradually decrease in size and the $I$ domains would increase...'.
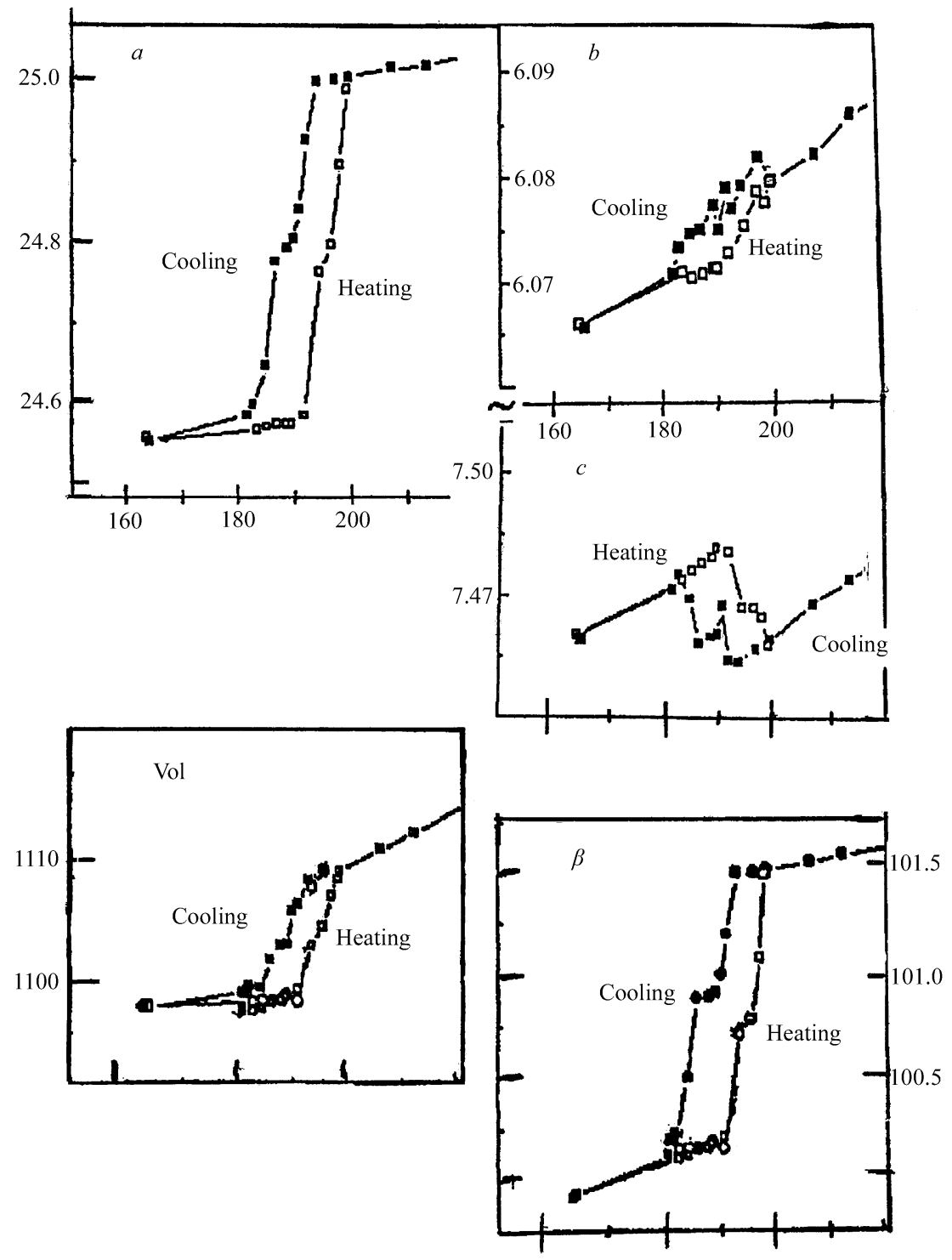

Figure 34

4,4'-Dichlorobenzophenone - cell dimensions versus temperature. The abruptness of the changes in $a$ and $\beta$ indicate that the transition is first order; the complicated changes in $b$ and $c$ suggest that this is not the whole story. Adapted from Mitkevich et al. (1999).
Support for the above description comes from the four NQR frequencies observed in the intermediate state, in contrast to the single lines observed in the $C$ and $I$ phases (Wolfenson et al., 1990) shown in the upper portion of Fig. 36. A quotation from Pusiol et al. (1989) is appropriate at this point:

'The NQR spectrum outlines the microscopic environment of the resonant nuclei. In a commensurate system the number of NQR lines is determined by the chemically nonequivalent nuclear sites in the unit cell. In an incommensurate system, where the translational periodicity is lost, every nucleus is nonequivalent: therefore, there is a continuous frequency distribution which reflects the spatial variation of the order parameters. When the phase behavior of the incommensurate modulation is one-dimensional and linear in the crystal, the NQR spectrum is characterized by a broad line with two edge singularities (this is known as the 'wave-plane limit'; Blinc, 1981).'

The NQR spectra reported for the intermediate state (Fig. 36) fit the above description in a general sense, but there are serious discrepancies between the two independent sets of NQR measurements, and these were not resolved by Nakayama et al. (1994) who do refer to Wolfenson et al. (1990). One cannot describe the intermediate state beyond noting that there seem to be four independent $\mathrm{Cl}$ atoms and that the structure appears to be modulated.

The sound velocities from Brillouin spectra show hysteresis and complications between 185 and $189 \mathrm{~K}$ (Ecolivet et al., 1987) as do the Raman spectra of Peretti \& Ranson (1979) in the range 180-190 K. Thus, there is an accumulation of evidence from physical measurements suggesting the existence of an intermediate region without contributing to its detailed description.

What is the order of the transition? Can the wealth of detail in Figs. 34 and 35 help? The behavior of $a$ and $\beta$ (perhaps $V$ ) is similar to that in the first-order transition in $\mathrm{NH}_{4} \mathrm{Cl}$ (Fig. $8 a$ ), but this is not so for $b$ and $c$. The temperature dependence of the intensities of the 031 and 111 reflections shown in Fig. 35 each behaves separately in a manner analogous to that found in $\mathrm{NH}_{4} \mathrm{Cl}$, but the values of $T_{0}$ (estimated as averages for heating and cooling regimens) differ by $\sim 9^{\circ}$ (shown by $T_{0}^{\text {low }}$ for 031 and $T_{0}^{\text {up }}$ for 111). The calorimetric measurements (Fig. 37; Ecolivet et al., 1987) show endotherms at 185 and $190 \mathrm{~K}$ (enthalpies of transition were not reported), suggesting two first-order transitions. The XRD evidence also supports the occurrence of 
first-order transitions, but not without complications.

The overall situation is described as follows by Mitkevich et al. (1999): 'the phase transformation... occurs as a sequence of two separate first-order transitions, with an intermediate state between the low-temperature $I 2 / c$ and $C 2 / c$ high-temperature phases'. This description immediately reminds one of Ubbelohde's concept of hybrid crystals (Scheme 3), but there is an essential difference - the intermediate structure is not a simple agglomeration of room- and low-temperature structures. Can these observations be accommodated within the 'nucleationand-growth' model? Study by microscopy has not been reported.

4,4'-Dichlorobenzophenone and 4,4'-difluorobenzophenone (Maginn \& Davey, 1994) are isomorphous at room temperature, but the fluoro compound has not yet been studied crystallograhically over a range of temperatures. Heatcapacity measurements show transitions at 54 and $110 \mathrm{~K}$ (K.
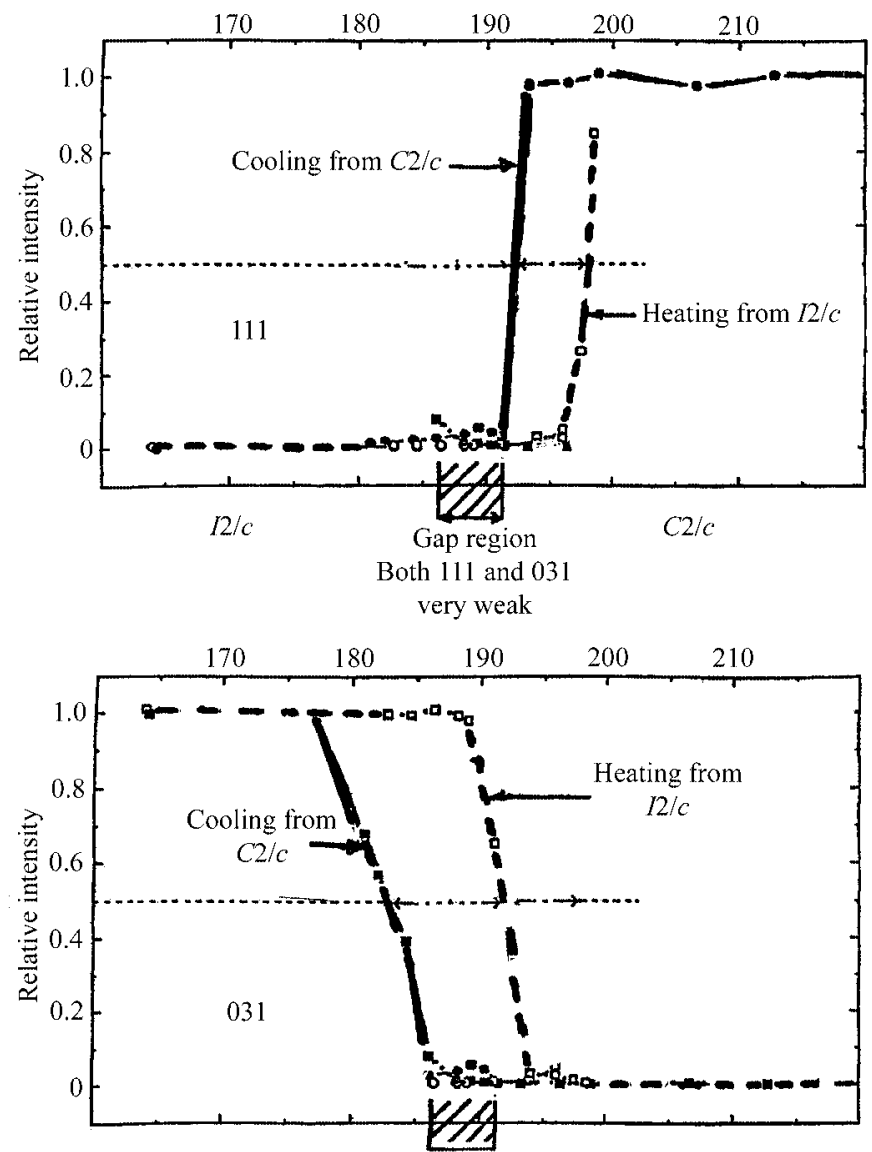

Figure 35

4,4'-Dichlorobenzophenone - dependence of the intensities of representative reflections on temperature. The upper diagram shows the heating and cooling curves for the 111 reflection present in the highertemperature $C 2 / c$ phase and absent in the lower-temperature $I 2 / c$ phase. The converse applies to the 031 reflection. Each pair of heating-cooling curves follows the pattern of Fig. 4, but the mean temperatures, which would be expected to approximate to $T_{0}$ for the system, are displaced by about 8 K. Adapted from Mitkevich et al. (1999).
Saito, 1992, private communication to Nakayama et al., 1995). We quote from Nakayama: 'The lower phase transition is of second order with the entropy of transition $0.334 \mathrm{~J} \mathrm{~mol}^{-1} \mathrm{~K}^{-1}$. The higher one has an unusual characteristic that the transition takes place over a very wide temperature range between 110 and $130 \mathrm{~K}$ and that the temperature at which the transition starts on heating depends on the thermal history'. It is quite possible that there may be similarities in the low-temperature behavior of 4,4'-dichloro- and 4,4'-difluorobenzophenone. 4,4'-Dimethylbenzopheneone (FEVMUO), and 4, $4^{\prime}$ Dibromo- and 4,4'-diiodobenzophenone (which are an isomorphous pair) have different structures and are not relevant in the present context.

\section{2. $\mathrm{Fe}\left(2\right.$-picolylamine) ${ }_{3} \mathrm{Cl}_{2} \cdot \mathrm{C}_{2} \mathrm{H}_{5} \mathrm{OH}$}

Several first-row transition metal complexes, known as spincrossover complexes, can be switched between high-spin (HS),

4,4'-Dichlorobenzophenone ${ }^{35} \mathrm{Cl}$ NQR
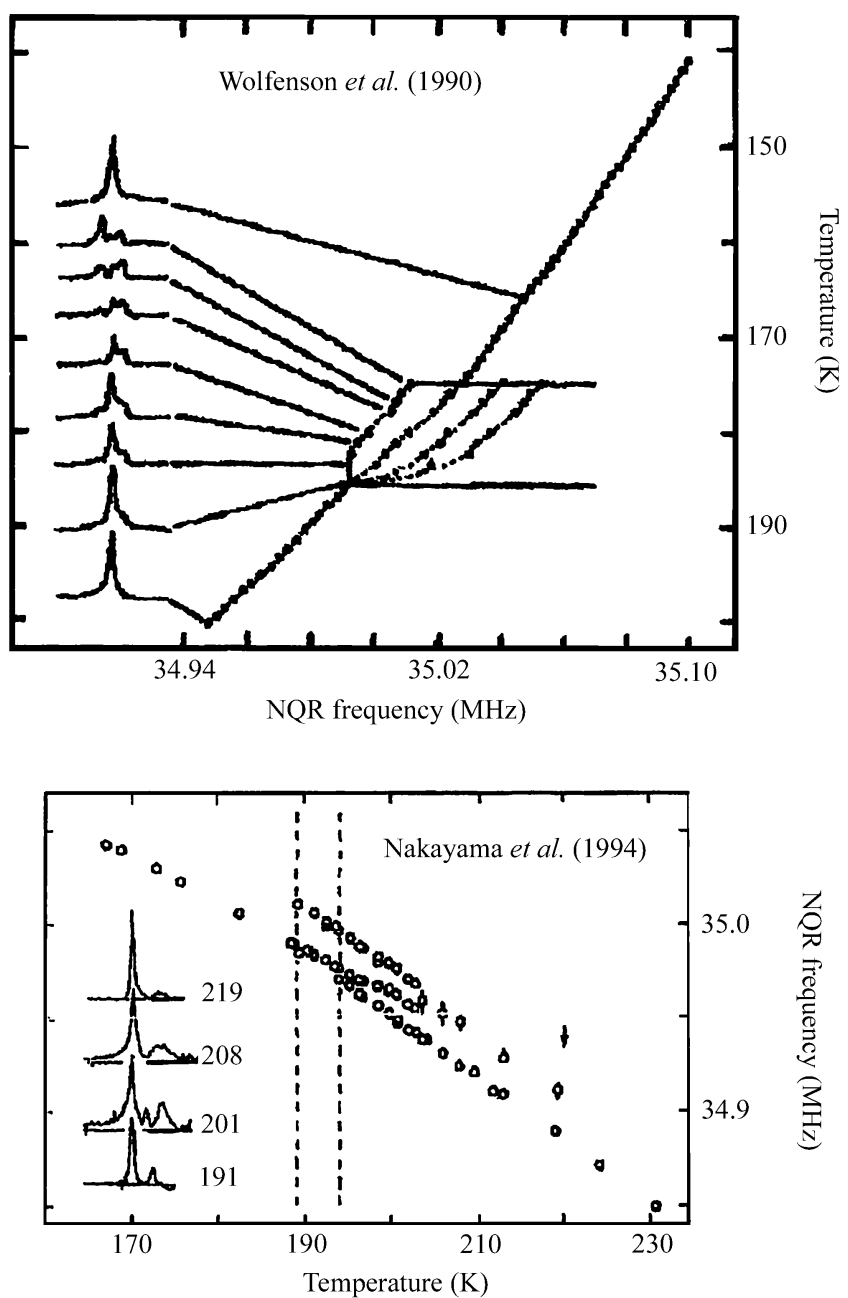

Figure 36

4,4'-Dichlorobenzophenone - two independent reports of the ${ }^{35} \mathrm{Cl} \mathrm{NQR}$ spectra as a function of temperature. The diagrams are qualitatively similar, but differ quantitatively - the difference has not yet been resolved. Note that temperature is the ordinate in the upper diagram, but the abscissa in the lower diagram. Adapted from Wolfenson et al. (1990) and Nakayama et al. (1994). 
intermediate-phase (IP) and low-spin (LS) states by changes of temperature (and other perturbations not of immediate interest here). HS, IP and LS states are stable at high, intermediate and low temperatures. The particular complex to be discussed here is the much-studied tris(2-picolylamine)iron(II)chloride-ethanol $\left\{\mathrm{Fe}(2-\mathrm{pic})_{3} \mathrm{Cl}_{2} \cdot \mathrm{EtOH}\right\}$ [2-pic is 2(aminomethyl)pyridine]. The heat capacity (at constant pressure) of $\left\{\mathrm{Fe}(2-\mathrm{pic})_{3} \mathrm{Cl}_{2} \cdot \mathrm{EtOH}\right\}$ in the range $13-315 \mathrm{~K}$ has been reported by Kaji \& Sorai (1985). There are two sharp maxima at 114.04 and $122.21 \mathrm{~K}$, the $122 \mathrm{~K}$ peak being much higher than the $114 \mathrm{~K}$ peak (Fig. 38); the enthalpy of transition (for the two events combined) is $6.14 \mathrm{~kJ} \mathrm{~mol}^{-1}$. Quantitative details about the heat capacity were not given.

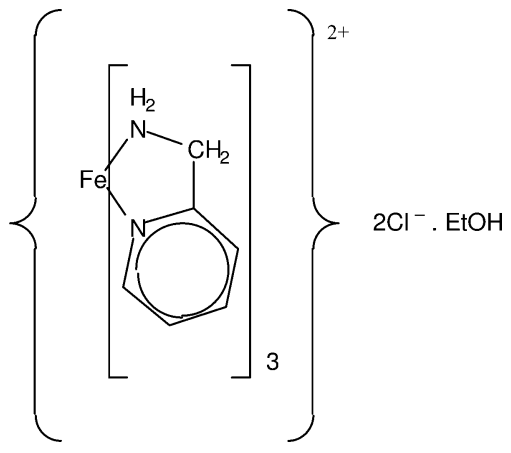

Scheme 8

$\left\{\mathrm{Fe}(2-\text { pic })_{3} \mathrm{Cl}_{2} \cdot \mathrm{EtOH}\right\}$ has many entries in the CSD (FEPICC, with suffixes 02-04, 20-37). The crystal structures of HS at 298 and $150 \mathrm{~K}$, and of LS at $90 \mathrm{~K}$ were reported 25 years ago (Mikami et al., 1980; FEPICC04, 20, 21); the cell dimensions are essentially the same (except for the effects of temperature) and the space groups are the same; there are

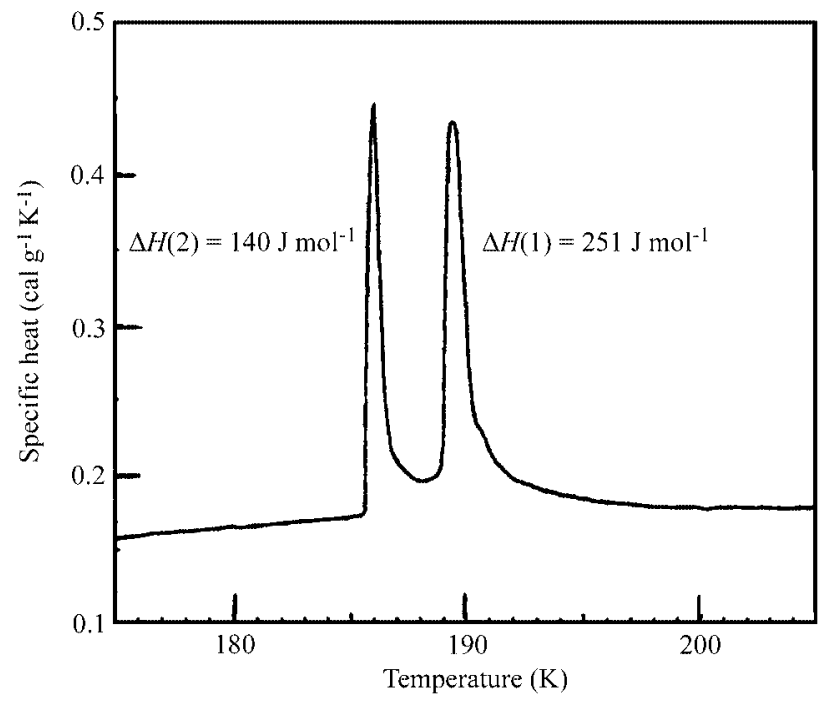

Figure 37

$4,4^{\prime}$ - Dichlorobenzophenone-specific heat of a single crystal between 175 and $205 \mathrm{~K}$ at a scanning rate of $5 \mathrm{~K} \mathrm{~min}^{-1}$. The enthalpies of transition (computed for a scanning rate of $2.5 \mathrm{~K} \mathrm{~min}^{-1}$ ) are shown. Adapted from Ecolivet et al. (1987).

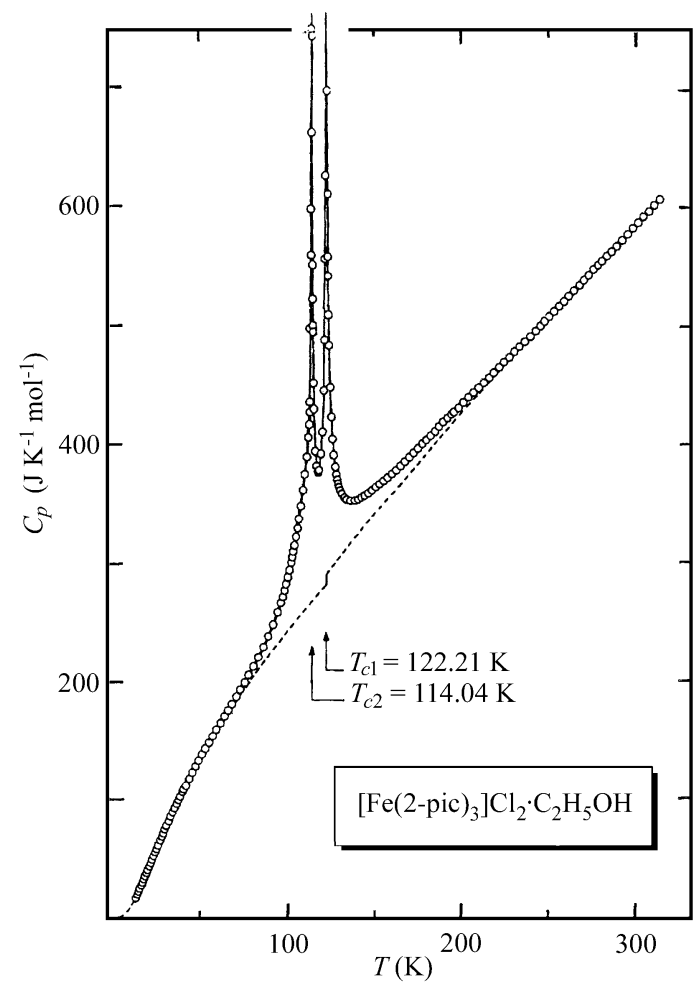

Figure 38

Tris(2-picolylamine)iron(II) chloride ethanol $\left[\mathrm{Fe}\left(2-\mathrm{pic}_{3} \mathrm{Cl}_{2} \cdot \mathrm{EtOH}\right]-\right.$ heat capacity (sample mass $15 \mathrm{~g}$ ) between 13 and $313 \mathrm{~K}$. This diagram should be compared with Fig. 37; unfortunately, quantitative details are not given for Fig. 38, thus not allowing appropriate scaling for a more direct comparison. Adapted from Kaji \& Sorai (1985).

differences in $\mathrm{Fe}-\mathrm{N}_{\mathrm{pyr}}$ bond lengths, while 'solvate ethanol molecules, hydrogen bonded to $\mathrm{Cl}^{-}$, exhibit orientational disorder in the HS state, but a regular arrangement in the LS state'. Cell dimensions were measured for the temperature range $100-300 \mathrm{~K}$, i.e. including the IP state, and showed irregular behavior in the 100-130 K region (see Fig. 7 of Wiehl et al., 1986). The IP structure was not studied by Mikami et al. nor by Wiehl et al. A crystal structure at $115 \mathrm{~K}$ was reported by Katz \& Strouse (1979). ${ }^{\mathbf{1 8}}$ Novel features of the system were uncovered by Chernyshov et al. (2003) in a study that included measurement of cell dimensions and determination of crystal structures at 12, 50, 100 (all LS), 111, 113, 115, 117, 119, 121, 123 (all IP), 125, 130, 143, 165, 200 and $298 \mathrm{~K}$ (all HS). The most important new finding (in the present context) was that the IP was an ordered phase with a unit cell of twice the volume of the LS and HS phases. For ease of comparison the LS and HS cells were expressed in terms of the non-standard space group $B 2_{1} / c$, while the IP phase has the standard space group $P 2_{1} / c$; now all unit cells have essentially the same volume and axial orientation. One of the (independent) iron atoms is predominantly in the LS state and the other predo-

\footnotetext{
18 Chernyshov et al. (2003) mention that crystal structures at 115, 148, 171, 199 and $227 \mathrm{~K}$ were determined by Katz \& Strouse (1979); these were for the orthorhombic methanol solvate. Katz \& Strouse determined the structure of the ethanol solvate only at $115 \mathrm{~K}$; a comparison of the cell volumes suggests that this was the LS structure.
} 
minantly in the HS state. There are other differences in detail for the description of which the reader is referred to Chernyshov et al. (2003).

None of the several groups states explicitly that the phase transitions are 'single crystal to single crystal', as would be expected from the resemblance in cell dimensions, but this presumably was considered obvious. The fact that the HS phase is yellow and the LS phase red should facilitate a microscope study, but this does not appear to have been made. There is no mention of hysteresis. Chernyshov et al. (2004) have discussed the transition in terms of 'Landau theory', but this is well outside the boundaries of the present paper. The changes in cell dimensions as a function of temperature are shown in the restricted range $90-145 \mathrm{~K}$ in Fig. 39 (corresponding diagrams for the complete range $12-298 \mathrm{~K}$ are deposited (Fig. 39A). The detailed behavior is intriguing, but not yet explained; $a$ and $c$ each show one abrupt and one smooth change, that for $a$ being at the LS/IP boundary and that for $c$ at the IP/HS boundary. $b$ and $\beta$ show abrupt changes at both boundaries. These changes at the phase boundaries, abrupt as they are, seem rather modest when compared with the striking changes in the heat capacity (Fig. 38). However, the occurrence of an intermediate phase is clearly established.

\subsection{Comparison of the transitions in 4,4'-dichlorobenzo- phenone and $\mathrm{Fe}$ (2-picolylamine) ${ }_{3} \mathrm{Cl}_{2} \cdot \mathrm{C}_{2} \mathrm{H}_{5} \mathrm{OH}$}

There is a striking resemblance between the behavior of these two crystals in that both have a sequence of two firstorder transitions separated by an intermediate state $c a 10 \mathrm{~K}$ wide. The structure of the intermediate phase has been determined in some detail for $\mathrm{Fe}$ (2-picolylamine) ${ }_{3} \mathrm{Cl}_{2}$-$\mathrm{C}_{2} \mathrm{H}_{5} \mathrm{OH}$ and cannot be described as an agglomeration of high- and low-temperature structures, while the less complete description for 4,4'-dichlorobenzophenone reminds one of an agglomeration, even if this is not simple. The high- and lowtemperature states are isostructural for $\mathrm{Fe}$ (2-picolylamine $)_{3} \mathrm{Cl}_{2} \cdot \mathrm{C}_{2} \mathrm{H}_{5} \mathrm{OH}$, but different for $4,4^{\prime}$-dichlorobenzophenone (similar cell dimensions but different space groups).

\section{A detailed study of a complex system}

10.1. Dimethyl 3,6-dichloro-2,5-dihydroxyterephthalate transformation of the yellow phase (stable below $413 \mathrm{~K}$ ) to the white phase (stable above $413 \mathrm{~K}$ )

Studies of colour changes in this system (Scheme 9) go back to Hantszch (1915). Initially it was thought that there were only two polymorphs - yellow (Y) and white $(\mathbf{W})$, whose (room-temperature) structures and solid-state interconversion were investigated in some detail by Byrn et al. (1972). Later studies by Yang et al. (1989) and Richardson et al. (1990; see also the discussion by Dunitz, 1995) showed that there was a third polymorph - light-yellow (LY) - not recognized earlier. These are concomitant polymorphs, obtainable by slow cooling of ethanol or ether solutions and easily separable by hand according to colour and morphology; all three forms are indefinitely stable at room temperature and below. Our account is based on the very comprehensive studies by the Dunitz group that included determinations of crystal structures for $\mathbf{Y}$ at $105,180,230,296$ and $353 \mathrm{~K}$, for $\mathbf{W}$ at 98,296 and $353 \mathrm{~K}$, and for $\mathbf{L Y}$ at 97, 179, 226, 296 and $343 \mathrm{~K}$, and extended to thermodynamic and microscope studies; however, the earlier concurring but more limited results of Byrn et al. (1972) are not neglected. The $\mathbf{Y}$ and $\mathbf{W}$ phases are enantiotropically related, their transition being of primary interest

Figure 39

$\left[\mathrm{Fe}(2 \text {-pic })_{3} \mathrm{Cl}_{2} \cdot \mathrm{EtOH}\right]$ - cell dimensions of the three phases (LS, below $115 \mathrm{~K}$; IP 115-123 K; HS above $123 \mathrm{~K}$ ). The abrupt changes are best shown in the plots of $b$ and $\beta$ against $T$. Data from Chernyshov $e t a l$. (2003). 
Table 12

Cell dimensions reported originally and those of the reduced cells for the three phases of dimethyl 3,6-dichloro-2,5-dihydroxyterephthalate; only roomtemperature values are given here, but values at other temperatures are available (MCHTEP to MCHTEP17).

All phases are triclinic. Results reported by Yang et al. (1989) for yellow and white (not listed) are in good agreement with those of Byrn et al. (1972). The ${ }^{35} \mathrm{Cl}$ NQR spectra (Curtin \& Byrn, 1969) are in agreement with the crystal data for MCHTEP (36 $650 \mathrm{Mhz})$ and MCHTEP01 (35 $290 \mathrm{and} 35360 \mathrm{Mhz})$

\begin{tabular}{|c|c|c|c|c|c|c|}
\hline Phase/refcode & $a / \alpha$ & $b / \beta$ & $c / \gamma$ & $V / \mathrm{mol}$ & $Z$ & Remarks \\
\hline $\begin{array}{l}\text { Yellow (as reported by } \\
\text { Byrn et al., 1972)/MCHTEP }\end{array}$ & $\begin{array}{l}9.595(1) \\
114.32(2)\end{array}$ & $\begin{array}{l}4.301(1) \\
94.97(2)\end{array}$ & $\begin{array}{l}7.970(1) \\
106.15(2)\end{array}$ & 280.2 & 1 & Molecule at $\overline{1}$ \\
\hline Reduced cell & $\begin{array}{l}4.301 \\
101.53\end{array}$ & $\begin{array}{l}7.334 \\
100.04\end{array}$ & $\begin{array}{l}9.360 \\
97.98\end{array}$ & & & Type (II) cell \\
\hline $\begin{array}{l}\text { White (as reported by } \\
\text { Byrn } \text { et al., 1972)/MCHTEP01 } \\
\text { Reduced cell }\end{array}$ & $\begin{array}{l}9.842(4) \\
116.38(3) \\
7.841 \\
63.55\end{array}$ & $\begin{array}{l}7.841(3) \\
124.17(3) \\
9.074 \\
88.98\end{array}$ & $\begin{array}{l}10.576(5) \\
88.98(3) \\
9.842 \\
68.56\end{array}$ & 287.3 & 2 & $\begin{array}{l}\text { Two independent } \\
\text { molecules at } \overline{1} \\
\text { Type (I) cell }\end{array}$ \\
\hline $\begin{array}{l}\text { Light yellow (as reported by } \\
\text { Yang et al., 1989)/MCHTEP02 }\end{array}$ & $\begin{array}{l}3.898(<1) \\
70.42(2)\end{array}$ & $\begin{array}{l}8.034(2) \\
89.10(1)\end{array}$ & $\begin{array}{l}9.491(2) \\
86.68(2)\end{array}$ & 279.57 & 1 & Molecule at $\overline{1}$, type (I) cell \\
\hline
\end{tabular}

in the present context, while $\mathbf{L Y}$ is monotropic (see $§ 12)$.<smiles>CC(=O)c1c(O)c(Cl)c(C(=O)O)c(O)c1Cl</smiles>

The most unequivocal evidence comes from the crystal structure studies. Although the crystal data (Table 12) do not show any obvious relations among the three phases, this is an oversimplification, as Richardson and co-workers (Richardson et al., 1990) show, by comparing packing diagrams, that the crystal structures, especially of $\mathbf{Y}$ and $\mathbf{L Y}$, are quite similar. ${ }^{\mathbf{1 9}}$ However, the molecules in the various phases do differ in both arrangement and conformation, being planar in $\mathbf{Y}$ and with the carbomethoxyl groups approximately perpendicular to the ring plane in $\mathbf{W}$ ( 85 and $70^{\circ}$ for the two symmetry-independent molecules), and with an interplanar angle (carbomethoxy/ring plane) of $c a 40^{\circ}$ in $\mathbf{L Y}$. Thus, one could expect 'single crystal to polycrystal' transformations and this indeed happens in the $\mathbf{Y}$ to $\mathbf{W}$ transition. However, a closer look leads to 'this [transformation] process has been shown to involve nucleation followed by highly anisotropic migration of the reaction front through the crystal. Optical goniometry in conjunction with the X-ray results shows that the migration of the front is rapid in directions normal to (110), the long axis of the crystal and slow in the [110] direction' (Byrn et al., 1972, Abstract). At this point we present (with permission) a quotation from Richardson et al. (1990, p. 659):

'Given the crystal structures of the three polymorphs, it is tempting to assume that the transitions occur by the simplest imaginable deformation of one structure into the other,

\footnotetext{
19 'Any similarity that may exist between triclinic structures is not necessarily seen to best advantage by transforming the cells to their reduced form' (Richardson et al., 1990, p. 658).
}

involving translations and rotations of the individual molecules. For the transformation of $\mathbf{Y}$ and $\mathbf{L Y}$ to $\mathbf{W}$, there is no feasible pathway for such a 'least motion' mechanism; starting from these structures, half the molecules would need to be rotated $180^{\circ}$ about an axis in the benzene ring, a process that would require a very high activation energy and which can hardly be imagined without total disruption of the existing structure. On the other hand, the $\mathbf{Y}$ and $\mathbf{L Y}$ structures are sufficiently similar that the transformations $\mathbf{Y} \leftrightarrow \mathbf{L Y}$ could be imagined to proceed by the kind of mechanism just described. Such a notion might even be encouraged by the observation that the forward process sometimes occurs by a single crystal to single crystal transformation. However attractive this notion might appear, it seems highly unlikely to be correct. The optical and thermal observations leave little doubt that the transitions involve nucleation and growth of the new phase outside the domains of the existing one. In other words, molecules must be transferred somehow from the unstable phase to the growing, stable one, across phase boundaries. At the present state of our knowledge, there seems little point in proposing any kind of detailed mechanism for such a process. We have no possibility for checking it'.

The phase transitions were studied by simultaneous DSC and microscope observations recorded by a video camera ( $c f$. $\$ 4.4)^{\mathbf{2 0}}$ and the relative stabilities of the various phases determined by dissolution studies. The order of thermodynamic stability was summarized by the Dunitz group as

$$
\begin{aligned}
& \text { at room temperature and below }: \mathbf{Y}>\mathbf{L Y}>\mathbf{W} \\
& \text { above } 360 \mathrm{~K}: \mathbf{W}>\mathbf{Y}>\mathbf{L Y} .
\end{aligned}
$$

$\mathbf{Y}$ and $\mathbf{W}$ form an enantiotropic cluster and their relationship is of primary concern in the present context. $\mathbf{W}$ shows consistent melting behaviour, with $\Delta H_{\text {fus }} \simeq 42 \mathrm{~kJ} \mathrm{~mol}^{-1}$ at $\sim 455 \mathrm{~K}$. The solid-state transition of $\mathbf{Y}$ to $\mathbf{W}$ was found by both groups to be rather erratic, ${ }^{21} \Delta H_{\text {trans }} \simeq 2.5 \mathrm{~kJ} \mathrm{~mol}^{-1}$ at $\sim 392 \mathrm{~K}$. Single

\footnotetext{
20 'Visual observations can sometimes be more sensitive indicators of phase changes than the DSC measurements' (Richardson et al., 1990, p. 655).

${ }^{21}$ The following quotation from Byrn et al. (1972) for $\mathbf{Y}$ to $\mathbf{W}$ is typical: 'The onset temperature was quite unpredictable and ranged from 383 to $413 \mathrm{~K}$ '.
} 

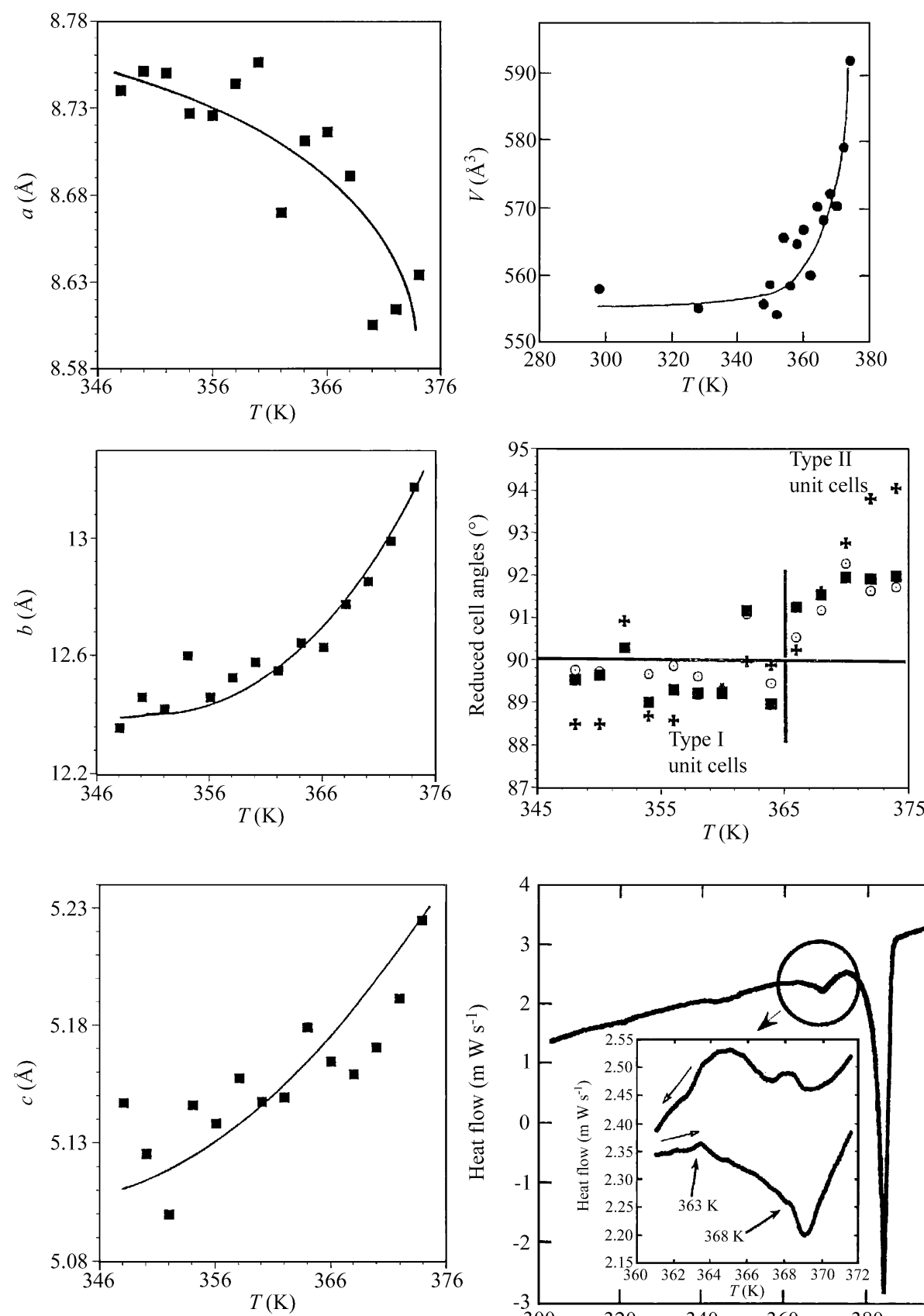

Figure 40

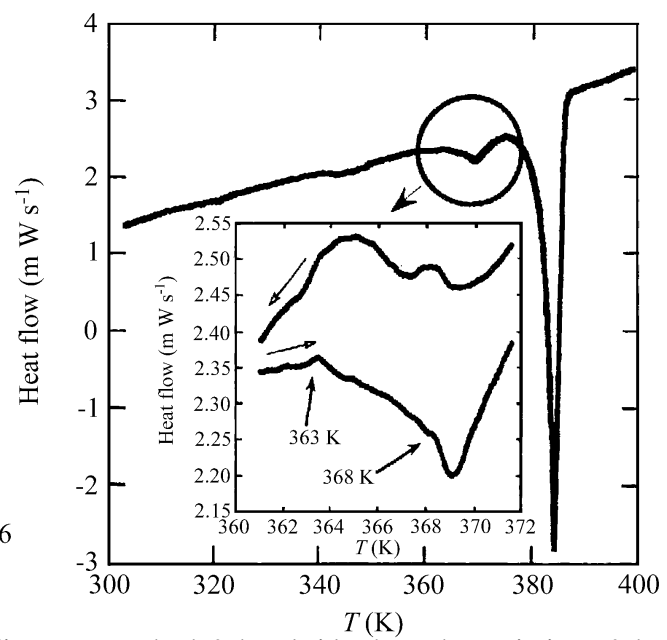

1-Ethyl-3-(4-methylpentanoyl)urea - the three diagrams on the left-hand side show the variation of the edges of the reduced triclinic cell with temperature in the region of change. The scatter of the experimental points suggests that the errors (random plus systematic) are at least an order of magnitude larger than the error estimates (bracketed values) given in Table 13. The temperature dependence of the cell volume is shown on the right-hand side and below that the variation of the angles of the reduced cell on temperature, and the DSC trace (lower curve: heating endotherm, upper curve: exotherm obtained on cooling, with hysteresis). The diagrams use data given by Hashizume et al. (2003).

similar to the behavior of the thallium picrate polymorphs (see, for example, Botoshansky et al., 1994; Herbstein, 2004).

$\mathbf{L Y}$ is monotropic, but its inclusion is important in the context of the behavior of a real system. The transitions of $\mathbf{L Y}$ must be unidirectional as they are from a metastable to a more stable phase, usually $\mathbf{W}$ but sometimes, depending on the conditions, Y. Richardson et al. (1990, p. 656) note that the only transition that is single crystal to single crystal is $\mathbf{L Y}$ $\Rightarrow \mathbf{Y}$. When crystals of LY transform to $\mathbf{W}$ the phase boundary moves along [110], which is usually the long axis of the crystal. Some other examples of metastable to stable transitions are given below (\$12).

\section{Apparently aberrant results in systems close to the melting point}

Phase transitions are found to occur over a wide range of temperatures - some at very low and low temperatures, and others close to the melting point of the substance being considered. Acetonitrile (\$8.1) is an example of the latter type and appears to behave quite normally. However, we have encountered a few examples whose behavior appears to be aberrant and two are described here.

\subsection{1-Ethyl-3-(4-methylpenta- noyl)urea - the reversible single crystal to single crystal phase transition at $\sim 365 \mathrm{~K}$}

The phase transition at $\sim 365 \mathrm{~K}$ in 1-ethyl-3-(4-methylpentanoy1)urea [Scheme 10; m.p. $383 \mathrm{~K}$; triclinic, $P \overline{1}$, at $98 \mathrm{~K}, 8.704(1)$, 12.204 (3), 4.975 (1) А, 93.02 (1),

crystals of $\mathbf{Y}$ transform to polycrystals of $\mathbf{W}$ (these possibly showing some preferred orientation); the erratic behavior is evidence for the importance of crystal defects in triggering the transition. Richardson et al. (1990, see p. 656) suggest that LY could be a transient intermediate in the $\mathbf{Y} \Rightarrow \mathbf{W}$ transition. Both groups report that $\mathbf{W}$ reverts to $\mathbf{Y}$ when allowed to stand in contact with a saturated solution [of the compound]. This is $\left.90.62(<1), 90.32(1)^{\circ}, Z=2\right]$ has been studied by a combination of calorimetric and $\mathrm{X}$-ray diffraction techniques (Hashizume et al., 2003). The DSC measurements (Fig. 40, bottom right) show the onset of the (heating) endotherm at $363 \mathrm{~K}\left(\Delta H_{\text {trans }}=1.1 \mathrm{~kJ} \mathrm{~mol}^{-1}\right.$, while $\Delta H_{\text {melting }}=$ $\left.17.3 \mathrm{~kJ} \mathrm{~mol}^{-1}\right)$; there is some evidence for hysteresis of a few degrees on cooling. Seventeen single-crystal data sets were 
Table 13

Reduced triclinic cells in standard form for 1-ethyl-3-(4-methylpentanoyl)urea.

The original data originate from Hashizume et al. (2003). The values in parentheses are errors of the reduced parameters calculated by $B L A F$ after reduction; they are similar to the experimental errors given by Hashizume et al. (2000). The cell volumes (not given in the table) are unchanged from the original values (see Fig. 40).

\begin{tabular}{llllllll}
\hline$T(\mathrm{~K})$ & $a$ & $b$ & $c$ & $\alpha$ & $\beta$ & $\gamma$ & Type $\dagger /$ comments \\
\hline 98 & $4.975(1)$ & $8.704(1)$ & $12.204(3)$ & $90.32(1)$ & $90.02(1)$ & $90.616(7)$ & $($ II) \\
298 & $5.0963(1)$ & $8.8173(3)$ & $12.434(1)$ & $89.85(1)$ & $87.09(1)$ & $89.876(3)$ & (I) \\
328 & $5.111(1)$ & $8.782(2)$ & $12.381(2)$ & $89.589(9)$ & $87.509(8)$ & $89.836(9)$ & (I) \\
348 & $5.147(1)$ & $8.740(2)$ & $12.357(2)$ & $89.53(1)$ & $88.491(8)$ & $89.76(1)$ & (I) \\
350 & $5.1254(9)$ & $8.751(2)$ & $12.460(2)$ & $89.642(8)$ & $89.490(5)$ & $89.727(9)$ & (I) \\
352 & $5.0998(3)$ & $8.750(2)$ & $12.421(1)$ & $90.29(1)$ & $90.921(8)$ & $90.28(1)$ & (II)-aberrant \\
354 & $5.1459(3)$ & $8.7270(4)$ & $12.601(1)$ & $89.001(9)$ & $88.683(9)$ & $89.67(1)$ & (I) \\
356 & $5.138(1)$ & $8.726(3)$ & $12.460(3)$ & $89.300(3)$ & $88.577(6)$ & $89.86(1)$ & (I) \\
358 & $5.1573(4)$ & $8.7438(6)$ & $12.527(1)$ & $89.224(3)$ & $89.198(6)$ & $89.612(7)$ & (I) \\
360 & $5.1472(6)$ & $8.756(1)$ & $12.579(1)$ & $89.216(6)$ & $89.32(1)$ & $89.293(6)$ & (I) \\
362 & $5.1490(5)$ & $8.670(1)$ & $12.5515(9)$ & $91.166(4)$ & $89.964(7)$ & $91.078(4)$ & Aberrant \\
364 & $5.1787(6)$ & $8.711(1)$ & $12.645(1)$ & $88.953(4)$ & $89.866(7)$ & $89.443(4)$ & (I) \\
Change from Type I to Type II cells occurs at 365 K & & & \\
366 & $5.1642(7)$ & $8.716(1)$ & $12.6307(7)$ & $91.243(5)$ & $90.22(1)$ & $90.522(6)$ & (II) \\
368 & $5.1587(1)$ & $8.6912(5)$ & $12.7757(6)$ & $91.537(2)$ & $91.614(2)$ & $91.168(6)$ & (II) \\
370 & $5.170(1)$ & $8.605(2)$ & $12.855(2)$ & $91.940(8)$ & $91.74(2)$ & $92.266(9)$ & (II) \\
372 & $5.191(1)$ & $8.614(2)$ & $12.994(3)$ & $91.901(6)$ & $93.80(1)$ & $91.62(1)$ & (II) \\
374 & $5.224(2)$ & $8.634(1)$ & $13.178(2)$ & $91.97(1)$ & $94.05(1)$ & $91.71(2)$ & (II) \\
\hline
\end{tabular}

$\dagger$ The type (I) cell has all angles $\leq 90^{\circ}$; type (II) has all angles $>90^{\circ}$.

collected over the temperature range $98-374 \mathrm{~K}$ and structure analysis carried out for each; in the $348-374 \mathrm{~K}$ region the data sets were collected at $2 \mathrm{~K}$ intervals. The closely spaced structure determinations give a series of 'stopped-motion photographs' called 'detailed temperature-resolved measurements'; similar methods have been used by Chernyshov et al. (2003) and others. There was no splitting of Bragg spots, but four separate crystals had to be used because of sample loss due to sublimation (crystals changed at 356, 358 and $372 \mathrm{~K}$ ). Most of the structure determinations were carried out at temperatures only some $40-20^{\circ}$ below the melting point and this led to difficulties. The cell dimension-temperature curves given by Hashizume et al. (2003; their Fig. 2) show changes beginning at $\sim 350 \mathrm{~K}$; these changes are more marked for the cell angles than for the cell edges and are without the discontinuities of the kind usually found in first-order phase transitions.<smiles>CCNC(=O)NC(=O)CCCC(C)C</smiles>

Inspection of the Hashizume results shows that not all the triclinic cells reported by these authors were reduced. We have reduced the triclinic cells using the computer program $B L A F$ (Table 13 and Fig. 40). The cell edges are the same as those given by Hashizume but cell angles differ, with details given in
Table 13. The striking feature is that there is a change from Type I unit cells to Type II unit cells at $365 \mathrm{~K}$. It seems reasonable to describe the phase transition in terms of this change rather than in terms of the cells given by Hashizume. However, some unexplained features remain - why is the $98 \mathrm{~K}$ cell (expected to be the best defined) Type II rather than Type I, and how does one account for the two aberrant results shown in Table 13?

The structural description of the transition (by Hashizume) was separated into two parts - one molecular and one supramolecular (i.e. pertaining to the crystal structure). Above $\sim 368 \mathrm{~K}$ the 3-methylbutyl group becomes disordered over two sites with a drastic conformational change (Fig. 41); the major and minor occupancies are 0.765 and 0.235 at $372 \mathrm{~K}$. The conformational change leaves void space in the crystal and the supramolecular structure adjusts to fill these voids by adopting the Type II cell. It is not clear whether these changes occur continuously or by a nucleation and growth mechanism; a microscope study has not been reported.

\subsection{Ortho-ethoxy-trans-cinnamic acid}

A DSC trace shows that there is a reversible single-crystal to single-crystal phase transition at $333 \mathrm{~K}$ from the $\alpha$ to the $\alpha^{\prime}$ phase of ortho-ethoxy-trans-cinnamic acid (Scheme 11). Both phases are triclinic but have quite different reduced cells that are, however, similar after (axial) transformation (Table 14).

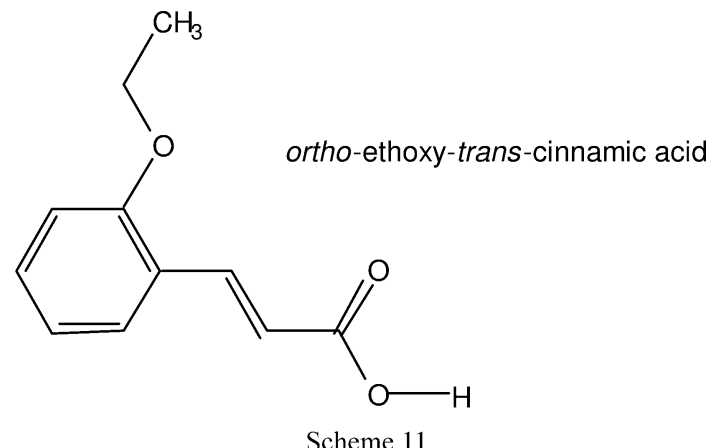

The transition could also be followed by single-crystal diffractograms. The transition is clearly first-order, although a value for $\Delta V$ at $333 \mathrm{~K}$ could not be extracted from the published report nor were values given for the enthalpies of transition and melting (Fernandes et al., 2004). A careful comparison was made of the crystal and molecular structures in the two phases; details are given in the publication. A few points regarding the transition should be noted. Hot-stage optical microscopy showed that the "phase change was 
Table 14

Cell parameters for the $\alpha$ polymorph [original (reduced) unit cell], the transformed unit cell $\left(\alpha_{\text {trans }}\right.$, after applying the matrix $\left.[0 \overline{1} 0 / \overline{1} 01 / \overline{2} 1 \overline{1}]\right)$ and the $\alpha^{\prime}$ polymorph. The space groups are all $P \overline{1}$ and $Z=3,6$ and 6 (taken from Table 5 of Fernandes et al., 2004).

\begin{tabular}{llll}
\hline Polymorph & $\alpha(173 \mathrm{~K})$ & $\alpha$ (transformed cell, 173 K) & $\alpha^{\prime}(345 \mathrm{~K})$ \\
\hline$a(\AA)$ & $6.6992(6)$ & $8.6807(8)$ & $8.7336(4)$ \\
$b(\AA)$ & $8.6807(6)$ & $10.1254(8)$ & $10.9590(7)$ \\
$c(\AA)$ & $10.0151(9)$ & $17.2967(12)$ & $17.2709(10)$ \\
$\alpha\left({ }^{\circ}\right)$ & $72.019(2)$ & $98.850(7)$ & $91.232(4)$ \\
$\beta\left({ }^{\circ}\right)$ & $71.464(2)$ & $91.793(4)$ & $92.703(4)$ \\
$\gamma\left({ }^{\circ}\right)$ & $87.867(2)$ & $93.214(3)$ & $109.472(4)$ \\
$V\left(\AA^{3}\right)$ & $499.54(8)$ & $1498.6(2)$ & $1555.5(2)$ \\
\hline
\end{tabular}

completely reversible, with the crystals remaining intact after several phase transformations, even though the crystal dimensions changed [from $1.00 \times 0.36 \mathrm{~mm}$ to $1.11 \times$ $0.32 \mathrm{~mm}$ ]'. Such behavior does not seem to have been encountered previously. The crystals 'hopped' (jumped) as they passed through the transition; this has been encountered previously for phase transitions in other materials. Finally, 'heating a crystal of the $\alpha^{\prime}$ polymorph would cause a front to move through the crystal at around $393 \mathrm{~K}$, which after further examination was found to be due to a phase transformation to the $\gamma$ polymorph'. Passage of an interface is usually found in epitaxic single-crystal to single-crystal phase transitions, while their Fig. 3 shows that transition to the $\gamma$ phase is single crystal to textured polycrystal.

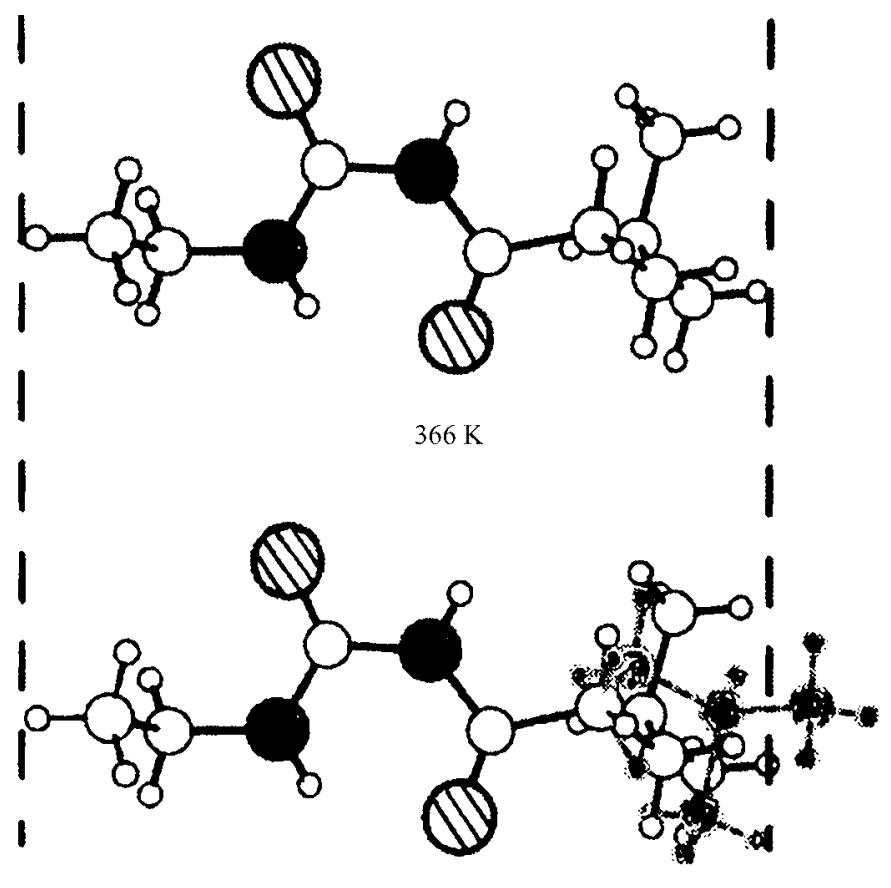

$368 \mathrm{~K}$

Figure 41

1-Ethyl-3-(4-methylpentanoyl)urea - the conformations of the 3methylbutyl group below $366 \mathrm{~K}$ (upper diagram) and above $368 \mathrm{~K}$ (lower diagram where the minor conformation is shown with filled circles). $\mathrm{O}$ atoms are lined, $\mathrm{N}$ atoms filled, $\mathrm{C}$ atoms open smaller circles and $\mathrm{H}$ atoms smallest open circles. Adapted from Fig. 5 of Hashizume et al. (2003).

\section{A reprise on single crystal to single crystal transitions in monotropic systems}

My original intention was to limit this paper to enantiotropic phase transitions, but a number of examples were encountered of studies of the transition from a metastable monotropic phase to the stable phase. Such a transition takes place in only one direction (metastable to stable) and is irreversible; there is no transition temperature characteristic of such a system. In many instances this distinction appears not to have been appreciated. There are resemblances and differences between the two types of transition. Our examples range from 1964 through 1977 to the present; see also the last paragraph in $\S 10.1$.

\section{1. $p$-Nitrophenol}

This is a monotropic system where the metastable $\beta$ phase $\left[P 2_{1} / n, \quad Z=4 ; 3.681(<1), \quad 11.115(<1), 14.645(<1) \AA\right.$, $92.80(<1)^{\circ}$; molecular volume $149.6 \AA^{3}$; NITPOL02] transforms into the stable $\alpha$-phase $\left[P 2_{1} / c, Z=4 ; 6.166(<1)\right.$, $8.837(<1), 11.543(<1) \AA, 103.39(<1)^{\circ}$; molecular volume $153.0 \AA^{3}$; NITPOL03]; crystal data at $110 \mathrm{~K}$ from Kulkarni et al. (1998) replacing the earlier results of Coppens \& Schmidt (1965). Experiments with thin films and single crystals showed that the orientation of the $\alpha$-phase product was not determined by the orientation of the parent $\beta$-phase crystallite (Cohen et al., 1964). Although both phases have the same basic structural element (head-to-tail hydrogen-bonded ribbons along [100]), the transformation is not displacive but 'the lattice is completely reconstructed in spite of the similarity between the two structures, the retention of the external shape, and the formation of single product crystals'.

\subsection{2-(4'-Methoxyphenyl)-1,4-benzoquinone transition from the yellow to the red form}

The conversion in the solid state of the yellow to the red form of 2-(4'-methoxyphenyl)-1,4-benzoqunone (Scheme 12) has been reported by Desiraju et al. (1977); the crystal structures and the anisotropy of the rearrangement were studied. It seems quite clear that the red and yellow crystals form a monotropic system with the red phase stable from low temperatures to the melting point. The red phase [orthorhombic, $P b c a, 12.783$ (2), 6.969 (2), 23.369 (5) A, cell volume $=2082 \AA^{3}, Z=8$; PANQUO01] was obtained by slow evaporation from 1:1 benzene-hexane or petroleum ether, m.p. 394-395 K. The yellow form is also orthorhombic [Pbca, 6.719 (2), 7.168 (3), 44.206 (18) $\AA$, cell volume $=2129 \AA^{3}, Z=$ 8 ; PANQUO] and was obtained by cooling a hot solution in 1:1 benzene-hexane, As the yellow crystals transform to the red form within a minute at $363 \mathrm{~K}$ it is not possible to give a melting point. 'Single crystals (of yellow) rearrange by a process which begins at a limited number of reaction sites and spreads by migration of well defined fronts... The yellow crystals on standing or heating showed a tendency which varied enormously from crystal to crystal to rearrange to the red. Some underwent the change in a few hours at room temperature; others underwent rearrangement only when 
heated above $100^{\circ} \mathrm{C}^{\prime}$. This is illustrated in Fig. 42 .

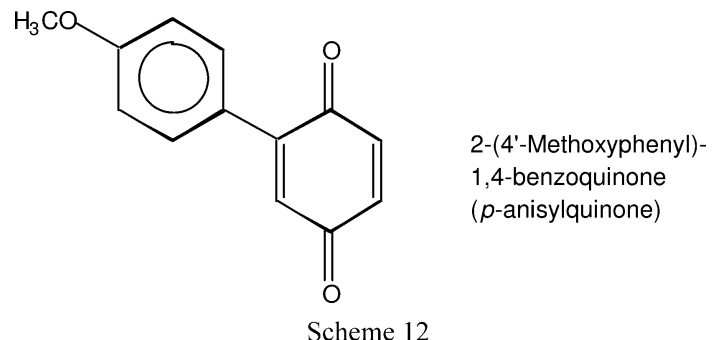

Desiraju et al. (1977) discuss possible mechanisms for the rearrangement in terms of the two crystal structures that they determined. It is particularly interesting to note that (in 1977!) they quote Mnyukh as follows:

'...Mnyukh et al. (1975; also see Mnyukh \& Panfilova, 1973) in an analysis of a number of phase transitions have suggested that rearrangement occurs at a series of microcavities at the reactant-product interface, when as here the orientations of reactant and product lattices are not correlated. They concluded that 'There is no indication that a polymorphic transition can be achieved by a 'shift', a 'turn', a 'displacement', an 'expansion', a
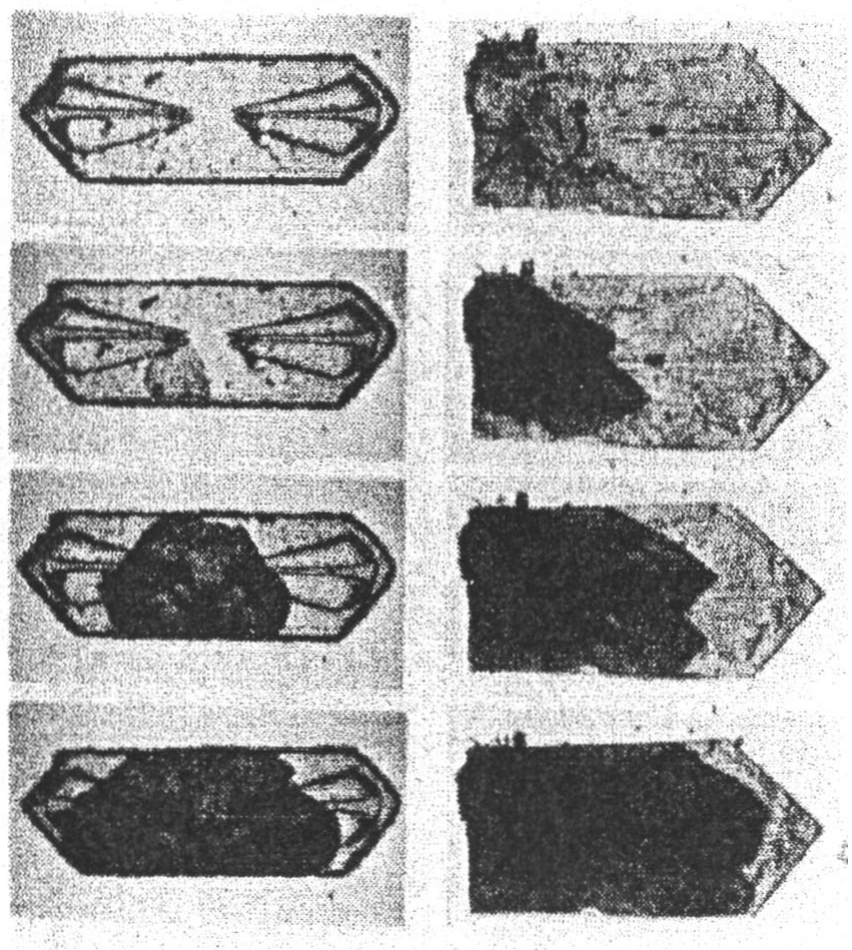

Figure 42

2-(4'-Methoxyphenyl)-1,4-benzoquinone - thermal rearrangement of the metastable yellow polymorph to the stable red polymorph. Left series: A crystal heated at $c a 360 \mathrm{~K}$. Photographs were taken at intervals of a few seconds. Note that although there were imperfections in the crystal before reaction began (top photograph), they had no discernible effect on the progress of the reaction. Right series: Reaction of a second crystal at $360 \mathrm{~K}$, showing more clearly the preference for frontal development in the [110] and [110] directions. Reprinted with permission from Desiraju et al. (1977). Copyright 1977 American Chemical Society. 'deformation' or an 'overturn' of the original crystal lattice to the final one'.

This agrees with the conclusions of Cohen et al. (1964) some ten years earlier and those of Dunitz and coworkers some 20 years later. However, there is a caveat - Mnyukh's remarks apply to enantiotropic systems while those of Cohen et al. (1964) and Byrn et al. (1972), and, in part, those of the Dunitz group, refer to monotropic systems. Nevertheless, these three examples are important because they show that similar considerations of nucleation, growth and interfaces govern solid-state transitions whether in enantiotropic (equilibrium conditions) or monotropic (non-equilibrium conditions) systems.

\section{3. $\mathrm{N}$-(4-Hydroxyphenyl)acetamide (paracetamol)}

This widely studied system (Scheme 13) has two polymorphs (perhaps there is an elusive third), monoclinic $[\alpha$ or (I)] stable (m.p. $442 \mathrm{~K}$ ) and orthorhombic [ $\beta$ or (II)] metastable, long recognized to be in a monotropic relation, with $\beta$ transforming to $\alpha$ even below room temperature. We give three leading references: neutron diffraction study of the $\alpha$ phase between 20 and $330 \mathrm{~K}$ (Wilson, 2000); XRD of the $\beta$ phase (Nichols \& Frampton, 1998); calorimetry of the system (Boldyreva et al., 2004). The orthorhombic phase transforms to monoclinic at $383 \mathrm{~K}$ along a diagonal front (Fig. 43; Nichols, 1998); surprisingly, the transition appears to be 'single crystal to single crystal', despite the apparent lack of resemblance in the crystal structures of the two phases.

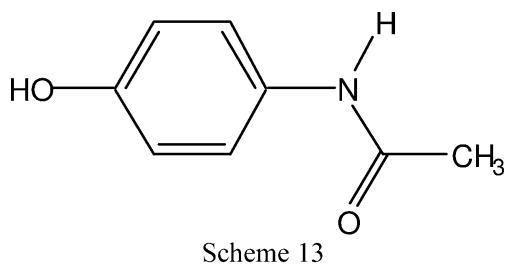

\section{Discussion}

We consider separately two groups of enantiotropic first-order phase transitions - in the first group there is an appreciable difference between the structures of low-and high-temperature phases, while in the second group there is a close resemblance. The designators 'appreciable difference' and 'close resemblance' have not been defined quantitatively nor do we know whether the boundary between the two groups is sharp or diffuse, but there seems to be a clear operational distinction between them (more examples are needed before this wording can be strengthened). In the first group there is no orientational relation between parent and daughter phase; in the second group there is an epitaxic relation between the two phases. Although sometimes beguiling pathways can be proposed for the passage from one phase to the other in the first group, there is no evidence that such occur in practice and the transition is always through nucleation and growth. This was established by Mnyukh's studies of eight different tran- 
$298 \mathrm{~K}$

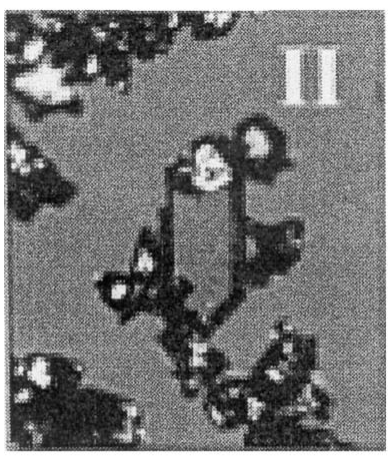

Figure 43

Paracetamol - phase transformation of metastable orthorhombic form (II) to the stable monoclinic form (I). At $298 \mathrm{~K}$ (left photograph), the crystal in the centre of the field is shown extinguished under crossed polarizers. The [001] axis is vertical and the large face is (210) (see Fig. 4 of Nichols, 1998). The conversion takes place at $383 \mathrm{~K}$ along a front which moves from lower left to upper right. The conversion is approximately $50 \%$ completed in the central photograph and essentially complete in the right-hand photograph. Other evidence (e.g. from Boldyreva et al., 2004) suggests that, although the external form of the crystal is unchanged, the product is actually polycrystalline monoclinic paracetamol. Thus, the crystal nature (single crystal or polycrystal) of the transformed phase requires clarification. Micrographs from Nichols (1999) reproduced with permission. sitions; Ubbelohde (Scheme 1) concurred, as did Cohen et al. (1964), Byrn et al. (1972) and the Dunitz group (Yang et al., 1989; Richardson et al., 1990). Mnyukh also pointed out that transitions were first order even when the two phases had a 'close resemblance', this having been first shown by Dinichert in his 1942 (Dinichert, 1942) study of $\mathrm{NH}_{4} \mathrm{Cl}^{\mathbf{2 2}}$ Another illustration comes from the first-order transition in \{TTF...chloranil) where the two phases are epitaxically related.

Some controversy remains about the second group. Ubbelohde introduced the idea of 'continuous' or 'smeared' transitions and described the transition phase as a 'hybrid':

'It was particularly interesting to find that well below $T_{0}$ or well above it, the structure behaved like any other single crystal. However, in the transition region itself, the solid assumed a hybrid structure with regions or domains of 1 and 2 coexisting side by side'.

This terminology was rejected by Mnyukh, the 'hybrid' region being construed as a two-phase region in the process of transforming from one phase to the other.

Comparison of the transitions in 2-(2,4-dinitrobenzyl)-3methylpyridine, 4,4'-dichlorobenzophenone and $\mathrm{Fe}$ (2-picolylamine $)_{3} \mathrm{Cl}_{2} \cdot \mathrm{C}_{2} \mathrm{H}_{5} \mathrm{OH}$ shows that there are real differences among these apparently similar systems. The three transitions all appear to have a sequence of two first-order transitions separated by an intermediate phase about $10 \mathrm{~K}$ wide. However, the DSC trace for 2-(2,4-dinitrobenzyl)-3-methylpyridine appears to be quite normal (Fig. 26) and the relative

${ }^{22}$ However, it is not known whether the two phases of $\mathrm{NH}_{4} \mathrm{Cl}$ are epitaxic. phase in 4,4'-dichlorobenzophenone appears, from the (limited) diffraction evidence, to be a one-dimensional modulated system along the [001] direction, possibly mediated by stacking faults. A shift of every second sheet would bring about a transformation from $C$ to $I$; half of these shifts (i.e. $\mathbf{c} / 4)$ would give a primitive monoclinic cell with four $\mathrm{Cl}$ atoms in the asymmetric unit. This is in agreement with the NQR evidence that there are four crystallographically independent ${ }^{35} \mathrm{Cl}$ atoms in the asymmetric unit. As noted earlier, Zuniga \& Criado (1995; see p. 887) suggest that 'a plausible explanation... [for the diffraction effects]... would be the coexistence of... domains of $I$ and $C$-centering with zones of alternate centered cells CICICI... When decreasing the temperature the domains of $C$-centering would gradually decrease in size and the $I$-domains would increase.... It is not difficult to reconcile this description with Ubbelohde's 'hybrid' intermediate state model. This use of 'hybrid' agrees with one of the definitions for this word given in the Concise Oxford English Dictionary (Fowler \& Fowler, 1983) - '(Fig.) thing, word composed of incongruous elements', for example horses and donkeys, the translation to the present situation being (for heating) 'transformed crystals of the HT phase together with not-yet transformed crystals of the LT phase'. However, the intermediate phase appears to have a more complex structure not yet determined in detail.

The existence of an intermediate phase in $\mathrm{Fe}$ (2-picolylamine) ${ }_{3} \mathrm{Cl}_{2} \cdot \mathrm{C}_{2} \mathrm{H}_{5} \mathrm{OH}$ is also established, but its nature differs from that found in 4,4'-dichlorobenzophenone. Rather than being a mélange of the low- and high-temperature phases, here an ordered phase is found, based on these phases but different from them. In this sense 'hybrid' refers to the other (converse) definition: 'Offspring of two animals or plants of 
different species or varieties'. A mule is neither a horse nor a donkey; perhaps it would be best to avoid 'hybrid' entirely.

What of the future? Certainly a broad survey is needed to find out how many phase transitions have been recognized and what fraction of these have been carefully investigated. Are 4,4'-dichlorobenzophenone and $\mathrm{Fe}$ (2-picolylamine) ${ }_{3} \mathrm{Cl}_{2} \cdot-$ $\mathrm{C}_{2} \mathrm{H}_{5} \mathrm{OH}$ singular examples or representative of a subset where the situation is more complex than envisaged in the standard 'nucleation-and-growth' approach?

What of the potential contribution of the more powerful instrumentation that has become available since Mnyukh's pioneering studies? Surely atomic force microscopy has a great deal to offer. The examples given above, apart from ammonium chloride, are all molecular crystals. The 'nucleation-and-growth' description of phase transitions should be universally applicable within the bounds of the crystalline state and so extension of this survey to metal and inorganic systems, so rich in phase transitions with so many of great practical importance, is a gap waiting to be filled. A great deal of information, much of it obtained from electron microscopy, has been published and re-assessment of the applicability of the 'nucleation-and-growth' description to inorganic and metallic systems should surely pay dividends.

Finally, it would be naïve to expect an essentially macroscopic description, as 'nucleation-and-growth' inevitably is, to reproduce all the complexities of a transition from one phase to another. Some idea of these complexities can be obtained from a thermosonometric study of the EII-(III) to EI-(II) phase transition in hexachloroethane (cooling monoclinic to orthorhombic) at $317 \mathrm{~K}$ (Lee et al., 1990). Short duration acoustic signals of frequencies up to $1000 \mathrm{kHz}$ were emitted during the phase transition. Empirical pattern recognition methods were used for their study as it was considered that their theoretical interpretation is a highly complex and perhaps intractable problem.

\section{List of conclusions}

(i) A wide-ranging review of the evidence about the (socalled $\Lambda$ ) phase transition in $\mathrm{NH}_{4} \mathrm{Cl}$ confirms that it is firstorder and discontinuous, in agreement with the experimental results of Dinichert and the conclusions of Ubbelohde and Mnyukh. 'Lambda' behavior is not always found in first-order phase transitions (for example, see Fig. 23); when it does appear, it seems to be evidence for pre-monitory effects.

(ii) The neutral to ionic phase transition in $\{\mathrm{TTF} \cdots$ chlorchloranil\} is confirmed as first order and discontinuous on the basis of the experimental studies of Buron-Le Cointe and coworkers.

(iii) Results reported for partial studies of the effects of pressure on both these systems indicate that further investigations of the pressure-temperature domain should provide a connection to Landau's theory of phase transitions.

(iv) Review of more recent work on the eight systems (\$\$7.1-7.8) studied by Mnyukh confirms his conclusions (apart from some minor details that require further study) that enantiotropic phase transitions proceed by a process of nucleation and growth. Mnyukh's distinction between the behavior of systems with large and small differences between the structures of low- and high-temperature phases is particularly apposite. When the differences are large, there is no orientational correlation between the two phases; when the difference is small there is an epitaxic relation and a moving interface separates the two phases as the transition proceeds. Ubbelohde's description of the 'large-difference' phase transitions matches those of Mnyukh, but Ubbelohde's depiction of 'hybrid crystals' is not supported except, possibly, for 4,4'dichlorobenzophenone ( $\$ 9.1)$.

(v) The evidence summarized in $\$ 4$ supports Mnyukh's classification of solid-state phase transitions (his $\$ 2.8 .7$ ) '...The only real molecular mechanism is the contact crystal growth [distinguished as] (i) oriented (epitaxic) crystal growth (ii) non-oriented crystal growth'. However, in my view, this classification applies only to first-order transitions; second-order transitions, not considered in this review, may well constitute a different situation.

(vi) Mnyukh's insistence on the importance of microscope studies of phase transitions is supported by a review of studies carried out subsequent to his pioneering efforts.

(vii) Post-Mnyukh studies of phase transitions in a number of systems are compatible with his views; these include both 'large difference' $(\$ \S 8.1,10.1)$ and 'small difference' (§§\$8.2.18.2.3) systems.

(viii) Some phase transitions near the melting point ( $\$ \$ 11.1$ and 11.2) appear to show aberrant behavior, but this is not always so (§8.1).

(ix) Transformation of a metastable to a stable phase in some monotropic systems ( $\$ \$ 12.1-12.3)$ has crystallographic features similar to those found in enantiotropic systems.

\section{APPENDIX $A$}

\section{A1. Nomenclature of polymorphs}

The 'Report of an IUCr Working Group on Phase Transition Nomenclature' (Tolédano et al., 1998; see also Tolédano et al., 2001; Brown et al., 2005) provides background information and a proposal for a 'Six-field phase-transition nomenclature'. This proposal has the virtue of completeness, but the deficiencies of not distinguishing enantiotropic and monotropic systems, and of using only inorganic substances as illustrative examples. A more compact nomenclature for convenient designation within a text has been proposed (Herbstein, 2001, see p. 118). This revises an earlier proposal of McCrone (1965, pp. 736-737) and incorporates part of the information included in the Working Group proposal. A shortened version is given here:

Polymorphs of a compound are designated as follows: Enantiotropic system: Name (of Compound) [EI (Enantiotropic system: Name (of Compound) [EI $\left(<T_{1} \mathrm{~K}\right)$ (other information); Name (of Compound) EII ( $T 1-T 2 \mathrm{~K}$ )(other information);...]. The polymorphs are listed as (I), (II),... in 
order of increasing temperature stability ranges, which is the inverse of McCrone's suggestion. $<T_{1}, T 1-T_{2} \ldots$ give the regions of temperature stability. The 'other information' can include former designations, the number of molecules in the unit cell, space group etc. Newly discovered polymorphs would have to be inserted between known examples, perhaps with revision of the previous (I), (II)... order. We illustrate for perylene: [EI (<420 K(?))- $(\beta ; Z=2)$; EII (420 (?)-551 K)- $(\alpha$; $Z=4)$ ]. These designations have been abbreviated in the text.

Monotropic system: Name [MI (other information); MII (other information)]. A combination of the two types of nomenclature will be needed when the compound has both enantiotropic and monotropic systems. Only temperature has been used in the above examples, atmospheric pressure being assumed but pressure as a variable can be accommodated.

\section{APPENDIX $B$}

\section{B1. Simon, Sir Francis Eugene (1893-1956) - biographical notes}

Francis (Franz) Simon received a classical education, but developed a strong interest in science and went to Munich in 1912 to read physics. He was called up for military service in 1913 and from 1914 to 1918 served as a lieutenant in field artillery. He resumed his studies at the University of Berlin in 1919, and in 1920 started work for his PhD under Nernst. Simon's research concerned measurement of specific heats at low temperatures, which remained the basis of his scientific interest throughout his life. He received his doctorate in 1921 and in 1924 became 'Privatdozent', then Associate Professor in 1927. In 1931 he was appointed to the chair of Physical Chemistry at the Technical University of Breslau. He resigned in June 1933 after the Nazi takeover and accepted the invitation of F. A. Lindemann (later Lord Cherwell, 1886-1957) to work at the Clarendon Laboratory in Oxford. In 1935 he was appointed Reader in Thermodynamics and then Professor, 1945-1956. He succeeded Lindemann as Lee's Professor of Experimental Philosophy, but died only a few weeks after his appointment. He was elected to the Royal Society in 1941, and received the Rumford Medal in 1948, the first Kamerlingh Onnes Medal of the Dutch Institute of Refrigeration in 1950, and the Linde Medal in 1952. Also in 1952 he was elected a honorary foreign member of the American Academy of Arts and Sciences. For his war work on atomic energy he received the CBE in 1946. He was knighted in 1955 (abbreviated from Kurti, 1958).

\section{APPENDIX C \\ C1. Ubbelohde, Alfred Rene Jean Paul (1907-1988) - biographical notes}

Ubbelohde was born in Antwerpen to a patrician banking family. His father, a merchant, moved the family to London in October 1914. Ubbelohde contracted poliomyelitis at the age of seven with unpleasant physical consequences. He was educated at St Paul's School and Oxford (chemistry; DSc 1941). He became a British national in his mid-twenties.
Ubbelohde spent 1931-1932 with Eucken in Göttingen; Clusius, Teller, Lothar Meyer and Max Born were contemporaries. Ubbelohde was at the Royal Institution (then directed by Sir William H. Bragg) from 1936 to 1940. Among his contemporaries were Kathleen Lonsdale, J. Monteath Robertson and H. A. Jahn. During the War he worked in Swansea on explosives research and then became Head of the Department of Chemistry at Queens University, Belfast from 1945 to 1954 (elected FRS 1951). He became Professor of Thermodynamics at Imperial College in 1954, staying there until he retired in 1975, remaining on, however, as Senior Research Fellow until his death.

His biographer, Professor F. J. Weinberg, FRS, writes 'Some men make it their life's work to excavate one deep mine of knowledge in a particular field, others scoop shallower pits over a wide area. A. R. J. P. Ubbelohde was an exceptional polymath who dug deeply in many fields and permanently altered our view of their landscapes. He contributed to subjects ranging from chemical thermodynamics, over combustion, explosives and detonations, to ionic melts, graphite and intercalation compounds. He was an enthusiastic farmer with a penchant for intelligent pigs, an expert on Chinese cloisonné ceramics and other antiques, an authority on literature, wines and a devotee of salmon fishing. He wrote six books (among some 400 publications) and was regarded as a leader of research by diverse groups of workers who were barely aware of his contributions to other areas. His elegant and erudite writings included literary critique, biography and The marriage of art and science (for the Royal Society of Arts) effortlessly negating C. P. Snow's concept of 'two cultures'. For the biographer it is a curious experience to encounter so many people who believe his main contributions to lie entirely in their own particular fields; very much like writing the memoirs of several men'.

Abbreviated from Weinberg (1990).

\section{APPENDIX $D$}

\section{D1. Mnyukh, Yuri (b. 1926) - biographical notes}

Dr Mnyukh was trained in the former Soviet Union (DSc 1959 from the Institute of Crystallography of the Soviet Academy of Sciences) and worked with A. I. Kitaigorodski for many years. He was Director of the Crystallophysics Laboratory, Research Institute of Biological Physics, USSR Academy of Sciences from 1966 to 1973. Together with, among others, Sakharov and Sharansky he participated in the human rights movement and was forced to emigrate because of this involvement. Since 1978 he has been associated with New York University.

\section{APPENDIX $E$}

\section{E1. Dinichert, Paul (1914-1997) - biographical notes}

Dinichert was born in Berne, matriculated there and studied in Berlin with P. J. W. Debye from 1937 to 1939, his thesis being in the field of low-temperature magnetism. Outbreak of the Second War led to his return to Geneva, where he earned a 
second doctorate in low-temperature physics (including the work on ammonium chloride discussed above). After this he joined the Swiss Institute for Horology (LSRH) in Neuchatel, becoming director in 1962 . He also taught at the University of Neuchatel. Dinichert had wide interests in the physical sciences, including electron microscopy, crystallography and military applications. He was, inter alia, a member of the Swiss Crystallographic Society and the American Physical Society.

\section{APPENDIX $\boldsymbol{F}$}

\section{F1. Other studies on $\mathrm{NH}_{4} \mathrm{Cl}$}

Under pressure the transition becomes continuous and there is a tricritical point (the junction of the first-order and second-order regions of a phase line) around $150 \mathrm{MPa}$ (1.6 kbar). The volume discontinuity between the two phases decreases linearly between atmospheric pressure and the tricritical pressure. The effects of pressure on the $\Lambda$ transition in $\mathrm{NH}_{4} \mathrm{Cl}$ and $\mathrm{ND}_{4} \mathrm{Cl}$ have been summarized by Wirths \& Schneider (1981).

A Mössbauer study of ${ }^{57} \mathrm{Fe}^{2+}$ doped $\mathrm{NH}_{4} \mathrm{Cl}$ (Gibb et al., 1972) gives more information about the behavior of the ${ }^{57} \mathrm{Fe}^{2+}$ cation, which appears to be accommodated at a face center of the $\mathrm{Cl}^{-}$cube with a pair of $\mathrm{NH}_{4}^{+}$vacancies to preserve charge balance, than about the parent matrix.

Dilatometric measurements of $\mathrm{NH}_{4} \mathrm{Cl}$ and $\mathrm{ND}_{4} \mathrm{Cl}$ by Smits et al. (1937) suggested that $\mathrm{ND}_{4} \mathrm{Cl}$ has a second-order transition. However, this was refuted by Yelon \& Cox (1972), who used neutron diffraction intensity measurements to show that there was a discontinuous change at $\sim 249 \mathrm{~K}$; the width of the hysteresis loop was $0.035 \mathrm{~K}$. Thomas \& Staveley (1951a) made dilatometric studies of $\mathrm{NH}_{3} \mathrm{DCl}$ and $\mathrm{ND}_{3} \mathrm{HCl}$, and also investigated the effects of particle (or crystallite) size on the curves. A DSC study (Shikano et al., 1999) of the effects of isotope substitution on transition temperatures and widths of the hysteresis loops has been carried out for the 242 and $457 \mathrm{~K}$ transitions; only the former is of interest here. The isotopes used were ${ }^{15} \mathrm{~N},{ }^{35} \mathrm{Cl}$ and deuterium, substituting for the natural abundance compositions. Only D has an appreciable effect.

The spectroscopy of $\mathrm{NH}_{4} \mathrm{Cl}$ in the vicinity of the $\Lambda$ transition at $242 \mathrm{~K}$ has been considered in a long series of papers (we reference an early and a recent paper - Yurtseven \& Sherman, 1984; Yurtseven et al., 2001). The solid-state behavior and properties are analyzed experimentally and theoretically for the first-order transition at $P=0$, the tricritical point at $P=1.6$ kbar and the second-order transition at $P=2.8$ kbar. These studies concern the properties of the individual phases and not the mechanism of the transition between them. The dependence of the order of the transition on the pressure is of great interest, but beyond the scope of this review.

I am grateful to Dr Yuri Mnyukh for a copy of his book and helpful comments, to Professor J. D. Dunitz FRS (Zürich) for his comments and interest, to Professor B. Santarsiero (University of Illinois in Chicago) for unpublished information about hexamethylbenzene, to Professor Y. Matsuoka (Tokyo University of Agriculture and Technology) for unpublished information about $\gamma$-D,L-methiohine, to Professor Howard Flack (University of Geneva) for information about Dinichert, to Professor H.-B. Bürgi (Bern) in connection with $\S 9.2$, and the staff of the Chemistry-Biology Library at Technion for supplying copies of many papers.

\section{References}

American Chemical Society (2004). SciFinder Scholar, Version 2004.2. http:www.cas.org/SCIFINDER/SCHOLAR/.

Atoji, M., Oda, T. \& Watanabe, T. (1953). Acta Cryst. 6, 868.

Bendeif, E.-E., Dahaoul, S., Francois, M., Benali-Cherif, N. \& Lecomte, C. (2005). Acta Cryst. B61, 700-709.

Bernstein, J. (2002). Polymorphism in Organic Crystals. IUCR Monograph on Crystallography No. 14. Oxford: Clarendon Press.

Bertinelli, F. \& Stremmenos, C. (1973). J. Chem. Soc. Faraday II, 69, 889-901.

Blinc, R. (1981). Phys. Rep. 79, 332-398.

Boldyreva, E. V., Drebushchak, V. A., Paukov, I. E., Kovalevskaya, Y. A. \& Drebushchak, T. N. (2004). J. Therm. Analys. Calorim. 77, 607-623.

Bond, W. L. (1960). Acta Cryst. 13, 814-818.

Boonstra, E. G. \& Herbstein, F. H. (1963). Acta Cryst. 16, 252-255.

Botoshansky, M., Ellern, A., Gasper, G., Henck, J.-O. \& Herbstein, F. H. (1998). Acta Cryst. B54, 277-290.

Botoshansky, M., Herbstein, F. H. \& Kapon, M. (1994). Acta Cryst. B50, 589-596.

Briske, C. \& Hartshorne, N. H. (1967). Trans. Farad. Soc. 63, 15461552.

Brown, I. D., Abrahams, S. C., Berndt, M., Faber, J., Karen, V. L., Motherwell, W. D. S., Villars, P., Westbrook, J. D. \& McMahon, B. (2005). Acta Cryst. A61, 575-580.

Buerger, M. J. (1951). Phase Transformations in Solids, ch. 6, pp. $183-$ 211. New York: Wiley.

Buron-Le Cointe, M., Lemée-Cailleau, M. H., Cailleau, H., Toudic, B., Moreeac, M., Moussa, F., Ayache, C. \& Karl, N. (2003). Phys. Rev. B, 68, 064103-1-7.

Byrn, S. R., Curtin, D. Y. \& Paul, I. C. (1972). J. Am. Chem. Soc. 94, 890-898.

Celotti, G., Bertinelli, F. \& Stremmenos, C. (1975). Acta Cryst. A31, 582-585.

Chattaway, F. D. \& Lambert, W. J. (1915). J. Chem. Soc. 107, 17731781.

Chernyshov, D., Bürgi, H.-B., Hostettler, M. \& Törnroos, K. W. (2004). Phys. Rev. B, 70, 094116-1-8.

Chernyshov, D., Hostettler, M., Törnroos, K. W. \& Bürgi, H.-B. (2003). Angew. Chem. Int. Ed. 42, 3825-3830.

Chihara, H. \& Nakamura, M. (1972). Bull. Chem. Soc. Jpn, 45, $133-$ 140.

Chihara, H. \& Seki, S. (1948). Nature, 162, 773-774.

Christian, J. W. (1965). The Theory of Transformations in Metals and Alloys. First edition 1965; second edition 1975. Part I, Equilibrium and General Kinetic Theory. Oxford: Pergamon Press.

Cingolani, A. \& Berchiesi, G. (1974). J. Therm. Anal. 6, 87-90.

Cohen, M. D., Coppens, P. \& Schmidt, G. M. J. (1964). J. Chem. Phys. Solids, 25, 258-260.

Coppens, P. \& Schmidt, G. M. J. (1965). Acta Cryst. 18, 654-663.

Curtin, D. Y. \& Byrn, S. R. (1969). J. Am. Chem. Soc. 91, 1865-1866.

Dalhus, B. \& Görbitz, C. H. (1996). Acta Cryst. C52, 1761-1764.

David, W. I. F. (2005). Private communication.

Delaplane, R. G., David, W. I. F., Ibberson, R. M. \& Wilson, C. C. (1993). Chem. Phys. Lett. 201, 75-78.

Desiraju, G. R., Paul, I. C. \& Curtin, D. Y. (1977). J. Am. Chem. Soc. 99, 1594-1601.

Dinichert, P. (1942). Helv. Phys. Acta, 15, 462-475.

Dinichert, P. (1944a). Helv. Phys. Acta, 17, 400-404.

Dinichert, P. (1944b). Helv. Phys. Acta, 17, 389-399. 
Dolling, G., Powell, B. M. \& Sears, V. F. (1979). Mol. Phys. 37, 1859 1883.

Dunitz, J. D. (1995). Acta Cryst. B51, 619-635.

Dupré La Tour, F. (1932). C. R. Acad. Sci. Paris, 194, 622-623.

Dworkin, A., Figuiere, P., Ghelfenstein, M. \& Szwarc, H. (1976). J. Chem. Thermodyn. 8, 835-844.

Ecolivet, C., Bertaut, M., Mierzejewski, A. \& Collet, A. (1987). In Dynamics of Molecular Crystals, edited by J. Lascombe, pp. 187192. Amsterdam: Elsevier.

Ehrenfest, P. (1933). Proc. Acad. Sci. Amsterdam, 36, 153-157.

Enjalbert, R. \& Galy, J. (2002). Acta Cryst. B58, 1005-1010.

Estop, E., Alvarez-Larena, A., Belaaraj, A., Solans, X. \& Labrador, M. (1997). Acta Cryst. C53, 1932-1935.

Everett, D. H. \& Edwards, N. J. B. (1958). Special publication No. 12, p. 245. London: The Chemical Society.

Extermann, R. \& Weigle, J. (1942). Helv. Phys. Acta, 15, 455-461.

Fernandes, M. A., Levendis, D. M. \& Schoening, F. R. L. (2004). Acta Cryst. B60, 300-314.

Fowler, H. W. \& Fowler, F. G. (1983). Editors. Concise Oxford English Dictionary, 4th ed. revised by E. McIntosh. Oxford: Clarendon Press.

Frankosky, M. \& Aston, J. G. (1965). J. Phys. Chem. 69, 31263132.

Freer, S. T. \& Kraut, J. (1965). Acta Cryst. 19, 992-1002.

Fujiwara, T., Inaba, A., Atake, T. \& Chihara, H. (1992). J. Chem. Thermodyn. 24, 863-881.

Fukai, M., Matsuo, T. \& Suga, H. (1991). Thermochim. Acta, 183, $215-$ 243.

Gafner, G. \& Herbstein, F. H. (1960). Acta Cryst. 13, 706-716.

Gafner, G. \& Herbstein, F. H. (1964). Acta Cryst. 17, 982-985.

Gallier, J., Toudic, B., Délugeard, Y., Cailleau, H., Gourdji, M., Péneau, A. \& Guibé, L. (1993). Phys. Rev. B, 47, 1168811695.

Gibb, T. C., Greenwood, N. N. \& Sastry, M. D. (1972). J. Chem. Soc. Dalton Trans. pp. 1896-1899.

Goedkoop, J. A. \& MacGillavry, C. H. (1957). Acta Cryst. 10, 125127.

Gopalan, R. S., Kumradhas, P., Kulkarni, G. U. \& Rao, C. N. R. (2000). J. Mol. Struct. 521, 97-106.

Gourdji, M., Guibé, L., Péneau, A., Gallier, J., Toudic, B. \& Cailleau, H. (1991). Z. Naturforsch. Teil A, 47, 257-260.

Granger, M. M. \& Coillot, M. F. (1985). Acta Cryst. C41, 542-543.

Grunenberg, A., Bougeard, D. \& Schrader, B. (1984). Thermochim. Acta, 77, 59-66.

Hamilton, W. C., Edmonds, J. W., Tippe, A. \& Rush, J. J. (1969). Disc. Farad. Soc. 48, 192-204.

Hantszch, A. (1915). Chem. Ber. 48, 797-816.

Harding, M. M., Kariuki, B. M., Williams, L. \& Anwar, J. (1995). Acta Cryst. B51, 1059-1062.

Hashizume, D., Miki, N., Yamazaki, T., Aoyaki, Y., Arisato, T., Uchiyama, H., Endo, T., Yasui, M. \& Iwasaki, F. (2003). Acta Cryst. B59, 404-415.

Herbstein, F. H. (1996). Cryst. Rev. 5, 181-226.

Herbstein, F. H. (2001). Advances in Structure Analysis, edited by R. Kuzel \& J. Hasek, pp. 114-154. Praha: Czech and Slovak Crystallographic Association.

Herbstein, F. H. (2004). Cryst. Growth Des. 4, 1419-1429.

Herbstein, F. H., Kapon, M., Reisner, G. M., Lehman, M. S., Kress, R. B., Wilson, R. B., Shiau, W. I., Duesler, E. N., Paul, I. C. \& Curtin, D. Y. (1985). Proc. R. Soc. London A, 399, 295-310.

Hohlwein, D., Nägele, W. \& Prandl, W. (1979). Acta Cryst. B35, 29752978.

Hovi, V., Mutikainen, P. \& Pirinen, J. (1973). Ann. Acad. Sci. Fenn. Ser. A6, 464, 3-12.

Jagannathan, N. R. \& Rao, C. N. R. (1987). Chem. Phys. Lett. 140, 4650 .

Johnson, F. B. (1956). Nature (London), 178, 590.

Kaji, K. \& Sorai, M. (1985). Thermochim. Acta, 88, 185-190.
Katz, B. A. \& Strouse, C. E. (1979). J. Am. Chem. Soc. 101, 6214 6221.

Kawamura, T., Mijazaki, Y. \& Sorai, M. (1997). Chem. Phys. Lett. 273, $435-438$.

Kitaigorodsky, A. I., Mnuykh, Yu. V. \& Asadov, Yu. G. (1965). J. Phys. Chem. Solids, 26, 463-472.

Koga, Y. (1987). Physica B, 146, 408-415.

Koga, Y. \& Miura, R. M. (1978). Trans. Farad. Soc. 74, 1913-1921.

Koide, T., Tsujino, M., Sawada, K. \& Oda, T. (1974). Bull. Chem. Soc. Jpn, 47, 2998-3000.

Koningsveld, H. van \& Baas, J. M. A. (1984). Acta Cryst. C40, 311313.

Krzystek, J., Kwiram, A. B. \& Kwiram, A. L. (1995). J. Phys. Chem. 99, 402-409.

Kühnert-Brandstätter, M. \& Moser, I. (1981). Mikrochim. Acta (Wien), I, 411-420.

Kulkarni, G. U., Kumaradas, P. \& Rao, C. N. R. (1998). Chem. Mater. 10, 3498-3505.

Kurti, N. (1958). Biogr. Mem. Fellows R. S. 4, 225-256.

Kusto, W. J. (1981). Mater. Sci. 7, 219-222.

Le Cointe, M. (1994). Doctoral thesis, University of Rennes I.

Le Cointe, M., Gallier, J., Cailleau, H., Gourdji, M., Péneau, A. \& Guibé, L. (1995). Solid State Commun. 94, 455-459.

Le Cointe, M., Lemée-Cailleau, M. H., Cailleau, H. \& Toudic, B. (1996). J. Mol. Struct. 374, 147-153.

Le Cointe, M., Lemée-Cailleau, M. H., Cailleau, H., Toudic, B., Toupet, L., Heger, G., Moussa, F., Schweiss, P., Kraft, K. H. \& Karl, N. (1995). Phys. Rev. B, 51, 3374-3386.

Le Maguéres, P. L., Lindemann, S. V. \& Kochi, J. K. (2001). Organometallics, 20, 115-125.

Lee, O., Koga, Y. \& Wade, A. P. (1990). Talanta, 37, 861-873.

Lemée-Cailleau, M. H., Le Cointe, M., Cailleau, H., Luty, T., Moussa, F., Roos, J., Brinkman, D., Toudic, B., Ayache, C. \& Karl, N. (1997). Phys. Rev. Lett. 79, 1690-1693.

Levy, H. A. \& Peterson, S. W. (1952). Phys. Rev. 86, 766-770.

Maginn, S. J. \& Davey, R. J. (1994). Acta Cryst. C50, 254-255.

Mandel, G. \& Donohue, J. (1972). Acta Cryst. B28, 1313-1316.

Mathieson, A. McL. (1952). Acta Cryst. 5, 332-341.

Mathieson, A. McL. (1953). Acta Cryst. 6, 399-403.

Matsumoto, M., Yajima, H. \& Endo, R. (1987). Bull. Chem. Soc. Jpn, 60, 4139-4140.

Matsuoka, M., Yamanobe, M., Tezuka, N., Takiyama, H. \& Ishii, H. (1999). J. Cryst. Growth, 198/199, 1299-1306.

Mayerle, J. J., Torrance, J. B. \& Crowley, J. I. (1979). Acta Cryst. B35, 2988-2995.

McCrone, W. C. (1965). Physics and Chemistry of the Organic Solid State, edited by D. Fox, M. M. Labes \& A. Weissberger, Vol. II, pp. 726-767. New York: Interscience.

Mikami, M., Konno, K. \& Saito, Y. (1980). Acta Cryst. B36, 275287.

Miltenburg, J. C. van \& van den Berg, G. J. K. (1989). Thermochim. Acta, 151, 305-308.

Mitkevich, V. V., Lirtsman, V. G., Strzhemechny, M. A., Avdeenko, A. A. \& Eremenko, V. V. (1999). Acta Cryst. B55, 799-806.

Mitkevich, V. V., Strzhemechny, M. A., Lirtsman, V. G. \& Avdeenko, A. A. (2001). Mol. Cryst. Liq. Cryst. 361, 19-24.

Mnyukh, Yu. (1983). Speculations Sci. Tech. 6, 275-285.

Mnyukh, Yu. (2001). Fundamentals of Solid State Phase Transitions, Ferromagnetism and Ferroelectricity. 1st Books. ISBN: 0-75960219-0.

Mnyukh, Yu. V. \& Panfilova, N. A. (1973). J. Phys. Chem. Solids, 34, 159-170.

Mnyukh, Yu. V., Panfilova, N. A., Petropavlov, N. N. \& Uchvatova, N. S. (1975). J. Phys. Chem. Solids, 36, 127-144.

Mnyukh, Yu. V. \& Petropavlov, N. N. (1972). J. Phys. Chem. Solids, 33, 2079-2087.

More, M., Baert, F. \& Lefebvre, J. (1977a). Acta Cryst. B33, 36813684. 
More, M., Baert, F. \& Lefebvre, J. (1977b). Acta Cryst. B33, 38623865.

Morrison, J. D. \& Robertson, J. M. (1949). J. Chem. Soc. pp. 10011008.

Nakayama, H., Eguchi, T. \& Nakamura, N. (1994). Z. Naturforsch. Teil A, 49, 267-272.

Nakayama, H., Eguchi, T. \& Nakamura, N. (1995). J. Mol. Struct. 345, 273-276.

Nichol, G. S. \& Clegg, W. (2005). Acta Cryst. B61, 464-472.

Nichols, G. (1998). Microscope, 46, 117-122.

Nichols, G. (1999). 1st Int. Symp. on Aspects of Polymorphism and Crystallization-Chemical Development Issues, Scientific Update, pp. 199-209.

Nichols, G. \& Frampton, C. S. (1998). J. Pharm. Sci. 87, 684-693.

Parker, S. B. (1983). Editor-in-Chief. Dictionary of Scientific and Technical Terms, 3rd ed., p. 789. Ohio: McGraw-Hill.

Pascal, P. (1913). Compt. Rend. 154, 883.

Peretti, P. \& Ranson, F. (1979). J. Raman Spectrosc. 8, 209-212.

Petropavlov, N. N., Tsygankova, I. G. \& Teslenko, L. A. (1988). Sov. Phys. Crystallogr. 33, 853-855.

Pippard, B. (1964). The Elements of Classical Thermodynamics. Cambridge University Press.

Powers, R. \& Rudman, R. (1977). Mol. Cryst. Liq. Cryst. 41, 97-102.

Pusiol, D. J., Wolfenson, A. E. \& Brunetti, A. H. (1989). Phys. Rev. B, 40, 2523-2528.

Putnam, W. E., MacEachern, D. M. \& Kilpatrick, J. E. (1965). J. Chem. Phys. 42, 749-755.

Rahkmenkulov, F. S., Gutov, S. A. \& Paukov, I. E. (1975). Russ. J. Phys. Chem. 49, 1605.

Rao, C. N. R., Ganguly, S. \& Swamy, H. R. (1982). Croat. Chem. Acta, 55, 207-221.

Reynolds, P. A. (1977). Acta Cryst. A33, 185-191.

Richardson, M. F., Yang, Q.-C. \& Dunitz, J. D. (1990). Acta Cryst. B46, 653-660.

Royer, J., Bayard, F., Decoret, C. \& Skalli, M. (1990). J. Chim. Phys. 87, 1061-1067.

Royer, J., Skalli, M., Bayard, F. \& Decoret, C. (1993). J. Cryst. Growth, 130, 280-286.

Santarsiero, B. D., Bronikowski, M. J. \& Samson, S. O. (1985). Am. Abstract Winter Meeting. 13, 55.

Santarsiero, B. D., Valente, E. J. \& Bronikowski, M. J. (2005). Private communication.

Schaum, K., Schaeling, K. \& Klausing, F. (1916). Liebigs Ann. 411, 161-195.

Schmidt, A., Kababya, S., Appel, M., Khatib, S., Botoshansky, M. \& Eichen, Y. (1999). J. Am. Chem. Soc. 121, 11291-11299.

Seki, S. \& Momotani, M. (1950). Bull. Chem. Soc. Jpn, 23, 30-31.

Shields, K. G. \& Kennard, C. H. L. (1977). J. Chem. Soc. Perkin Trans. II, pp. 463-465.

Shigenari, T., Kojima, E., Ino, Y. \& Abe, K. (1991). Phys. Rev. Lett. 66, 2112-2115.

Shikano, K., Katoh, K. \& Shimada, S. (1999). Thermochim. Acta, 336, 127-131.

Simon, F. (1922). Ann. Physik, 68, 241-280.

Simon, F., von Simson, Cl. \& Ruhemann, M. (1927). Z. Phys. Chem. A, 129, 339-348.

Smits, A. \& MacGillavry, C. H. (1933). Z. Phys. Chem. A, 166, 97-112.

Smits, A., Muller, G. J. \& Kröger, F. A. (1937). Z. Phys. Chem. B, 38, 177-186.

Sonoyama, M., Yajima, H., Nakano, T., Matsumoto, M., Tsukushi, I. \& Ishii, T. (2000). Chem. Lett. pp. 558-559.

Srivastava, P. K., Singh, K. P. \& Jain, P. C. (1986). Solid State Commun. 58, 147-149.

Steinmetz, H. (1905). Z. Phys. Chem. 52, 449-466.
Stride, J. A. (2005). Acta Cryst. B61, 200-206.

Taniguchi, I., Takaki, Y. \& Sakurai, K. (1980). Bull. Chem. Soc. Jpn, 53, 803-804.

Thalladi, V. R., Nüsse, M. \& Boese, R. (2000). J. Am. Chem. Soc. 122, 9227-9236.

Thomas, D. G. \& Staveley, L. A. K. (1951a). J. Chem. Soc. pp. 1420 1425.

Thomas, D. G. \& Staveley, L. A. K. (1951b). J. Chem. Soc. pp. 2572 2579.

Tolédano, J.-C., Berry, R. S., Brown, P. J., Glazer, A. M., Matselaar, R., Pandey, D., Perez-Mato, J. M., Roth, R. S. \& Abrahams, S. C. (2001). Acta Cryst. A57, 614-620.

Tolédano, J.-C., Glazer, A. M., Hahn., Th., Parthé, E., Roth, R. S., Berry, R. S., Metselaar, R. \& Abrahams, S. C. (1998). Acta Cryst. A54, 1028-1033.

Tolédano, P. \& Dmitriev, V. (1996). Reconstructive Phase Transitions (in Crystals and Quasicrystals), pp. xvii +397 . Singapore: World Scientific.

Torrie, B. H. \& Powell, B. M. (1992). Mol. Phys. 75, 613-622.

Tseneva, M. A. (1969). Sov. Phys. Dokl. 185, 302-303.

Tseneva, M. A. \& Godovskii, Yu. K. (1967). Zh. Fiz. Khim. 41, 18271828.

Ubbelohde, A. R. (1952). Nature (London), 169, 832.

Ubbelohde, A. R. (1956). Br. J. Appl. Phys. 7, 313-321.

Ubbelohde, A. R. (1957). Q. Rev. 11, 246-272.

Ubbelohde, A. R. (1962). K. Ned. Akad. Wet. Proc. B, 65, 459-471.

Ubbelohde, A. R. (1963). Z. Phys. Chem. N. F. 37, 183-195.

Ubbelohde, A. R. (1966). J. Chim. Phys. 62, 33-42.

Vatulev, V. N. \& Prikhot'ko, A. F. (1965). Sov. Phys. Solid State, 7, 29 31.

Warren, B. E. (1990). X-ray Diffraction. New York: Dover Publications Inc.

Watanabe, T., Saito, Y. \& Chihara, H. (1949). Sci. Papers Osaka Univ. 2, 9-14.

Weinberg, F. J. (1990). Biogr. Mem. Fellows R. S. 36, 383-402.

Westrum, E. F. Jr \& McCullough, J. P. (1963). Physics and Chemistry of the Organic Solid State, edited by D. Fox, M. M. Labes \& A. Weissberger, Vol. I, pp. 1-178 (see also pp. 75, 151). New York: Interscience.

Wheeler, G. L. \& Colson, S. D. (1975). Acta Cryst. B31, 911-913.

Wheeler, G. L. \& Colson, S. D. (1976). J. Chem. Phys. 65, 12271235.

Wiebenga, E. H. (1935). Z. Anorg. Allg. Chem. 225, 38-42.

Wiedemann, H. G. \& Bayer, G. (1985). J. Thermal Anal. 30, 173181.

Wiehl, L., Kiel, G., Köhler, C. P. \& Gütlich, P. (1986). Inorg. Chem. 25, $1565-1571$

Wilson, C. C. (2000). Z. Kristallogr. 215, 693-701.

Wilson, M. A., Vassallo, A. M., Burgar, M. I., Collin, P. J., Skelton, B. W. \& White, A. H. (1986). J. Phys. Chem. 90, 3944-3948.

Wirths, M. \& Schneider, G. M. (1981). J. Chem. Thermodyn. 13, 701702.

Wolfenson, A. E., Pusiol, D. J. \& Brunetti, A. H. (1990). Z. Naturforsch. Teil A, 45, 334-338.

Yang, Q.-C., Richardson, M. F. \& Dunitz, J. D. (1989). Acta Cryst. B45, 312-323.

Yelon, W. B. \& Cox, D. E. (1972). Solid State Commun. 11, 1011-1013. Yoshimoto, Y., Fujiwara, T., Atake, T. \& Chihara, H. (1985). Chem. Lett. pp. 1347-1350.

Yufit, D. S., Kozhushkov, S. I., Howard, J. A. K. \& de Meijere, A. (2002). Acta Cryst. B58, 673-676.

Yurtseven, H. \& Sherman, W. F. (1984). J. Mol. Struct. 143, 21-24.

Yurtseven, H., Tari, O. \& Bas, M. (2001). J. Mol. Struct. 598, 109-116.

Zuniga, F. J. \& Criado, A. (1995). Acta Cryst. B51, 880-888. 